\title{
EXPLORING CURRICULUM AS AN EXPERIENCE OF CONSCIOUSNESS TRANSFORMATION
}

by

\author{
(Elise) Ling-Hui Chu \\ M.Sc., Feng Chia University, Taiwan, 1994 \\ B.Sc., Feng Chia University, Taiwan, 1989
}

A THESIS SUBMITTED IN PARTIAL FULFILLMENT OF

THE REQUIREMENTS FOR THE DEGREE OF

MASTER OF ARTS

in

THE FACULTY OF GRADUATE AND POSTDOCTORAL STUDIES

(Curriculum Studies)

THE UNIVERSITY OF BRITISH COLUMBIA

(Vancouver)

September 2016

(C) (Elise) Ling-Hui Chu, 2016 


\section{Abstract}

The purpose of this study is the exploration of curriculum as an experience of consciousness transformation. Moved by a deep concern over education's inappropriate reliance on classical science, which I believe has contributed to the radical commercialization of human values, I argue for curriculum imbued with spiritual wisdoms. My argument has three parts: First, drawing on the curriculum scholarship of Dwayne Huebner, I identify openness to the transcendent and a non-dualistic worldview as two of the most prominent aspects of spiritual truth that can counter absolutism and objectivism. Second, I explore the relationship between truth and education in light of Martin Heidegger's interpretation of Plato's allegory of the cave and assert that the essence and purpose of education can be found in the four-stage transition of the essence of truth assumed by an individual-from taking the mere shadows as the ultimate reality to suspecting and penetrating the pretended and disguised, and then returning for the ultimate liberation of all the others. For the purpose of verifying the truthfulness of Plato's allegory of the cave and its existential significance for human beings, my third move is to conduct a dialogue between Buddhism and quantum physics and to demonstrate a startling convergence of the two branches of thought regarding the true nature of consciousness, self and reality. On the basis of Huebner's and other curriculum theorists' works, Heidegger's explication of Plato's allegory of the cave, the dialogue between Buddhism and quantum physics, I propose the transformation of consciousness as the essence and purpose of education. Drawing specifically on the concepts and process of Buddhist spiritual practices, I explore six elements of consciousness transformation that may be helpful to educators, including understanding the nature of consciousness, self and reality, learning to appreciate human temporality, cultivating 
impartiality and bodhicitta, becoming responsibly responsive, cultivating selflessness, and learning to embody a non-dualistic worldview. 


\section{Preface}

This thesis is an original, unpublished work by the author, (Elise) Ling-Hui Chu. 


\section{Table of Contents}

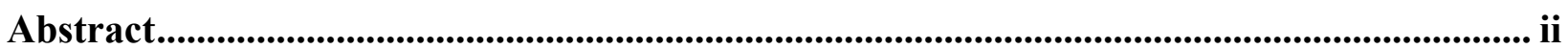

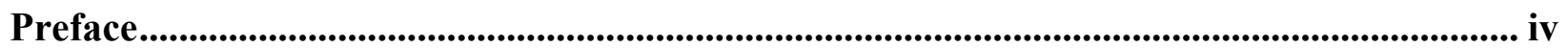

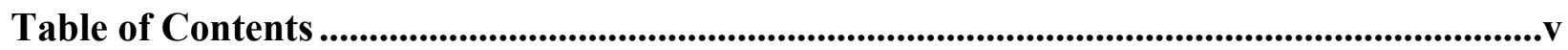

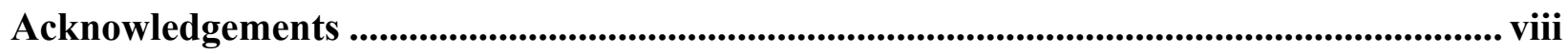

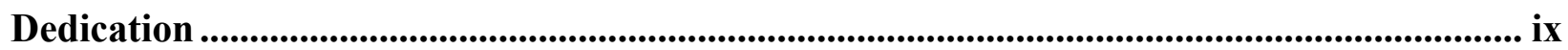

Prologue: A Personal Introduction ...........................................................................................................

Chapter 1: Introduction to the Problem .....................................................................................................1

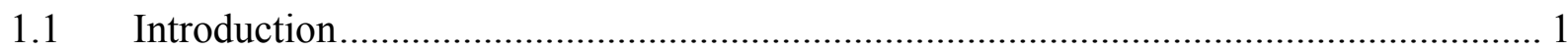

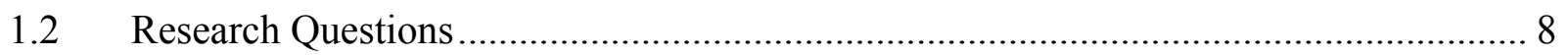

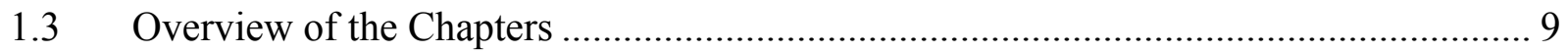

Chapter 2: Review of Educational Literature.....................................................................................11

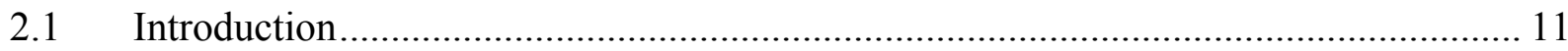

2.2 The Concepts of Spirituality in the Educational Literature .................................... 15

2.3 Significant Epistemological Concerns over Education......................................... 21

2.4 The Relationship Between Truth and Education ............................................... 29

Chapter 3: Conceptual Framework-A Dialogue between Buddhism and Quantum Physics38

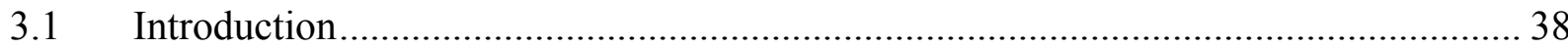

3.2 The Concepts of Truth in Buddhism—A Preliminary Exploration ........................... 38

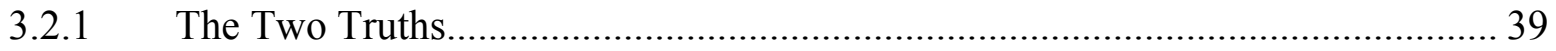

3.2.2 The Four Noble Truths............................................................................ 54

3.3 A Dialogue between Buddhism and Quantum Physics ........................................ 58 
3.3.1 The Quantum Measurement Problem, Uncertainty and Superstring Theory, and

Buddhism ..... 59

3.3.2 Holographic Principle and Buddhism .................................................... 64

3.3.3 Quantum Entanglement, Theory of It from Bit and participatory Universe, and

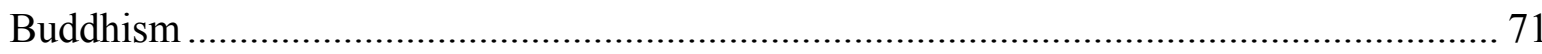

3.4 The Implications of This Dialogue for Education .............................................. 76

Chapter 4: Curriculum as an Experience of Consciousness Transformation..........................83

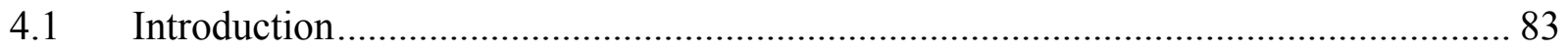

4.2 The Concepts and Process of Consciousness Transformation in Buddhism ............... 84

4.2.1 The Two Barriers to Consciousness Transformation...................................... 84

4.2.2 The Transformation of Consciousness into Four Transcendental Wisdoms ........ 86

4.2.3 The Five-Stage Gradual Path of Consciousness Transformation in Buddhism.... 87

4.2.4 The Union of Wisdom-Side and Method-Side Practices for Consciousness

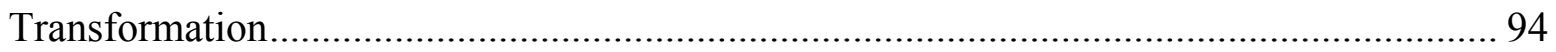

4.2.5 The Approach of Negation-The Core Approach to Consciousness

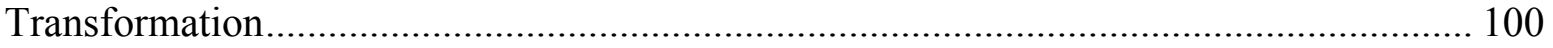

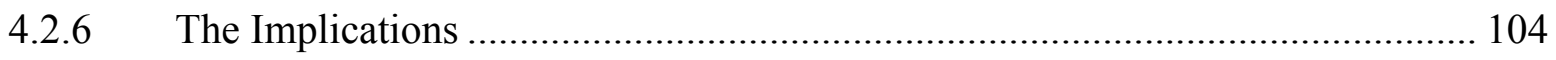

4.3 Curriculum as an Experience of Consciousness Transformation ............................ 107

4.3.1 Understanding the Nature of Consciousness, Self and Reality....................... 107

4.3.2 Learning to Appreciate Human Temporality ............................................ 122

4.3.3 Cultivating Impartiality and Bodhicitta ................................................... 132

4.3.4 Becoming Responsibly Responsive ..................................................... 146

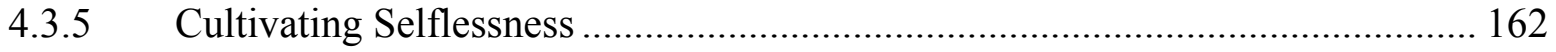


4.3.6 Learning to Embody a Non-Dualistic Worldview

Chapter 5: Conclusion and Implications .........................................................................185

5.1 Brief Summary, Conclusion and Implications ............................................... 185

5.2 Limitations of This Study and Questions for Further Inquiry ............................. 189

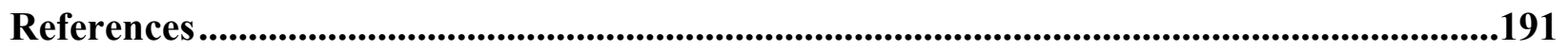




\section{Acknowledgements}

I would like to express my deepest gratitude and respect to my supervisor Dr. Anne Phelan. I deeply appreciate her acceptance of my request to be her student and to investigate into the realm of curriculum studies. With the aspiration to become a wise, caring and selfless teacher like her, I started this wonderful journey. This thesis would not have been possible without her openminded and attentive listening, wise guidance, and caring encouragement.

My heartfelt gratitude also goes to my committee member Dr. Susan Gerofsky. I deeply appreciate her advices on this thesis and her patient guidance during the earliest stage of my study at UBC.

I would also like to express my immense gratitude to my dear parents, family, parents-in-law, and family-in-law for their incessant and unconditional love and supports. Lastly, my most profound love and gratitude go to my dearly beloved late husband. His profound love, affection and wisdom have continued to give me courage and strength in the face of various challenges during the process of doing this research, and will be accompanying and supporting me unceasingly during my life. 


\section{Dedication}

For my dearly adored and beloved husband, in memoriam. 


\section{Prologue: A Personal Introduction}

I was born and grew up in a sedate country town in Taiwan where the folk religion that blends Taoism, Buddhism and Confucianism is the most popular belief. At the core of the folk religion are the reverence for the transcendent source of the Nature and for the gods and ancestors, the moral reciprocity and the law of karma, the energy that animates the universe (Qi), the belief of personal destiny, fateful coincidence and potential relationships, and the existence of the six realms, meaning six directions of reincarnation, including hell, hungry ghost, animal, asura (malevolent nature spirits), human existence, deva (heavenly existence). My father was an elementary school teacher and my mother was a kindergarten teacher, both of them are from families of farmers. In the countryside village where my grandparents lived, like many other countryside villages in Taiwan, the majority of the inhabitants worship Guanyin bodhisattva (Avalokiteśvara, or Goddess of Mercy) at their home. Guanyin, meaning perceiving the sounds (of the world), is also well known as an incessant listener and a compassionate fearlessness giver. In my childhood, I had heard of many testimonies regarding the manifestation of Guanyin bodhisattva during World War II when the Japanese air force was bombarding Taiwan.

In my family, before my parents formally worship Guanyin bodhisattva at home, taking the elders' suggestion, my parents worshiped Tudigong (Lord of the Soil and the Ground) as the guardian of the family. When I was an elementary school student, although my mother had been piously offering incense and fruits everyday incessantly for many years, she encountered a belief crisis when she prayed for a cure of my father's health problem but in vain. With deep frustration, she asked Tudigong in her mind: "Do you really exist? Do gods really exist?" In the 
next morning of that day at around 5 a.m., when my mother was sweeping the ground of the backyard with my 6-year-old younger sister who was playing on the ground on another corner, my younger sister curiously found a half-transparent elder dressing resplendently with ancient clothes that was largely the same with the picture of Tudigong smiling at her, and she immediately called my mother: "Mom, look! An elder!" When my mother turned around and saw the elder, she was severely startled and dropped her broom due to huge shock. Afterward, the elder kindly looked at her and spoke to her that, "Devout lady, I am the Tudigong!" and then faded away. This dramatic event greatly increased our confidence in religious doctrines and profoundly influenced the worldview of my whole family.

However, in educational circumstances of Taiwan, religious language is forbidden, eliminating superstitions has long been a slogan, and existential inquiries are largely ignored. When I was a high school student, I strongly questioned the worldly values imposed on us in school. In my own efforts to find alternative values, I found that enlightened monks' biographies, D. T. Suzuki's books on Zen, and William Blake's poems were most appealing to me as these works all point to transcendental something that is beyond our ordinary perception. Yet, at that time, the nature of human existence and the meaning of life remained vague for me. Another encounter that further reshaped my worldview occurred in the third year of my university days when my mother was introduced to a prestigious and selfless Taoist abbot who had been a medium of Guanyin bodhisattva for around 20 years then since 1968. In trance states, he turned to be a multilingual and responded to people from around Taiwan and the world, including politicians, merchants, business leaders, agriculture researchers, scientists, etc. in their language and gave abstruse professional advice as well as prophetic insights. In my first encounter with 
this embodied Guanyin bodhisattva, I was so touched and surprised by the precision of his description of my unspoken prayer for my parents a few days ago. In the following twenty years, countless similar heartwarming experiences of being genuinely heard, known, cared and guided, while remain precious and deeply treasured and appreciated, become normal for us. One of such episodes took place around 10 years ago. In a morning, when my mother stepped into the Taoist temple, the Taoist abbot, our ShiFu, meaning a father-like teacher, came to her and asked her if she had an elder sister who passed away when she was still a middle school student. My mother was surprised and answered, "Yes! What happened?" ShiFu continued, "Your sister came to my vision last night wearing a middle-school uniform. She told me that she is your elder sister and she comes to seek bodhisattva's help because your third elder brother, a government officer, is currently falsely accused of taking bribes and is going to be sentenced, but he can hardly redress the injustice." My mother was startled since my uncle who lived in another county never mentioned that. Afterwards, ShiFu arranged a meeting with my uncle. In that meeting, Guanyin bodhisattva came and drew a picture of the man who actually took bribes and used my uncle as a scapegoat, and told my uncle that the last name of this person is Huang. At that time when bodhisattva confirmed his conjecture, my uncle could hardly believe it because it turned out that the person who framed him was someone he would never suspect—a colleague, his best friend. It was thanks to this clue that my uncle finally redressed this wrong accusation.

During my journey from being a critical spectator to becoming a respectful witness of the embodied Guanyin bodhisattva's awe-inspiring bearing and stunning demonstration of bodhisattva's deeds that are far beyond human capacities, I developed certain degree of spiritual discernment in various spiritual language and qualities, such as selflessness, equanimity, 
omniscience, prophecy, bodhicitta, and transcendental wisdom, and no longer consider spiritual language in various religions as merely mythic fabrication, exaggerated rhetoric, impossible status, or groundless superstitions. In my university days, such experiences brought me to Buddhist and Taoist scriptures and treatises, Brian Weiss's books on past lives and reincarnation, Raymond Moody's research on near death experiences, books regarding extrasensory perception, Michael Talbot's book The Holographic Universe, breakthroughs in contemporary physics, etc. The knowledge acquired from the aforementioned literature, along with my idiosyncratic encounters with the Otherness or Moreness, rendered me broadened perspectives for contemplating the meaning of life, the nature of human existence, and the purpose of education.

As a math major, during my career as first-year calculus teaching assistant and instructor in a university, due to the absence of spiritual wisdom in the educational context, every year, I encountered hundreds of freshmen searching for meaning in classrooms. While I was concerned about students' academic performance in their studies of calculus, I was more profoundly concerned about how the relentless power of the education system drove everyone forward and left questions of meaningfulness to the youngsters as "their own business". As an educator, I questioned: Is this really none of our business?

In 2011, possessing Buddhist philosophy and the holographic perspective of universe, I enrolled in the MA program in Math Education at UBC. Given my professional background as a calculus teacher, despite my enthusiasm for existential inquiries, at first I saw no alternative but to investigate into calculus reform. Fortunately, taking the course Introduction to Curriculum Issues and Theories taught by Dr. Anne Phelan not only changed my conditioned impressions of 
what curriculum and education are and may be, the transformative power of this course also renewed my aspiration and changed my compromised life. With a new vision, I made the decision to alter my program of study from math education to curriculum studies. I deeply appreciate Dr. Phelan's open-minded listening and practical wisdom that opened for me new possibilities of investigating my genuine research interests, articulating the formerly silenced voice, and living with authenticity.

As beneficiary of the existential tradition of curriculum, I deeply treasure this opportunity of investigating into Dwayne Huebner's works and sincerely hope that this thesis would make a contribution to this tradition by means of enriching it with the language of Buddhism and quantum physics that are well informed by my idiosyncratic life experiences. 


\section{Chapter 1: Introduction to the Problem}

\subsection{Introduction}

Intrinsic in human temporality, there exist existential questions about the meaning and significance of life. While generations of curious youngsters enter into education systems anticipating acquiring a good grasp of the answers to these questions, school and university curricula seemingly fail to provide sufficient wisdom for addressing such inquiries. This might be attributed to the fact that the cultural wealth for approaching such existential questions is largely considered as religious, and therefore excluded from the scope of the curriculum as a consequence of intentional distancing of education from religions. For example, in the United States, educators have made efforts to distance their work from their origins in Christian traditions for several decades, and the place of religious traditions in education became gradually substituted by scientific and technical enterprises as exhibited in the symbiotic relationship of testing industry and schooling (Huebner, 1985c/1999, p. 340). Huebner (1985c/1999) observed that, the questions of values and ends, despite not possibly being suppressed, altered the rhetoric and increasingly cloaked it in scientific or developmental language (pp. 340-341). As he pointed out, despite the facts that Western and Eastern religious traditions "all acknowledge the spiritual as an integral aspect of human life, ... human beings participate in a spiritual dimension of existence, something more than the material, the sensory, and the quantitative" (Huebner, 1985c/1999, p. 342) and that the “questions of life's meaning and significance loom large within the religious traditions, the dependency of education upon those traditions appeared to yield to dependency upon the traditions of science" (Huebner, 1985c/1999, p. 340). The main problem of such substitution is that, during the period of the merger of educational and scientific 
traditions, being rooted in classical (Newtonian) physics, positivism and its associated absolutistic and objectivistic worldview as well as materialist social values were dominating. As a result, the spiritual wisdom of longstanding religious traditions was largely rejected.

Formally founded and named by sociologist and philosopher August Comte (1798-1857) in the 1830s as a distinctive movement, positivism maintains the Newtonian world-as-machine worldview (Nickle, 2005, p. 1854), and rejects "the possibility of knowledge of unobservable physical objects ... [and regards] metaphysical speculation as failing to keep imagination limited by observation" (Sullivan, 2009, p. 395). Owing to the rejection of the speculation of spiritual wisdoms, human beings become forgetful of the grand sources that give life profound meanings and purposes. The exclusion of spiritual language and wisdoms in education also hides from us "what we are really about when we educate" (Huebner, 1985b/1999, p. 359). In the absence of spiritual wisdoms in education, we forget that "knowing is a relation between the person and the other" (Huebner, 1985b/1999, p. 365). By failing to recognize knowledge as an invitation to join hands with someone else in their involvement with earth, ... [and] an invitation to establish a relationship of care and being cared for-a relationship of duty, love, and reverence, ... we make the objects of the world care for us. We harness these objects, their qualities and characteristics, to our needs and wants, frequently destroying them, and gradually the earth, so they can serve us. (Huebner, 1985b/1999, p. 366) Huebner (1985b/1999) lamented that, "the mutuality of love and reverence is broken in technical communities, for we no longer care for that which care for us" (p. 366). This mutuality of duty, love and reverence became gradually replaced by the absolutistic and objectivistic worldview that assumes the mind-independence of reality (Bryman, 2004) and a sharp distinction between 
the observer and the observed, and by Charles Darwin's theory of evolution that is often interpreted or misinterpreted as connoting the life as war metaphor to represent human experiences (McTaggart, 2011, p. xxi).

In the educational context, in the absence of spiritual wisdom and the mutuality of duty, love and reverence, students are either blindly accepting of the absolutistic and objectivistic worldview, seeing competition among humans as human nature, viewing virtues as mere platitudinous and hypocritical dogma, or to the contrary, struggling strenuously to maintain their deep beliefs and values that are contradictory with and confused by the prevailing absolutistic and objectivistic worldview. On the societal and political levels, the absolutistic and objectivistic worldview and the materialist social values are reflected in the formulaic logic of The Market and the language of global competitiveness along with the formula of "Unless we do X, we will fall behind" (Smith, 2000, p. 18). Smith (2000) commented that this becomes "a simple and powerful recipe for the creation of Loser Culture" (p. 18), for winning implies losing, and that "any social and educational planning motivated by the sheer desire to win of necessity breeds not only hypercompetitiveness in the social realm, but also its adjunct effects of heightened social paranoia and the turning of friends into enemies" (p. 18). Also, since the winners by definition must be few, more and more people feel as if they are losers and life is a race (Smith, 2000, p. 18). He quotes Canadian philosopher of technology Franklin's remark that "the language of global competitiveness is the language of war" (p. 18), and said that, as educators, we might ask: "Who can survive it, and how?" (p. 18). Smith foresaw that the increasing forms of resistance against the radical commercialization of human values on a global scale may prefigure a global conversation regarding "what it means to live well humanly speaking" (p. 16), and indicated that 
"discussions regarding shared futures must inevitably involve religious questions, that is, questions about meaning, purpose, and what is truly required to nurture and sustain human life in its most noble and dignified senses" (p. 16).

Nowadays, the excessive desire to gain and win nurtured by the absolutistic and objectivistic worldview and the materialist social values has blinded humankind to the interconnectedness and interdependence of everything on earth and to infinite transcendental possibilities, and can lead to grave consequences for not only human beings but also the planet as a whole. In his lecture to the Nobel Peace Prize Committee at Oslo, Norway in 2007, Al Gore (2008) addressed the issue of global warming and cautioned: "We, the human species, are confronting a planetary emergency $-a$ threat to the survival of our civilization that is gathering ominous and destructive potential" (p. 55). Moreover, climate change is not the only global crisis we are facing. According to Lomborg (2004), the conference of Copenhagen Consensus in 2004 identified more than 30 major global challenges facing humanity, including conflicts and arms proliferation, terrorism, corruption, deforestation, chemical pollution and hazardous waste, depletion of the ozone layer and water resources, loss of biodiversity, vulnerability to natural disasters, malnutrition and hunger, etc.

The key to a resolution of the present crises and the unveiling of the true nature of human being that is "more than the material, the sensory, and the quantitative" (Huebner, 1985c/1999, p. 342), I believe, is in consciousness transformation by means of integrating the implications of quantum physics and the spiritual wisdoms of religious traditions into curriculum. Taking into consideration "the strange world of electromagnetic frequencies, matter and anti-matter, particles 
and waves" (Huebner, 1993/1999, p. 401) uncovered by modern physics, Huebner (1993/1999) underscored that "our sensory system, and social/political systems, are in touch with but a small part of the reality of the universe" (p. 401), and the "embodied images are no more a reality than are unembodied images a mere figment of an "unreality"' (p. 401). However, over the last three hundred years, while the development of physics has moved from classical to relativistic, and into quantum physics and the exploration of unified theory (Greene, 2004, p. 22) which differ profoundly from classic physics on the important matter of how the consciousness of human agents enters into the structure of empirical phenomena, ... until recently, virtually all attempts to understand the functional activity of the brain have been based, at least implicitly, on some principles of classic physics that have been known to be fundamentally false for three-quarters of a century (Schwartz, Stapp, \& Beauregard, 2005, p. 1309-1310).

Schwartz, et al. (2005), thereby, proposed an alternative conceptual framework for analyzing brain dynamics that is able to "represent more adequately than classic concepts" (p. 1309), and concluded that "the causal efficacy of mental effort is no illusion" (p. 1325). In the same vein, psychiatrist Bruce Greyson (2010) also appealed for expanding "models of mind to accommodate extraordinary experiences such as NEDs [near-death experiences]" (p. 43). Development of quantum physics has inspired many researchers from various realms to conduct research and experiments on consciousness (McTaggart, 2007). In 2008, a surprising level of agreement on the nature of consciousness emerged in a multi-disciplinary meeting on Neuroscience, Spirituality and Consciousness in Freiburg Germany (Forman, 2011, p. 279). In contrast to the reigning epiphenomenal model of consciousness, this new hypothesis suggests:

(i) Consciousness is a fundamental element of reality. (ii) Consciousness is mediated by 
the brain. ... Brains are transducers of consciousness. (iii) Consciousness is independent of the brain ..., though it remains so far unobservable unless transduced by brains. (iv) ... The ability to sense 'something larger' (which cannot itself be observed), a mystical ability, may be the skill distinguishing human beings from other hominids. (Forman, 2011, p. 279)

The development of contemporary physics and the emerging new models of consciousness not only remind us of the profoundity and believability of spiritual wisdoms conveyed by religious traditions, but also shed light on a new direction of educational thinking.

As an undeniable fact, breakthroughs in modern physics have forced, and continue to force, dramatic revisions to our picture of reality (Greene, 2004, p. 5), and to our surprise, these revisions reveal a strong resemblance to the spiritual wisdoms of various religious traditions that have been taught for thousands of years. In the face of pressing global crises, thanks to the development of quantum physics, human beings are concurrently given grand opportunities for getting closer to the ultimate truth of reality and the true nature of human being. In his contemplation of the ultimate question of life's value, theoretical physicist and string theorist Brian Greene (2004) concluded that, "an informed appraisal of life absolutely required a full understanding of life's arena-the universe" (p. 4). However, in sharp contrast to the absolutistic and objectivistic viewpoint, the "overarching lesson that has emerged from scientific inquiry over the last century is that human experience is often a misleading guide to the true nature of reality" (Greene, 2004, p. 5). Therefore, "assessing existence while failing to embrace the insights of modern physics would be like wrestling in the dark with an unknown opponent" (Greene, 2004, p. 5). As Greene said, only by "deepening our understanding of the true nature of 
physical reality, we profoundly reconfigure our sense of ourselves and our experience of the universe" (p. 5). The power of truth was demonstrated in Mahatma Gandhi's Satyagraha, meaning "truth force", which Gore (2008) explicated that, "in every land, the truth—once known, ... has the power to unite us and bridge the distance between 'me' and 'we', creating the basis for common effort and shared responsibility" (p. 57). Based on my belief in the truth force, I am convinced that the truths of the nature of consciousness, self and reality uncovered in the implications of quantum physics and the spiritual wisdoms of religious traditions would be conducive to not only the realization of the ultimate nature of human existence that is beyond our everyday perception, but also the resolution of present global crises.

In his concern for human temporality, Huebner (1967/1999) considered the role of educator as a "historian in reverse" (p. 133) and contended that history, not sociology, is the discipline which seems the most akin to the social study of education. The historian can be interpreted as looking back to where a society has been to determine how it arrived at a given point. In so doing, he identifies certain threads of continuity to unite diverse moments in time. In contrast, the educator looks forward. $\mathrm{He}^{1}$, too, seeks to identify threads of continuity to unite diverse moments in time, but these are moments of yesterday and tomorrow, not of two yesterdays. It might be said that an

\footnotetext{
${ }^{1}$ In this thesis, the usage of the masculine gendered language, such as "man" for humankind, "he" for s/he, etc., in the direct quotations from Huebner's early essays is not altered only to prevent the loss of meanings specific to the corresponding historical context. No gender discrimination is intended.
} 
educator is an historian in reverse. The curriculum person deserves to be chided for his ahistoricalism — not only is he ignorant of where his own field has been or is going, but he may also be missing a possibility that historical modes of thought might lead to more powerful tools for use in curriculum design. (p. 133)

It is due to the identification of threads of continuity between ancient wisdoms of religious traditions and the phenomena, theories and philosophies of quantum physics - the moments of yesterday and tomorrow - that I seek the possibility that the historical modes of thought of various religious traditions in tandem with the phenomena, theories and philosophies of quantum physics might provide a broadened perspective for deliberating the nature of human existence, the meaning and significance of life as well as the essence and purpose of education, and lead to more powerful tools for use in curriculum design. Based on this contemplation, in the following chapters, I explore the potentiality of the curriculum as an experience of consciousness transformation.

\subsection{Research Questions}

In this research, I ask the following questions:

- How do the phenomena, theories and philosophies of quantum physics resonate with the spiritual wisdoms of religious traditions, particularly the spiritual wisdoms of Buddhism regarding the nature of consciousness, self and reality?

- What does the resonance between Buddhism and quantum physics mean for education and educational purpose?

- How might educators begin to understand curriculum as an experience of consciousness transformation? 


\subsection{Overview of the Chapters}

In the following paragraphs, an overview of the contents of the thesis chapters is introduced.

In Chapter 2: Review of Educational Literature, I review the ongoing conversation regarding spirituality and education. Drawing mainly on the works of Dwayne Huebner, Parker Palmer and John Miller, my intent is to identify and discuss significant issues in relation to spirituality and education, particularly those pertaining to the integration of the implications of quantum physics and the spiritual wisdoms of religious traditions into curriculum. Furthermore, the issues and concepts identified in this review of literature are discussed in the light of Martin Heidegger's interpretation of Plato's allegory of the cave.

In Chapter 3: Conceptual Framework-A Dialogue between Buddhism and Quantum Physics, a conversation is conducted for the purpose of exploring how quantum physics and its implications resonate with the spiritual wisdoms of religious traditions, particularly the wisdoms of Buddhism regarding the nature of consciousness, self and reality, and what the resonances between Buddhism and quantum physics mean for education and educational purposes. First, I explore the concepts of truth in Buddhism and how these concepts resonate with the notions of spirituality and spiritual truth found in educational literature. Second, I conduct a dialogue between the concepts of truth in Buddhism and their corresponding phenomena or theories in quantum physics, and demonstrate how the two branches of thoughts resonate with each other. Lastly, based on this deepened and extended understanding of spirituality, spiritual truth, the 
whole spiritual path and the relationship between education and truth, I explore the implications of this dialogue between Buddhism and quantum physics for education and educational purposes.

In Chapter 4: Curriculum as an Experience of Consciousness Transformation, following the new realization of the essence and purpose of education attained in Chapter Three, I explore the main concepts and process of Buddhist spiritual practices of consciousness transformation to gain deeper insights into the whole spiritual path for educational use. Based on this understanding, I explore how we might understand curriculum as an experience of consciousness transformation by examining six elements, including understanding the nature of consciousness, self and reality, learning to appreciate human temporality, cultivating impartiality and bodhicitta, becoming responsibly responsive, cultivating selflessness, and learning to embody a non-dualistic worldview.

In Chapter 5: Conclusion and Implication, I summarize the main concepts explored in this thesis, I discuss the limitations of this work, and I identify questions for further study. 


\section{Chapter 2: Review of Educational Literature}

\subsection{Introduction}

Over several decades, as Tara Fenwick (2003) indicated, we have witnessed "an unusual and significant outpouring of deep human longing, expressed in what Charles Taylor (1996) described as a 'wild' explosion of spirituality" (p. 10). In the 1950s and 1960s, the interest in higher or deeper consciousness had pointed to popular concerns or even needs to acknowledge the supra-sensory, and these concerns or needs were supported by a variety of scholarly or popular works (Huebner, 1985c/1999, p. 343). For instance, in Beyond the Post-Modern Mind published in 1972, Huston Smith "called attention to the increasing body of scientific and philosophical literature that questions today's prevailing mind-set . . . and acknowledged a sacred consciousness or spirit" (Huebner, 1985c/1999, p. 343).

In the educational context of the United States, after decades of efforts to distance the educational works from its Christian (primarily Protestant) origins, in the National Society for the Study of Education Yearbook of 1985, a chapter titled Spirituality and Knowing suggested "a new direction in the continuing dialogue between traditions of education and traditions of religion" (Huebner, 1985c/1999, p. 340). This concern for the spiritual also provides new perspectives for considering issues of values and ends (Huebner, 1985c/1999, p. 342). In the realm of curriculum studies, starting from the 1960s, curriculum reconceptualists posed large philosophical questions concerning the search for meanings, the purpose of life, and authenticity of self (Koetting \& Combs, 2005, p. 85). One of the most important minds among them was Dwayne Huebner (Pinar, 1999, p. xxiv). As a "seminal educational thinker who pointed the way 
beyond positivist and technological theories of pedagogic planning and evaluation" (Alexander, 2003, p. 231), Huebner gestured "beyond what can be expressed discursively to an ineffable 'other"' (p. 231) and "foreshadowed the spiritual revolution in late-20th century thought" (p. 231).

The growing concern about the spiritual in educational context were also reflected in the emerging of holistic education. The term "holistic education" was created when the first National Holistic Education Conference was held at The University of California, San Diego in July 1979 (Miller, 2005). As one of the most important holistic educators, John Miller grounded the holistic curriculum on the perennial philosophy which is the core wisdom underlying various spiritual traditions and teachings (Miller, 2007, p. 16). He explored spirituality in education from various perspectives in his book The Holistic Curriculum that was first published in 1988, and in his other later works, including Education and the Soul (Miller, 2000), Educating for Wisdom and Compassion (Miller, 2006), and Whole Child Education (Miller, 2010). The late 1980s and the early 1990s became the flourishing period for holistic education (Miller, 2007, p. vii). A survey showed that in the U.S. until 1994, there had been at least 7,500 alternative schools with holistic values in their philosophies of education (Forbes, 1996, p. 1; Mintz \& Muscat, 1994). While the values and vision of humanity in the holistic education movement were increasingly popular during the 1990s, Forbes (1996) observed and lamented that, "the insights of this vision are often clouded by misty-eyed New Ageism [although some fundamental aspects of the New Age Movement are profound], and a great deal that is valuable is dismissed because of this association" (pp. 1-2). However, since the late 1990s, the intimately related realm of spirituality in education has grown and many books on this topic were published; 
important publications include Parker Palmer's The Courage to Teach and Rachael Kessler's Soul in Education (Miller, 2007, p. vii).

In recent years, in response to a variety of critiques of school practices, quite a few educational scholars have also turned their attention to the exploration of spirituality and related issues (Koetting \& Combs, 2005, p. 83). These concepts and issues regarding spirituality range from the necessity of distinguishing between spirituality and religion (Fenwick, 2003; Koetting \& Combs, 2005; Palmer, 2003b; Walton, 1996), connectedness to a life force, the inner search for wholeness and the realization of interconnectedness to the others, an ongoing moving toward one's more authentic identity, healing, altruistic and emancipatory learning (Koetting \& Combs, 2005), the search for a deeper philosophical meaning and purpose of life (Iannone \& Obenauf, 1999; Koetting \& Combs, 2005), the change of mind (Vella, 2000), to the emerging spiritual tensions (Fenwick, 2003). In newly formed fields of contemplative education, mindfulnessbased education and art-based research, the significance of the spiritual and the embodied spiritual practices for education is also recognized (Park, 2014, pp. 52-54).

The explosion of spirituality as a phenomenon of interest is also reflected in the dramatically increasing number of specialized graduate courses dealing with spirituality and religion (Hodge \& Derezotes, 2008, p. 103). For instance, according to Hodge and Derezotes (2008), in the United States of America, there were only a couple of social-work graduate programs that offered elective courses on spirituality in 1990. However, their research revealed that the number rose constantly from 17 programs in 1995 to at least 50 programs in 2000, and in 2005, there were approximately 75 graduate programs offered courses on spirituality and religion. 
Moreover, the first Master of Education Degree program in Contemplative Inquiry and Approaches in North America offered by Simon Fraser University was just given approval in 2014 (Johnson, 2014).

While the explosion of spirituality represents a reaffirmation of the significance of spirituality for human beings, the popularity of spiritual practices, such as the practice of mindfulness, is coupled with the potential danger of being appropriated and trivialized as only "a quick fix to ease the stresses of modern life" (Anderson, n.d., as cited in Johnson, 2014), and the existential significance and wisdom behind it could be easily neglected. In other words, spiritual practices are at risk of being deprived of their existential significance and becoming merely another set of tools for instrumentalists. Yet, as Fenwick (2003) underscored, spirituality is not merely a shallow hurry-up-and-feel-good practice that focuses upon only "an inner journey of healing, personal peace and exploring the self" (p. 11). Fenwick discussed four emerging spiritual tensions in our society recognized by religious studies scholar Elizabeth Dreyer (p. 11). The first one is "the collapse of the 'wall separating church and state', represented most dramatically in the current international conflict, but also evident in the movement of private spiritual experience to the public stage" (Fenwick, 2003, p. 11). The second one is "the lack of interiority, where a superficial society caught in a bricolage of postmodern images, and desperately seeking authentic self-awareness, somehow is still unable or unwilling to nurture a contemplative interior life" (Fenwick, 2003, p. 11). The third is "a split between spirituality and religion related to a perceived failure of mainline religions to connect with the needs of a postmodern people yearning for meaning" (Fenwick, 2003, p. 11). The last "is the pluralism among different spiritualities which don't necessary listen to or work with one another to address common 
problem" (Fenwick, 2003, p. 11). These are also issues that deserve careful consideration by educators who seek the potentiality of the revival and renewal of the intimate relationship between spirituality and education.

In the following sections, for the purpose of identifying critical issues regarding spirituality and education, particularly issues pertaining to the integration of the implications of quantum physics and the spiritual wisdoms of religious traditions into curriculum, and the ongoing conversation about spirituality in relation to education, I explore the works of Huebner, Palmer, Miller. To do so, I draw on Martin Heidegger's interpretation of Plato's allegory of the cave.

\subsection{The Concepts of Spirituality in the Educational Literature}

Spirituality and religion are so intimately related that not everyone differentiates them. However, in educational contexts, many researchers emphasize the necessity of distinguishing between spirituality and religion. In the inquiry of "what distinctions among spiritualit(ies) are significant for educators?”, Fenwick (2003) raised her concern and stated that “'spirituality' in educational literature is too often essentialized as some sort of monolithic force blending deep cultural, political, and epistemological divides" (p. 11). She thus stressed the significance of multiple delineations of spirituality (Fenwick, 2003, p. 11). Likewise, Koetting and Combs (2005) stated that it is not possible to understand spirituality in terms of a single simple definition, and emphasized the importance of distinguishing between religion and spirituality. They underscored that in "reviewing writings on spirituality and education, it is important to establish at the very beginning of our discussion that spirituality does not mean organized religious beliefs as found in present day political discourse" (p. 83). Palmer (2003b) also contended that the 
distinction between religion and spirituality is essential in public education if we want to "raise spiritual topics in a way that respects the vast diversity of people's deeply held traditions and beliefs" (p. 380). The distinction between religion and spirituality is well portrayed by Walton (1996):

Religion may or may not play a role in individual spirituality and is quite distinct from spirituality ... Religion is described as a framework for beliefs, values, traditions, doctrine, conduct, and rituals ... Whereas spirituality is a much more encompassing term ... a spiritual individual may or may not be religious. (pp. 238-239)

Yet, Beck (1986) reminded us that, while one need not be religious to be spiritual, "large questions" of life have been explored for millennia by religious traditions; as such, religious traditions are bound to have a great many profound insights to offer regarding images, perspectives and principles of living, and these can be discerningly drawn on even by nonreligious people (p. 156).

The issues regarding the distinction between religion and spirituality, and their corresponding places in education are well addressed by Huebner. For Huebner (1985c/1999), "to speak of the 'spirit' and the 'spiritual' is not to speak of something 'other' than humankind, merely 'more' than humankind as it is lived and known" (p. 343), and that "talk of the 'spirit' and the 'spiritual' in education need not, then, be God talk ... Rather the talk is about lived reality, about experience and the possibility of experiencing" (p. 344). Nevertheless, he also maintained that the veins of language about the spiritual within various religious traditions should be mined for educators, although interpretation of the experiences that are stored in histories, stories, myths, and poems requires more hermeneutic skill and sufficient care to ensure that no single religion is 
consulted or ignored. He recognized the histories, stories, myths and poems in various religious traditions as symbols of "moreness," of otherness, of the transcendent, and as symbols that life as lived can be different. These symbols may be "stories of relationships—of struggle, conflict, forgiveness, love — during which something new is produced: new life, new relationships, new understandings, new forms of power and political control" (p. 344). There may be symbols that signify the wholeness and unity of body/mind, of self/others, of human/natural world, and of the past/present/future (p. 344). There are also "symbols of at-one-ness when the inchoate and disturbing cohere in new meanings" (p. 344), or the "symbols of liberation, of exodus from various forms of enslavement and domination: personal, interpersonal, or social” (pp. 344-345). For Huebner, these are "symbols of more than the present; more than current forms for life. These are the symbols of the spirit and the spiritual and how life as lived is, and can be, informed, reformed, and transformed" (p. 345). These symbols of the spirit and the spiritual point to not only dimensions of human experience that are beyond our sensory systems but also the fact that encountering, experiencing, and acknowledging the spiritual is possible (pp. 345,402 ), and these symbols are of great significance for education. As Huebner eloquently contended, everyone experiences, and continues to have the possibility of experiencing the transcending of present forms of life, of finding that life is more than is presently known or lived. This is what education is about. Education is only possible because the human being is a being that can transcend itself. (p. 345)

Nevertheless, being blinded by social and cultural systems, educators and students often "do not recognize their participation in the transcendent, in their ever open future" (Huebner, 1993/1999, p. 405), and do not realize that "we dwell in a near infinite world, that our possibilities are always more than we realize, and that life is a movement, change, or journey" (p. 404). Huebner 
$(1993 / 1999)$ thus underscored that "the question that educators need to ask is not how people learn and develop, but what gets in the way of the great journey - the journey of the self or soul" (p. 405), and education should be a way of attending to and caring for this journey.

Moreover, in addressing the issue of spirituality and knowing, Huebner (1985c/1999) emphasized that, the questions that are of primary interest to educators should be the relationship between knowing and the spiritual rather than "knowing the spiritual" or "spiritual modes of knowing", for these two expressions cannot exhaust the possible relationships between spirituality and knowing (pp. 345-346). While the vitality or power of life that makes people experience moments when present forms of behavior are somehow transcended are commonly labeled as "spiritual", Huebner (1985c/1999) elucidated that what is important is the experience itself, rather than the source, the reasons, or labels (p. 346), and that, "what is known from personal experience is not the spiritual, but the stories of one's life, its many transforming and transcending moments, ... Knowledge of one's self accompanies and follows these experiences, not knowledge of the spiritual" (p. 346). Besides, as records of those who have been transformed or have experienced the transcending moments, e.g. the originators and sages of major religions in the world, the language or symbols of religious traditions make possible knowledge of other people (pp. 346-347). These "are not modes of knowing the spiritual, but ways to know others, and consequently also ways to know one's self' (Huebner, 1985c/1999, p. 347). In addition, the moments of transforming and transcending are also stored by religious traditions in the spiritual disciplines (p. 347). These are not knowledge-producing disciplines, rather, these are "disciplines by which persons keep themselves open, available, and vulnerable so that they can be transformed and participate in experiences of transcendence" (p. 347). 
Therefore, "there are no modes of knowing the spiritual" (p. 348). The phrasing of knowing the spiritual in actuality refers to knowing one's self, others, and the disciplines for knowing one's self and others (p. 347). From this point of view, the denial or rejection of the spiritual in current education is in actuality equivalent to the rejection of genuine knowing of one's self, others, and the disciplines for knowing one's self and others.

Huebner (1985c/1999) continued that, there are also no spiritual modes of knowing, for claiming spiritual modes of knowing "is to assume privileged access to realms of experience" (p. 348), and if this is accepted, centuries of efforts to free diverse forms of knowing from the dogmas of particular religious traditions would be compromised (p. 348). However, Huebner underscored that,

an active dialectic between religious traditions and the many and diverse modes of knowing must be maintained. ... The understanding of religious traditions is usually enriched by new developments in the various fields of knowledge. The reverse is also true. To the extent that various modes of knowing are separated from religious traditions they become closed in upon themselves and lose their vitality, their 'spirit,' their creativity, and the possibility of being transcended. (p. 348)

As Huebner pointed out, "the qualities associated with the spiritual are foundational in every mode of knowing" (p. 349). Taking the scientific mode of knowing for example, Einstein (1930/1954) has maintained that, "the cosmic religious feeling is the strongest and noblest motive for scientific research" (p. 39) that gives a person the strength to remain true to their purpose (p. 40), and "only those who realize the immense efforts and, above all, the devotion ... are able to grasp the strength of the emotion out of which alone such work ... can issue" (p. 39). 
Since various modes of knowing, even everything that is done in schools and in preparation for school activities, e.g. the everyday teaching and study of various disciplines, in depth, are already infused with the spiritual despite the fact that traditional religious symbols may not be employed explicitly, what is needed is not to see the spiritual as something special that is outside of school curriculum and activities (Huebner, 1985c/1999, p. 348; Huebner, 1993/1999, p. 414), but "to probe deeper into the educational landscape to reveal how the spiritual ... is being denied in everything" (Huebner, 1993/1999, p. 414).

In the educational literature, more often than not, the concepts of spirituality are delineated by means of a list of personal characteristics or descriptions of certain aspects of spirituality without examining deeper into the nature of human existence. For example, Beck (1986) has attempted to approach the concepts of spirituality through a listing of specific characteristics typical of spiritual people, including awareness, breadth of outlook, a holistic outlook, integration, wonder, gratitude, hope, courage, energy, detachment, acceptance, love and gentleness (pp. 151-153). In the preceding section, we have also recognized some aspects of spirituality addressed by various researchers, such as connectedness to a life force, the inner search for wholeness and the realization of interconnectedness to others, an ongoing moving toward one's more authentic identity, healing, altruistic and emancipatory learning, the search for a deeper philosophical meaning and purpose of life, and change of mind. Although the identification of these characteristics or aspects regarding the concepts of spirituality is undoubtedly helpful and valuable, it fails to give us a full picture of what spirituality is. 
One reason for the failure of these characterizations of spirituality to give us an integral perception of spirituality is that, spirituality, rather than being merely some desirable qualities of humanity or special capabilities to be pursued, as discussed earlier, is "about lived reality, about experience and the possibility of experiencing" (Huebner, 1985c/1999, p. 344). It is a

foundational aspect of human knowing and an integral aspect of human life, and every aspect of human life is already infused with it. From this perspective, the attempt to understand or cultivate spirituality could be futile if it is done by means of merely focusing upon certain aspects of its phenomenal manifestation without probing deep into the nature of human existence. Huebner's elucidation of the significance of veins of religious language for education discussed in this section unveil the intimate relationship between spirituality and the nature of human existence and made clear why education need to be grounded on the acknowledgement of the transcending nature of human being. His suggestion that the need is not to see the spiritual as something special that is outside of ordinary school curriculum and activities, but to probe into how the spiritual is being denied in everything on the educational landscape points to the significant spiritual approach of negation that will be explored in Chapter Four. Following Huebner's suggestion, in the next section, for the purpose of exploring how the spiritual is being denied in everything in the educational landscape, significant epistemological concerns about education are examined.

\subsection{Significant Epistemological Concerns over Education}

As discussed in chapter one, during the period of the merger of educational and scientific traditions, positivism and its associated absolutistic and objectivistic worldview dominated. As a result, the spiritual wisdoms of longstanding religious traditions were largely rejected. By 
introducing the concept of "the transcendent", Huebner suggested a spiritual alternative to positivism (Alexander, 2003, p. 236). While tying education closely to spirituality, to the transcendent and religious symbols, Huebner did not rule out the connection between education and knowing. Rather, this tying merely transforms what we mean by knowledge, and what are ruled out in this epistemological change are the absolutism and objectivism that often associated with positivist science (Alexander, 2003, p. 237).

In contrast to absolutism, Huebner (1985c/1999) held that present forms of knowing are always incomplete, always fallible. Behind every confidence and certainty is residual doubt. As scientists have pointed out, the only thing known for certain is what is not true, what has been disproved. There is always a better way of being in the world, more complete prediction, more perfect expression of experience and feeling, more just meetings with others, better techniques and instrumentalities. (p. 349)

For Huebner, the possibilities of knowing, feeling, being, doing and speaking are always more than we realize. His emphasis on the dwelling of the transcendent in human being dismissed absolutism. As he said, "the human being dwells in the transcendent, or more appropriately, the transcendent dwells in the human being. To use more direct religious imagery, the spirit dwells in us. Our possibilities are always before us" (Huebner, 1993/1999, p. 404).

Contrary to objectivism, Huebner holds that knowledge entails subjective engagement (Alexander, 2003, p. 237), "every mode of knowing is also a mode of being in relationship. It is a relationship of mutual care and love" (Huebner, 1985c/1999, p. 349). He exemplified that, like 
the land, as the modern ecology movement suggested, will care for those who care for it, the knowledge between two people (e.g. parent and child, or two in love) also points to such dialectic between knowing and loving (p. 349). This dialectic is also manifested in the Biblical Hebrew word for "to know", which also means an intimate or sexual relationship (p. 349). He explicated that, only by "letting one's self be in the care of a part of the world one is informed by it. The distortion of this relationship of mutual care and love occurs only when caring is for the self and knowing becomes an act of control, often an act of violence" (p. 349). Knowledge as a symbolic and referential system, therefore, "points to something beyond those using it, is a twofold relationship. It depicts our love, or lack thereof, for the earth and those of us who people it. Thus, knowledge is also ... a manifestation of love and its distortions" (p. 365).

Likewise, drawing on philosophy of science, Palmer (1983/2003a) also criticized objectivism as wrongly "assuming a sharp distinction between the knower and the objects to be known" (p. 63). He cited Fritjof Capra that,

the electron does not have properties independent of my mind. In atomic physics, the sharp Cartesian split between mind and matter, between I and the world, is no longer valid. We can never speak of nature without, at the same time, speaking about ourselves. (p. 64)

Knowledge, therefore, is neither subjective nor objective, but something transcendent of both (Palmer, 1983/2003a, p. 65). Despite the fact that objectivism is no longer convincing, Palmer (1983/2003a) noted that it "is institutionalized in our educational practices, in the ways we teach and learn ... through the power of "hidden curriculum'" (p. 65). Through our conventional ways of teaching, "we form students in the objectivist worldview" (Palmer, 1983/2003a, p.65). He 
criticized some pedagogical experiments for dealing only with techniques but leaving the underlying epistemology unexamined and unchanged, and emphasized that to "find new ways of transmitting knowledge, we must first find a new knowledge. To find a better medium, we must find a better message" (Palmer, 1983/2003a, p. 66). The message that education should convey, Palmer argued, is truth. He traced the Germanic root of truth that is also the origin of the word "troth" as in the vow "I pledge thee my troth" (Palmer, 1983/2003a, p. 66). With this troth, "one person enters a covenant, a pledge to engage in a mutually accountable and transforming relationship, a relationship forged of trust and faith" (Palmer, 1983/2003a, p. 66). Therefore, "truthful knowing weds knower and the known. ... We find truth by pledging our troth, and knowing becomes a reunion of separated beings whose primary bond is not of logic but of love" (Palmer, 1983/2003a, p. 67). Truth demands the acknowledgement of the interdependence of the knower and the known that co-participate in a community of faithful relationships (Palmer, 1983/2003a, p. 67). While advocating the imperative to educate toward the truth, Palmer emphasized that it "does not mean turning away from facts and theories and objective realities" (Palmer, 1983/2003a, p. 67). Devoting ourselves to truth does not necessarily change the facts, what is changed "is our relation to the facts, or to the world that the facts make known" (Palmer, 1983/2003a, p. 67).

Both Huebner's and Palmer's philosophies reflect a non-dualistic or non-objectivistic worldview that weds the knower and the objects to be known, and espouse truthful knowing as being in a relationship of mutual care and love that is forged of trust and faith by pledging our troth to engage in a mutually accountable and transforming relationship. For both of them, knowledge does not always mean truth. Rather, in the absence of mutual care and love, knowledge can be 
mere distortions of truth, and knowing becomes an act of control or violence. As a manifestation of mutual love and care that weds the knower and the objects to be known, this non-dualistic worldview is what education should convey.

This non-dualistic worldview can also be understood in terms of the subject-subject attitude proposed by Huebner. For Huebner (1963/1999), although the dichotomy of the world into subject and object has been essential for the progress of classical science, it is also a barrier to conversation (p. 88). He proposed a subject-subject attitude, or what Buber called the I-Thou relationship in contrast to the I-It relationship, as an alternative to the objectivistic dichotomy of subject-object attitude (pp. 88-89). Within this subject-subject or I-Thou mode, the "butterfly and the fellow traveler and the rainbow and the pebble are no longer just objects and you a subject. They too become subjects which cannot be completely grasped. They have an existence alongside your existence" (Huebner, 1959/1999, p. 5), and the world of nature and people is no longer something to be studied, predicted, controlled and used, but to love, to live with, to communicate with, and to participate with (Huebner, 1963/1999, pp. 88-89).

However, for a communication to be a real dialogue or true conversation, it requires our willingness to be influenced by the others, and this willingness to be influenced demands openness towards the world of nature and people (Huebner, 1963/1999, p. 78). Drawing on Heidegger who speaks of truth as openness to being, Huebner (1985c/1999) maintained that truth "acknowledges the incompleteness and expects to uncover something else. This is the fissure in human knowing, the openness that is part of the spiritual" (p. 349). In other words, truth involves the openness to the transcendent that connoting infinite possibilities. Huebner 
(1963/1999) underscored that, however, real dialogue or true conversation also requires love, and in an ongoing helical process of true conversation, "man attempts to break through his solitude, affirm the existence of the other, and meet him as an equal— free, alone, and of infinite value" (p. 78).

Speaking from a practical perspective, Huebner's proposal of the subject-subject attitude and the concept of true conversation expand our understanding of the non-dualistic worldview and the concept of the transcendent. Together, the openness to the transcendent that connotes infinite possibilities and the non-dualistic worldview as a manifestation of mutual love and care that wed the knower and the objects to be known constitute two prominent aspects of spiritual truth and two of the most significant spiritual epistemologies that rules out absolutism and objectivism.

The openness to the transcendent and the non-dualistic worldview as two of the most significant aspects of spiritual truth and epistemology resonate with not only the characteristics of nature, but also the core wisdom common to various religious and spiritual traditions that is often referred to as the perennial philosophy. In Aldous Huxley's book on perennial philosophy written in 1970, a brief definition of perennial philosophy is:

the metaphysic that recognizes a divine Reality substantial to the world of things and lives and minds; the psychology that finds in the soul something similar to, or even identical with, divine Reality; the ethic that places man's final end in the knowledge of the immanent and transcendent Ground of all being - the thing is immemorial and universal. (as cited in Miller, 2007, p. 16)

Miller (2007) also identified the elements of perennial philosophy as: 
1. There is an interconnectedness of reality and a mysterious unity ... in the universe.

2. There is an intimate connection between the individual's inner self, or soul, and this mysterious unity.

3. Knowledge of this mysterious unity can be developed through various contemplative practices.

4. Values are derived from seeing and realizing the interconnectedness of reality.

5. This realization can lead to social activity designed to counter injustice and human suffering. (pp.17-18)

Huxley's brief definition of the perennial philosophy and the elements of perennial philosophy identified by Miller provide us with a glimpse at the essential consensus of various religious and spiritual traditions that recognize a divine Reality as the immanent and transcendent Ground of all being, the interconnectedness of reality, and the intimate connection of one's inner self to the mysterious unity. This essential consensus reveals the fact that the openness to the transcendent and the non-dualistic worldview - two of the most prominent aspects of spiritual truth, are common to various religious and spiritual traditions.

Grounding his holistic thinking upon perennial philosophy, Miller (2007) explored spirituality and its relationship with education from a holistic point of view (p. 16) and strove to "bring education into alignment with the fundamental realities of nature. Nature at its core is interrelated and dynamic" (p. 3). He argued that, if "nature is dynamic and interconnected and our education system is static and fragmented, then we only promote alienation and suffering" (Miller, 2007, p. 5). The characteristics of nature as being dynamic and interrelated are in resonance with the aforementioned spiritual truth that features the openness to the transcendent 
and the non-dualistic worldview. The dynamic and interrelated features of nature are also found in the perennial philosophy, which "acknowledges diversity and the fact that the universe is in process; however, underlying diversity and change is unity. This unity is not monistic; instead, the emphasis is on the [dynamic] relationship between the whole and the part" (Miller, 2007, p. 18). As Miller (2007) indicated, "it is this relationship that is at the heart of the perennial philosophy" (p. 18). However, despite the fact that the existence of a mysterious unity is essential to various religions, akin to Huebner's assertion that what is important about the transcendent moments is the lived experience itself rather than the source or labels of the spiritual, Miller, drawing on Gandhi, also emphasized that this unity or interconnectedness of reality is evident in everyday life, and "should not be relegated to remote forms of mysticism" (p. 18). The openness to the transcendent and the non-dualistic worldview as two of the most prominent aspects of spiritual truth, thus, need to be understood from the perspective of the everydayness and can well be mined by educators for educational purposes.

The above exploration of significant epistemological concerns over education, including absolutism and objectivism, not only reveals how the spiritual is being denied in everything in educational landscape, but also extends our understanding of the relationship between spirituality and knowing as well as the conception of spiritual truth and its relationship with education. In the next section, this extended understanding of the conception of truth and its relationship with education is discussed. 


\subsection{The Relationship Between Truth and Education}

In previous section, the openness to the transcendent and the non-dualistic worldview are recognized as two significant spiritual epistemologies for education that rule out absolutism and objectivism. By means of considering the openness to the transcendent and the non-dualistic worldview as two of the most significant aspects of spiritual truth, the conception of truth and its relationship with education are explored in the following.

On one hand, as discussed earlier, spiritual truth as "openness to being" acknowledges the dwelling of the transcendent or the spirit in the human being and the transcendent possibilities of human lives. It is the openness to the transcendent that makes possible various modes of knowing, and in turn, education. As Huebner (1985b/1999) eloquently articulated, education is the lure of the transcendent — that which we seem is not what we are for we could always be other. Education is the openness to a future that is beyond all futures. Education is the protest against present forms that they may be reformed and transformed. Education is the consciousness that we live in time, pulled by the inexorable Otherness that brings judgment and hope to the forms of life which are but the vessels of present experience. (p. 360)

Nonetheless, the lure of the transcendent is threatening (Huebner, 1985b/1999, p. 363). Huebner (1985b/1999) indicated that in the face of the threats of the unknown and the stranger outside and inside of us, we need the assurance that life can be whole again and will be enhanced rather than destroyed, and love is the assurance (pp. 363-364). As he maintained, "the power of love can acknowledge weakness. Love heals the differences within us. It reconciles the new tensions and divergences in our life" (p. 364). As reconciliation, love and care 
provide the patience, trust, collective memories and hopes, and conversation to heal the social body — to bring wholeness to the family, class, organization, or gathering which appeared to be disrupted by the newness. Love and care provide the assurance that the family or social gathering will not be destroyed if it gives up some of what it has come to value, but will find new life and new meaning. (p. 365)

The non-dualistic worldview, as a manifestation of omnipresent love and a significant aspect of spiritual truth that embraces truthful knowing as being in a relationship of mutual care and love, therefore, is crucial for the real happening of education. In tandem, the openness to the transcendent and the non-dualistic worldview as two of the most prominent aspects of spiritual truth and two of the most significant spiritual epistemologies for education that rule out absolutism and objectivism become the ground that ensure the possibilities and real happenings of education.

On the other hand, however, the "truth" that is assumed and grasped by individuals varies. Sometimes, these sorts of "truth" take the forms as static, absolute and objective knowledge. Nonetheless, for Huebner (1985c/1999), this kind of knowledge is but deadened knowledge rather than truth. Similar to Palmer's (1983/2003a) concern for the institutionalization of objectivism in our educational practices (p. 65), Huebner (1985c/1999) addressed the same issue and pointed out that the problem is that our schools and other educational institutions are not places of knowing, but places of knowledge which is a fallout from the knowing process and is form separated from life (p. 351). He underscored that, until the present forms of knowledge are once again brought into the process of truthful knowing, the knowledge is dead (p. 351). Also, "if the student is brought into the deadness of inert knowledge, the student is also deadened, 
alienated from the vitality that co-creates the worlds of self and others. By enlivening knowledge, the student is also empowered" (Huebner, 1985c/1999, p. 351). The way to enliven knowledge, Huebner (1985c/1999) indicated, is "to accept it with doubt and to place it back into the eternal cycle of openness, love, and hope" (p. 351) which is "the story of human life as celebrated in religious traditions" (p. 350). In other words, the enlivening of knowledge requires us to educate toward the spiritual truth based on the openness to the transcendent that connotes infinite possibilities and the non-dualistic worldview as a manifestation of mutual love and care that weds the knower and the objects to be known. Education, as the lure of the transcendent, therefore, entails the examining, overcoming, transforming, reforming, shifting and transcending of the presently assumed "truth" that is grasped by an individual.

The above perspective of education is not new, but has been "articulated and used by educators and philosophers for centuries" (Miller, 2007, p. 67). Miller (2007) referred to Hadot's (2002) book titled What is Ancient Philosophy and stated that, "Platonic dialogues were not just an intellectual exercise but a form of spiritual practice that demanded self-inquiry and selftransformation" (p. 68). According to Miller, in The Republic, Plato contended that education "should teach the person to see beyond the impermanence of the material world to intuit the "real world' of ideas" (p. 69). Besides, Heidegger (1942/1962) also noted that, in Book VII of The Republic, Plato opened it with the allegory of the cave, and introduced it by the sentence: "Next, said I, here is a parable to give us an aspect (of the essence) of education as well as of the lack of 
it, which fundamentally concerns our Being as men ${ }^{2}$ " (Heidegger, 1942/1962, p. 257). For Heidegger (1942/1962), Plato's allegory of the cave as a metaphor for education that concerns "our Being as men" also depicted a four-stage transition of the essence of truth presumed or realized by an individual (Heidegger, 1942/1962, pp. 251, 257).

As depicted in Heidegger's (1942/1962) work on Plato's doctrine of truth, in the first stage of this allegory, Plato likened human beings to a strange sort of prisoners in an underground cave who are chained and prevented from moving their legs and heads during all their lives (pp. 251252). Being so confined, they "would have seen nothing of themselves or of one another, except for the shadows (constantly) thrown by the fire-light on the wall of the cave facing them" (Heidegger, 1942/1962, p. 252), and would suppose the passing shadows as the real beings. Then, in the second stage, when one of them was set unchained, forced suddenly to turn his head and eyes around, and told that what he had formerly seen was only nothingness, he certainly would be "perplexed and believe what he formerly saw ... to be [more real and] more unhidden than the objects now shown to him" (Heidegger, 1942/1962, p. 252), and he would try to escape and turn back if he were forced to look at the fire-light itself that made eyes ache (Heidegger, 1942/1962, pp. 252-253). In the third stage, when the unshackled prisoner was dragged through the steep and rugged ascent to the upper world outside of the cave, he would need to grow

${ }^{2}$ In this thesis, the usage of the masculine gendered language, such as "men" for human, "he" for s/he, etc., in the direct quotations from Heidegger's works is not altered only to prevent the loss of meanings specific to the corresponding historical context. No gender discrimination is intended. 
accustomed before he could see things in this upper world lying in the sunlight and then, lastly, the sun as it is in itself with the realization that the sun is "the cause of all that he and his companions (who are remaining down in the cave) used to see" (Heidegger, 1942/1962, p. 253), and the sun as the highest and the primary first cause is called by Heidegger (1942/1962) as the divine, the Idea of the Good, the Idea of all ideas, or the Highest Idea (pp. 262, 264, 268), which cannot be grasped directly with the sensorial tools of the body, only sighted in the suprasensuous/nonsensuous ${ }^{3}$ glance (p. 268). At that time, when he remembered the cave and

${ }^{3}$ The phrase suprasensuous/nonsensuous glance refers to the experience outside of the cave depicted in the third stage of Plato's allegory of the cave. According to Heidegger (1942/1998), in passage (516), Plato depicts the adaptation of the gaze to the ideas outside of the cave (to look at the sun as it is in itself in it own domain, rather than just at its reflection) and says (516 c3): Thinking goes ... "beyond" those things that are experienced merely in the form of mere shadows and images, and goes ... "out toward" these things, namely, the "ideas." (p.180). Heidegger explicated that

these are the suprasensuous, seen with a nonsensuous gaze; they are the being of beings, which cannot be grasped with our bodily organs. And the highest in the region of the suprasensuous is that idea which, as the idea of all ideas, remains the cause of the subsistence and the appearing of all beings. Because this "idea" is thereby the cause of everything, it is therefore also "the idea" that is called "the good." This highest and first cause is named by Plato and correspondingly by Aristotle ... the divine. (p. 180) In Chapter Three, I explore how the concept of the "ideas" might be understood as information carried by particles and radiation. 
his fellow prisoners, he would surely be happy for himself in the change and feel sorry for them, and would never "be likely to covet the prizes or envy the men exalted to honor or power in the cave", and would "endure anything rather than go back to his old beliefs and live in the old way" (Heidegger, 1942/1962, p. 253). Finally, when he returned to the cave and managed to free the other prisoners, he would face the ridicule from the prisoners and also risk being killed by those who were so obsessed with their own "opinions" and rejected to surmise even the possibility that what they considered as real "is only real in a shadowy sense" (Heidegger, 1942/1962, p. 255).

On one hand, Heidegger (1942/1962) argued that, the significant force of Plato's allegory of the cave is that it makes the essence of education visible and knowable by virtue of illustrating the transitions from one stage to another that always demand a reorientation of the soul (pp. 255256). At the same time, Heidegger (1942/1962) reasoned that, Plato also wanted to show that the essence of education

is not in pouring mere knowledge into the contrary, where there is pure education the soul itself is seized and transformed as a whole, while at the same time man is transplanted to the region of his essence and oriented to it. (p. 256)

On the other hand, Heidegger maintained that, "what underlies Plato's thinking is a change in the essence of truth" (p. 257). Given that this allegory can show both education and truth, Heidegger reasoned that, there must be an essential relationship between them (p. 257). Also, similar to what is maintained by Huebner $(1985 \mathrm{c} / 1999)$ that "education is only possible because the human being is a being that can transcend itself" (p. 345), Heidegger (1942/1962) indicated that this relationship between education and truth "is found in the fact that the essence of truth and the manner of its change first made 'education' in its fundamental structure possible" (p. 257). 
Besides, in resonance with what is found in previous discussion that education entails the overcoming and shifting of the presently assumed truth that is grasped by an individual, Heidegger also maintained that what links education and truth into an essential unity is the fact that the transplanting of man into the region of his essence in pure education "is only possible if everything commonly known to man up to this time and the way it was known become different. That which is persistently unhidden to man and the manner of this unhiddenness has to change" (p. 257). According to Heidegger, in this allegory, the word "unhiddenness" in Greek can also be translated as truth, and the change of the definition or essence of truth or unhiddenness presumed or realized by an individual always involves steady overcoming of a hiddenness of the hidden, which is the pretended and the disguised (pp. 257, 260-261).

Heidegger's standpoint not only underpins Huebner's (1985b/1999) contention that education is the lure of the transcendent (p. 360), but also suggests the imperative of an epistemological conversion - a conversion from absolutism and objectivism to the openness to the transcendent and a non-dualistic worldview—-for the possibility and real happening of education. As revealed in the above brief account of the allegory of the cave, in the first stage, the prisoners "would have seen nothing of themselves or of one another, except for the shadows (constantly) thrown by the fire-light on the wall of the cave facing them" (Heidegger, 1942/1962, p. 252). Due to seeing no interrelationship to themselves and each other and the fire and more real things that create the shadows, what is presented in the shadowy phenomena is presumed by the prisoners as the only truth. This lack of awareness of these interrelationships and the hidden possibilities intrinsic in these relationships becomes what traps the prisoners and what hinders real education. 
Besides, in the depictions of the first three stages, which represent three different levels of realization of the truth or unhiddenness, it is worth noting that the transitions from one stage to another require being unchained, told, forced and dragged by the others. However, as depicted in the final stage, we human beings, the prisoners, might be so reluctant to listen to the others who return from outside of the cave and so obsessed with our own opinions, and reject to surmise even the possibility that what we consider as real is only real in a shadowy sense. Although Heidegger (1942/1962) declared that this allegory does not only deal with truth, but also contains Plato's doctrine of truth, the questions are: What is the extent of the truthfulness of Plato's doctrine of truth in the allegory of the cave? What is the significance of the transitions of the essence of truth for human beings?

Thus, while the relationship between education and truth is well illuminated in Plato's allegory of the cave, the above two questions suggest the necessity of an in-depth exploration of the spiritual truth and a panorama of the whole spiritual path from different perspectives for pondering the truthfulness of the allegory and the significance of the transitions of the essence of truth for human beings that, as discussed earlier, are crucial for comprehending the essence and purpose of education. In other words, before we proceed to deliberate how we might educate toward the truth, we need to make clear why Plato likened human beings to a strange sort of shackled prisoners that view merely the shadows on the wall of the cave as truth and reality, and what is the significance of the transitions of presumed truth depicted in this allegory. Otherwise, for those who embrace classical science and grasp absolutism and objectivism as taken-forgranted truth, either consciously or unconsciously, spiritual truth might never be considered as more truthful truth than what they had in mind, and the whole discourse regarding truth, 
spirituality and education might be easily neglected or dismissed as having neither truthfulness nor significance. In light of my religious background as a Buddhist and my identification of the threads of continuity between spiritual wisdoms in Buddhism and the phenomena, theories and philosophies of quantum physics, I now turn to that systems of thought to further explore the questions about truthfulness and significance articulated above. In the next chapter, I develop a dialogue between Buddhism and quantum physics that is conducive to the deliberation of the essence and purpose of education found in this chapter. 


\section{Chapter 3: Conceptual Framework-A Dialogue between Buddhism and Quantum Physics}

\subsection{Introduction}

In this chapter, for the purposes of verifying the truthfulness of both the doctrine of truth in Plato's allegory of the cave and the concepts of spiritual truth, particularly the transcendent and the non-dualistic worldview, found in previous review of educational literature, and of exploring the significance of the transitions of the essence of truth for human beings, I first investigate the concepts of truth in Buddhism and exhibit how they are in resonance with the concepts of spiritual truth and the significance of educating toward the truth found in previous review of educational literature. Second, by means of conducting a dialogue between Buddhism and quantum physics, I display how the concepts of truth in Buddhism are supported and enriched by various phenomena, theories and philosophies of quantum physics. Lastly, on the basis of this dialogue, I explore how these enriched veins of thought along with the increased confidence in the truthfulness of spiritual truth and the reaffirmed recognition of the significance the transitions of the essence of truth for human beings might lead to deeper insights into the essence and purpose of education identified in the preceding chapter and provide powerful tools for educational thinking and curriculum design.

\subsection{The Concepts of Truth in Buddhism-A Preliminary Exploration}

In Buddhism, truth refers to the true nature of self and reality, and the concepts of truth are multifold. In this section, the two truths, the four noble truths and an overview of spiritual path 
as revealed in the four noble truths, and how they resonate with the concepts of spiritual truth and the significance of educating toward the truth found in earlier review of educational literature are explored.

\subsubsection{The Two Truths}

In Buddhism, two truths - the ultimate truth (absolute truth) and the conventional truth (phenomenal truth, commonsensical truth or relative truth) - are distinguished. The ultimate truth is "the object known by a mind discerning the final nature of things - emptiness" (Newland, 2009 , p. 131); the conventional truth refers to "objects found by conventional minds that are not analyzing the ultimate nature of things. This includes everything that exists except emptiness" (Newland, 2009, p. 125). The right view ${ }^{4}$ (sammä-ditthi/samyag-drsțti) of the ultimate truth,

\footnotetext{
4 "Right view" or "right-view" is the translation of sammā-dițthi or samyag-drști and refers to the "right seeing". However, the rendering of right view as "right views" is not accepted, "since it is not a matter of holding "views" (opinions) but of "seeing things as they really are" (Walshe, 2007). According to Fuller (2005), “the notion of 'view' or 'opinion' (ditthi) as an obstacle to 'seeing things as they are' (yathābhütadassana) is a central concept in Buddhist thought” (p. 1). While Buddhist literature talks about right-view (sammā-ditthi) and wrong-views (micchä-ditthi), right-view does not stand in opposition to, or corrects, wrong-views, neither does it mean the relinquishment of all views (Fuller, 2005, p.1). Rather, right-view is

a detached order of seeing, completely different from the attitude of holding to any view, wrong or right. Right-view is not a doctrine, a correct proposition . . Right-view is practiced, not adopted or believed in. ... A correct knowledge of doctrine should not
} 
which means the correct seeing of the ultimate nature of things, is the realization of emptiness; and the right view of the conventional truth is a proper understanding of the cause and effect of karma and its results (Sopa, 2005, p. 22). It is the confidence in the certainty of the process of cause and effect that "positive karma definitely produces happy results and negative karma will definitely produce suffering results" (Sopa, 2005, p. 22). According to Sopa (2005), the right view of both truths is "the basis of all white dharmas, meaning that all positive, happy, and blissful experience arises from that right view" (p. 22). Thus, a correct understanding of both truths is crucial for Buddhist spiritual practices.

In the doctrine of Buddhism, consciousness, self and reality are inseparable. All phenomena, including the inner self and the external reality, are perceived as with an illusionary and projective nature and only exist in consciousness. This view is rooted in the central doctrine of

involve attachment. A true statement, if it is an object of attachment, is micchā-ditthi [wrong-views], even though it is still true. Wrong-view is a form of greed and attachment, right-view the cessation of greed and attachment. Right-view signifies the cessation of craving, not the rejection of all views" (Fuller, 2005, p.1).

Usually, our attachment to views or opinions originates from our inclination to hypostatize, reify or "thingify" concepts, and then take what is only a useful form of speech to refer to some absolute and real entity. For a more detailed discussion on hypostatization and the middle way approach to attain the right view of both the ultimate truth and conventional truth, please refer to Chapter Four. 
Yogacara $^{5}$ (the Consciousness-Only School of Buddhism), which maintains that "nothing exists except in the consciousness" (Wei, 1973, p. L). According to Wei (1973), in Thirty Verses on

${ }^{5}$ Yogacara (Yogācāra, in Sanskrit) is composed of yoga, which means discipline, and cara, meaning practice. Yogacara Buddhism, then, is in essence Buddhist practice of discipline (Bulter, 2010, pp. 33-34). According to Wei (1973), centered at the doctrine of vijñapti-mātra or cittmata (usually translated as consciousness-only or mind-only), which means "all is mind only" (p. 39) or "nothing exist except in the consciousness" (p. L), Yogacara is called Wei-shih (Mereconsciousness) school of Buddhism by the Chinese (p. L). However, some modern researchers object the translation of vijñapti-mätra or cittmata as consciousness-only or mind-only and its accompanying label of absolute idealism or idealistic monism, and suggest representation-only is a better translation (Kochumuttom, 1989, p. 5). In western academics, Yogacara texts have been available for fifty years or so, and since then, "there has been a debate as to how Yogacara Buddhism should be interpreted" (Bulter, 2010, p. 33). For example, while Lusthaus (2002) interpreted Yogacara as Buddhist phenomenology and indicated that "idealism is too vague to be meaningful” (p. 4) and that the commonly used idealistic positions are inappropriate for Yogacara (p. 5), Bulter (2010) argued that, whereas Lusthaus is correct to recognize the phenomenological aspect of Yogacara, he incorrectly believed in that Yogacara is phenomenology only (p. 39). For Bulter, the idealistic and phenomenological claims of Yogacara are not mutual exclusive, and one cannot deny Yogacara is idealism. However, he emphasized that "Yogacara, though similar in many regards with idealisms in the West, must be viewed as its own form of idealism" (p. 42). 
Consciousness-Only, Vasubandhu ${ }^{6}$ indicated that the concepts of self and reality do not imply the existence of ultimately real self and reality, they are merely fictitious constructions, and the phenomena of self and reality are based on the manifestation and transformation of consciousness (p. LVII).

Regarding this point, the founder of Chinese consciousness-only school Hsuan Tsang (596-664 A.D.) illuminated that

the inner consciousness manifests itself in what seems to be an external sphere of objects. ... Although the phenomena of [self and reality] . . lie within the consciousness, yet, because of wrong mental discrimination or particularization, they are taken to be external objects [that are distinct from consciousness]. (Wei, 1973, p. LVIII)

Hsuan Tsang illustrated this conception by employing the analogy of "a man in a dream, who in that state believes all the images he sees to be real external objects, whereas actually they are only the projections of his own mind" (Wei, 1973, p. LVIII). As shown by Buddha in the King of Concentrations Sutra, "all phenomena are empty of absolute reality, illusory like the moon reflected in the lake. They appear one way, but that is not their ultimate mode of existence" (Sopa, 2005, p. 139). This illusory and projective nature of all phenomena is in accordance with

\footnotetext{
${ }^{6}$ As a Buddhist philosopher, Vasubandhu ( $4^{\text {th }}$ to $5^{\text {th }}$ century C.E. $)$ was a great light at the peak of India's resplendent Gupta empire (Gold, 2015). He set a new standard for Yogacara philosophy in three concise works, and thereafter, Yogacara became the mainstream Buddhist metaphysics in India for half a millennium (Gold, 2015).
} 
the implication of Plato's allegory of the cave, and is the common ground of both ultimate and conventional truths taught by Buddha.

As the ultimate nature of self and reality, emptiness is a profound insight attained by an "ultimate mind," a mind that gets at the basis of things, through both inferential reasoning and introspective meditation (Newland, 2009, pp. 17, 58). In Buddhist terminology, the Tibetan and Sanskrit words that are translated as emptiness ${ }^{7}$, according to Newland (2009), do literally mean "emptiness" (p. 6). However, rather than referring to the lack or absence of meaning or hope or existence, it is the lack of an exaggerated and distorted kind of existence-a false absolute ${ }^{8}$, essential, and independent existence - that we have projected onto things and onto ourselves (Newland, 2009, p. 6; Sopa, 2005, p. 138). At first, as Newland (2009) said, it can be frightening to doubt about the substantiality of reality, and we might feel that persons and things cannot exist at all if they do not exist in a substantial way we are accustomed to seeing them (p. 7). Yet, according to Newland, "if it were our essential nature to be as we are, we would always be exactly that. We would be locked into existence-just-as-what-we-are-now. There could be no life—everything would be static and frozen" (p. 7). Thus, "our utter lack of a self-existent selfan independently existing self, an ultimately real self—-does not mean that we do not exist at all. Persons and other phenomena do exist interdependently" (Newland, 2009, p. 8).

${ }^{7}$ Other translations of emptiness include non-substantiality, void, latency, or relativity.

${ }^{8}$ In Buddhist understanding and some Western schools of scientific thought, "only something that doesn't change, that can't be affected by time and circumstance, or broken down into smaller, connected parts, can be said to be absolutely real" (Mingyur, 2007, p. 63). 
According to Buddha, the meaning of emptiness is coterminous with dependent origination or dependent arising, which means that all that exists come to being in dependence upon causes and conditions (Newland, 2009, p. 32; Yin-shun, 1960/1998, p. 132). Based on the causality that "in dependence upon this, that arises" (Newland, 2009, p. 125), we see that things exist and appear due to causes and conditions (Yin-shun, 1960/1998, p. 166), and "since those causes and conditions are existent and have arisen, they naturally depend on other causes and conditions ... Where there is a cause, there is an effect, . . apart from causes and conditions, nothing can exist" (Yin-shun, 1960/1998, p. 166).

On one level, the doctrine of dependent origination reveals "how everything that exists in the world is relative, dependent on other parts" (Sopa, 2005, p. 359). While persons and things appear to us to be independent and have their own self-existence or essential reality, in actuality they are empty of such independent, absolute and intrinsic nature. On this level, Buddha "is revealing the final nature of all things - the emptiness of all phenomena” (Sopa, 2005, p. 359). As Sopa (2005) said, "the meaning of emptiness is dependent arising" (p. 138). In Fundamental Treatise, Nagarjuna ${ }^{9}$ also illuminated that, whatever arises dependently we explain as emptiness

\footnotetext{
${ }^{9}$ Nagarjuna "is a Buddhist philosopher of the second century and a key figure in the development of Mahayana Buddhism in ancient India. Few figure in the history of Buddhism stand out more prominently than Nagarjuna" (Walser, 2005, p. 1). He "is prominently represented in the transmission lineages for both the Zen tradition and the various Tantric
} 
(Newland, 2009, p. 32). From this perspective, we see that phenomena "exist only through their interconnections with other (equally empty) phenomena" (Newland, 2009, p. 69). Indeed, "it is just empty things that exist and are active in cause and effect relations" (Newland, 2009, p. 37). Thus, not only emptiness and dependent arising are fully compatible, they are in actuality two ways of talking about the same view of the nature of reality (Newland, 2009, p. 32). Buddha's way of teaching emptiness and dependent origination as an integrated, unified view of the true nature of things is highly praised by Tsongkhapa ${ }^{10}$ (Sopa, 2005, p. 359).

On another level, as demonstrated in the theory of the twelve links of dependent origination, the doctrine of dependent origination is also taught by Buddha to reveal the process of cause and effect by which the circumstances of samsara ${ }^{11}$ arise (Sopa, 2005, p. 325). According to Yogacara doctrine, each of our actions of body, speech, and mind will "deposit a [karmic] seed or impression [or information] on the consciousness, which carries that seed forward as a potential, will eventually ripen and yield a result in the form of some type of future life experience" (Sopa, 2005, p. 328). Precisely speaking, in Yogacara doctrine, the karmic seeds are

traditions. He has been cited as a source of authority by personages as diverse as Tsongkhapa in Tibet and Dogen and Shinran in Japan" (p. 1).

${ }^{10}$ Also translated as Tsong-kha-pa, the founder of the Gelug school of Tibetan Buddhism.

${ }^{11}$ The Sanskrit samsara literally means wheel or circle, and "refers to the wheel or circle of unhappiness, a habit of running around in circle, chasing after the same experiences again and again, each time expecting a difference result" (Mingyur, 2007, p. 117). 
deposited in the eighth consciousness, also known as Alaya or storehouse consciousness ${ }^{12}$ (Choi, 2011, pp. 53-54). Before ripening, the karmic seeds carried by consciousness will never get lost,

${ }^{12}$ Yogacara philosophy distinguishes eightfold of consciousness. According to Wei (1973), the first six consciousnesses includes the five senses consciousness - the sight, hearing, smell, taste, and touch consciousnesses — and the sixth consciousness, also known as sense-center consciousness or Manovijnana (p. LVIII). These are consciousnesses that perceive and discriminate between spheres of objects (Wei, 1973, p. LVIII). The seventh consciousness, also known as thought-center consciousness or Manas consciousness, is consciousness that cogitates or deliberates (Wei, 1973, p. LVII). The eighth consciousness, also known as Alaya consciousness or storehouse consciousness or Alayavijnana, is consciousness whose fruits (retribution) mature at varying times (Wei, 1973, p. LVII).

The Alaya consciousness can be understood as the synthesis of the Subconscious Mind and the Supermind (Wei, 1973, p. LX). It is the most important among the eight kinds of consciousness. It actively storing up the potentials or "seeds" (Bijas) for the development or activities of the other seven consciousnesses, also passively habituated or "perfumed" by defiling dharmas of the other seven consciousnesses, thus creates more "seeds" in it (Wei, 1973, p. LXI).

The Manas consciousness "has the nature and character of cogitation or intellection" (Wei, 1973, p. LXXII). This consciousness takes the eighth consciousness as its object and its supporting basis for manifesting itself. It "perpetually thinks about the ego (Atman), to which it clings, it has close relationship with the four fundamental Klesas or vexing passions (source of affliction and delusion)" (Wei, 1973, p. LXXII). 
and become the causes of various forms of reincarnations (Choi, 2011, pp. 55-56). The twelve links of dependent origination are ignorance, formative activity, consciousness, name and form, the six sense bases, contact, feeling, craving, grasping ${ }^{13}$, existence, birth, aging and death (Sopa, 2005, pp. 324-360). As the very first of this causal chain, ignorance, meaning being ignorant of the ultimate truth of emptiness, is the most fundamental root of samsara (Sopa, 2005, p. 325). It "is a fundamental inability to recognize the infinite potential, clarity, and power of our own minds" (Mingyur, 2007, p. 117). The very point of the twelve links of dependent origination is that "all the causes that give rise to cyclic existence are within the individual" (Sopa, 2005, p. 352). As both a description of the empty nature of all experiences and phenomena as well as a description of the causal chain that perpetuates the cyclic forms of life process, dependent origination, thus, well unite the right view of both truths - the doctrines of emptiness and the law of the cause and effect of karma.

The concept of dependent origination appears easy to understand; nevertheless, Buddha said to Ananda that, the "true meaning of 'all things arise interdependently' is very profound" (Yin-shun, 1960/1998, p. 165), and since the meaning of emptiness is dependent arising, so is the meaning of emptiness. For example, by means of observing school buildings we can easily conclude that they do not exist by ways of their intrinsic nature because if they do, they would not depend on causes and conditions, and would not change. However, Newland (2009) reminded us that, "we

\footnotetext{
${ }^{13}$ The two levels of attachment — craving and grasping — are "the critical factors in actualizing and ripening karmic seeds, and thereby bringing about rebirth and all the experience of cyclic existence" (Sopa, 2005, p. 335).
} 
should not therefore conclude that the very meaning of emptiness- - things' lack of intrinsic existence-is simply that things are impermanent or that things depend on causes" (p. 67). He explicated that,

often we speak of dependent arising as though it was shorthand only for the dependence of effects upon causes and conditions. However, dependent arising also includes the idea that wholes depend upon their parts as well as the idea that all things depend upon being designated or imputed by consciousnesses. For example, fire arises in dependence upon fuel as a causal condition; but fuel is something that a mind identifies as burnable and on that basis thinks, "There is fuel." Likewise, cars are physically built up out of auto parts, but auto parts are recognized and imputed by the mind in consideration of their connection with real or potential cars. (pp. 69-70)

In Madhyamaka (the Middle Way school of Buddhism), "the term 'dependent arising' includes the notion that all things exist in dependence upon conceptual designation ${ }^{14,}$ (Newland, 2009, p. 70). Nevertheless, Thompson (2015) emphasized that, “such conceptual dependence doesn't mean that nothing exists apart from our words and concepts, or that we make up the world with our mind" (p. 331). It means that, upon a basis of designation, the identity of something as a single whole depends on how we cognitively conceptualize this basis and refer to it with a term (Thompson, 2015, pp. 330-131). This is the subtlest level of dependent arising, and is crucial for attaining a proper understanding of emptiness. It is also the type of dependent arising that is of

${ }^{14}$ According to Tibetan exposition of Madhyamaka, dependent arising happens at three levels: causal dependence, whole/part dependence, and conceptual dependence (Thompson, 2015, p. $330)$. 
the greatest significance for education and will be discussed later in chapter four.

A proper understanding of emptiness involves a precise identification of the object of negation without refuting too much (by denying production) to undermine ethics and negate the conventional existence altogether and fall prey to the extreme of nihilism, or refuting too little (by affirming intrinsic nature) to slip into the other extreme of eternalism or reificationism and leave our ignorance intact (Newland, 2009, pp. 28-38). This point is crucial in Buddha's teaching of the middle way. Following Buddha's middle way doctrine,

Tsongkhapa identifies this actual object of negation as things having their own way of existing without being posited through the force of consciousness. This is what we mean by "self" or "intrinsic nature." The sheer absence of this is emptiness. Therefore, at bottom, to understand emptiness means understanding that things have no way of existing apart from minds that impute them. (Newland, 2009, p. 70)

In other words, to understand emptiness properly means understanding the profound meaning of dependent origination and the central doctrine of consciousness-only that maintains nothing exists except in consciousness. Moreover, from this perspective, "even emptiness is itself empty; that is, when one searches for the ultimate essence of emptiness, it too is unfindable. One finds only the emptiness of emptiness" (Newland, 2009, p. 31). However, this does not mean that emptiness does not exist at all. While "emptiness — as the ultimate nature — does not depend on causes or conditions, it still exists only in interdependence with other phenomena. For Tsongkha-pa, emptiness - like all other phenomena - depends on the mind that recognizes it and knows, 'Emptiness exists'” (Newland, 2009, p. 63). 
In the above exploration, we have attained certain conceptual understanding of emptiness, however, the hidden meaning of emptiness is profound and cannot be fully grasped by virtue of only analytical reasoning. As Newland (2009) said, while it is transformative to know with certainty by means of inferential reasoning that things do not exist as they appear to us, "it is still a conceptual and therefore a dualistic kind of understanding" (Newland, 2009, p. 17). It is not yet a direct and truthful knowing of the actual ultimate truth, emptiness itself. Aiming at refining the conceptual and dualistic sort of understanding of emptiness into nirvana - a liberating and direct, non-dualistic experience of emptiness—along the spiritual path, bodhisattva ${ }^{15}$ becomes more and more familiar with emptiness by means of introspective meditation that links analysis with serene one-pointed concentration (Newland, 2009, pp. 17, 64). According to Newland (2009),

this culminates in the profound experience of direct, nondualistic mental perception of emptiness. For this ultimate mind, totally switched over to [another channel of reality] ..., no conventional phenomena appear at all. This is what Tsong-kha-pa refers to as the actual ultimate truth. That is, the bodhisattva does not at that time think, "I am realizing emptiness," or "Oh, emptiness really does exist." Only emptiness appears. (p. 64)

When switching back to the conventional channel of reality from the ultimate channel experienced in deep meditation, bodhisattvas understand how our everyday reality is merely

\footnotetext{
${ }^{15}$ A bodhisattva is a spiritual practitioner of Mahayana Buddhism with spontaneous motivation of bodhicitta, meaning "the desire to attain complete enlightenment in order to be able to benefit all sentient beings" (Sopa, 2008, p.6).
} 
conventional and is not at all the only or final perspective (Newland, 2009, p. 42). Yet, this direct and non-dualistic experience of emptiness does not at all wipe out the conventional reality; instead, the conventional reality has its own kind of validity as objects known by conventional consciousness (Newland, 2009, p. 42). What is wiped out by this profound direct experience of oneness is the dualistic egoist view that hinders the realization of the true nature of human existence that signifies infinite possibilities and omnipresent love intrinsic in everything. This experience is identical to the realizing of a mysterious unity depicted in the perennial philosophy, which, as discussed in chapter two, is the core wisdom common to various religious and spiritual traditions. However, as revealed in chapter two, both Huebner and Miller emphasized that, what is important about the transcendent and non-dualistic moments is the lived experience itself rather than the label or source, and such moments should not be relegated to remote forms of mysticism. As underscored in perennial philosophy, "this realization can lead to social activity designed to counter injustice and human suffering” (Miller, 2007, p. 18).

As mentioned earlier, the right view of both the ultimate and conventional truths is the basis of all positive, happy, and blissful experiences. In the above exploration, we have attained certain conceptual understanding of the ultimate truth of emptiness, yet Sopa (2005) reminded us that, since the law of the cause and effect of karma was categorized by Buddha as the extremely hidden phenomena and "the details of the relationship between karma and its results is extremely profound and subtle; they are much more difficult to understand fully than emptiness" (p. 23). The complexity of the relationships between karma and its results can be found in the Jataka stories, or in sutras, such as The Sutra of the Wise and the Fool, etc. For the purpose of gaining 
deeper insights into the law of the cause and effect of karma, its related phenomena and theories of quantum physics will be explored in the next section.

Due to the misunderstanding of the meaning of emptiness, there has been a recurring quandary about the compatibility between emptiness and the law of the cause and effect of karma: "If there is no 'I', no 'mine', and all dharmas are utterly empty, how can the law of karma prevail?' (Chang, 1983, p. 411). Chang (1983) inferred that, it is precisely because everything is empty [of an independent, absolute nature] and there is no [absolute, essential and independent] self or 'I', that everything can exist and the principle of karma can prevail. If things were truly existent, i.e., with a definite, enduring substance or entity, then no change or flow would be possible. Because nothing has selfnature (svabhava), everything is possible. (p. 411)

In other words, it is because all phenomena, including the inner self and external reality, are not ultimately real, but have a dependent arising nature, the law of the cause and effect of karma is able to function (Sopa, 2005, p. 139). As Sopa (2008) said, "understanding causality and that things do not exist as they appear are not contradictory" (p. 219). Therefore, not only emptiness does not mean nothingness, on the contrary, as the twelfth Tai Situpa Rinpoche said, "emptiness is described as the basis that makes everything possible" (Mingyur, 2007, p. 59). Mingyur (2007) further illuminated that "without emptiness, nothing could appear; in the absence of phenomena, we wouldn't be able to experience the background of emptiness" (p. 63), and that "emptiness, or infinite possibility, is the absolute nature of reality. Everything that appears out of emptiness ... is a relative expression of infinite possibility, a momentary appearance in the context of infinite time and space" (p. 63). From this perspective, the concept of emptiness and the concept of the 
transcendent are coterminous descriptions of the ultimate nature of self and reality that signify infinite possibilities. Besides, as the truthful knowing of the ultimate nature of self and reality, the direct, non-conceptual and non-dualistic experience of emptiness attained through introspective meditation extends our understanding of the non-dualist worldview as a meditative insight that reveals the ultimate wholeness and interconnectedness of everything in the phenomenal world. Together, the conceptual understanding of emptiness attained through inferential reasoning and the non-conceptual and non-dualistic direct experience of emptiness attained through introspective meditation provide us with alternative perspectives for understanding the concepts of spiritual truth, particularly the openness to the transcendent and the non-dualistic worldview, found in the previous review of literature.

Additionally, grounded on the consciousness-only doctrine that maintains nothing exists except in the consciousness and suggests an illusory and projective dream-like nature of all phenomena, the ultimate truth of emptiness also echoes with Plato's allegory of the cave wherein human beings are paralleled to a strange sort of prisoners that view the shadows on the wall of the cave as the only truth and reality. The integrated view of the ultimate nature of self and reality that associates the consciousness-only doctrine, emptiness, dependent origination and the law of the cause and effect of karma not only suggests that the key to infinite possibilities is in our consciousness but also illuminates why to speak of the spiritual is not to speak of something other than humankind, why the phrasing of "knowing the spiritual" is actually referring to knowing one's self, others and the disciplines for knowing one's self and others, and why various modes of knowing is already infused with the spiritual. 


\subsubsection{The Four Noble Truths}

In addition to the two truths, for those who are ready for aiming at the ultimate liberation from all samsaric sufferings and cyclic forms of existence, Buddha also taught the four noble truths, which consist of the truth of suffering, the truth of the cause of suffering, the truth of cessation and the truth of the path (Sopa, 2005, p. 4). According to Sopa (2005), by means of teaching the truth of suffering as the first one of the four noble truths, Buddha pointed to the significance of generating the desire for liberation. From the Buddha's perspective, most worldly beings "were deceived by the mistaken view that apprehends the attractions of samsara as sources of pleasure and happiness, when in fact they produce only dissatisfaction and suffering" (Sopa, 2005, p. 194). Being deceived by the attractive appearance of objects of desire, which is not at all the true causes of happiness and joy, sentient beings are entrapped in the cyclic existence and suffer (Sopa, 2005, p. 194). As Sopa (2005) said, even if we are in the prison of cyclic existence, if we do not perceive it as a problem, we won't have any incentive to get out of it, instead, we are used to it and attached to it (p. 192). This is why we need to contemplate on the truth of suffering. One of the ways of meditating on the truth of suffering is to contemplate the eight types of suffering, including the sufferings of birth, aging, sickness, death, encountering the unpleasant, separating from the pleasant, not getting what you want, and the appropriating of aggregates (the combination of body and mind) (Sopa, 2005, pp. 198-224).

For the cessation of suffering, we need to find out the cause of suffering. In Buddha's doctrine, the samsaric suffering is caused by various forms of contaminated karma, and the contaminated karma is produced by inner afflictions rooted in ignorance, which means being ignorant of the ultimate truth of emptiness of self and reality, and as a result, "grasping at a false conception of 
self" (Sopa, 2005, pp. 195, 296, 326). On an essential level, "ignorance distorts the basically open experience of awareness into dualistic distinctions between inherently existing categories of 'self' and 'other'. Ignorance is thus a twofold problem" (Mingyur, 2007, p. 117). By means of perceiving the self as something permanent, essential and independent, we "impute upon the ever-changing aggregates a permanent sense of self—an egocentric, central 'I' ”' (Sopa, 2005, p. 195), and start to perceive whatever is not self as the other (Mingyur, 2007, p. 117). Mingyur (2007) analyzed that, as a result, "everything we experience becomes, in a sense, a stranger" (p. 117), and by locking ourselves into a dualistic mode of perception, we become unable "to recognize the infinite potential, clarity, and power of our own mind" (p. 117), and "begin looking [outwardly] at other people, material objects, and so on, as potential sources of happiness and unhappiness, and life becomes a struggle to get what we need in order to be happy before somebody else grabs it" (p. 117). This egoistic view that grasps a false ultimately existent nature of the self and all phenomena is the root of samsara (Sopa, 2005, p. 299). However, ignorancethe root cause of suffering - is able to be eliminated and, according to Tsongkhapa, the principle antidote of this ignorance is the wisdom that realizes the emptiness of self (Sopa, 2005, pp. 195, 299, 327). The key to the cessation of samsaric suffering, thus, is in the right view of the ultimate truth—-the realization of emptiness.

With this right view in mind, we need also the methods to actually attain liberation. The truth of the path that will lead to personal emancipation from all of the sufferings of cyclic existence is embodied in the three trainings, which include ethical conduct or discipline, meditative stabilization and wisdom (prajña) that realizes emptiness (Sopa, 2008, p. 4). While it is the training of wisdom that actually brings about the cessation of suffering, achieving that level of 
realization requires the training of meditative stabilization, and both goals rely on the firm foundation of ethical conduct (Sopa, 2008, p. 4). For those who have developed the bodhisattva's motivation—bodhicitta, meaning the aspiration of attaining the highest spiritual goal of the omniscience of enlightenment for the liberation all sentient beings in the same miserable situation, Buddha expanded the path of three trainings into the Mahayana practices of six perfections (six paramitas ${ }^{16}$ ): the perfections of generosity, ethical discipline, patience, joyous perseverance, meditative stabilization, and wisdom (Sopa, 2008, p. 8). According to Sopa (2008), each of the six perfections is a complex combination ${ }^{17}$ of methods (mainly the first four or the first five perfections) based on bodhicitta and wisdom (mainly the last two perfections or the sixth perfection) based on the realization of emptiness, and "each perfection supports and is part of the practice of the others" (p. 8). Thus, in the explanation and application of generosity, for example, there is the generosity of generosity, the ethical discipline of generosity, ... and the wisdom of generosity (Sopa, 2008, p. 209). Therefore, the six perfections are not a fixed set of religious dogma to be observed mechanically within the framework of subject-object duality, but a dynamic and recursive matrix corresponding to vicissitudinary existential situations for

\footnotetext{
${ }^{16}$ In Sanskrit, paramita literally means crossing over to the other shore. In Mahayana Buddhism, the six paramitas are the six spiritual practices that ferry one across the sea of suffering and mortality to the other shore of nirvana (Hsuan Tsang, 659/1973, p. 675).

${ }^{17}$ According to bodhisattva Maitreya, the six perfections or six paramitas can also be categorized into two groups: the first three perfections are the basis for helping other sentient beings, while the last two result in one's own goal of emancipation. The fourth perfection, joyous perseverance, is included in both groups (Sopa, 2008, p. 238).
} 
cultivating "the nonperceptual and with no object" (Sopa, 2008, p. 213) for approaching the ultimate truth of self and reality and for the liberation of both oneself and all the other sentient beings. Taking generosity as example, "generosity with no object refers to understanding that the gift, the giver, and the recipient are empty of inherent existence" (Sopa, 2008, p. 214), and "practicing giving with a realization of sunyata [emptiness] in the back of mind is nonperceptual generosity" (Sopa, 2008,p. 214). The other perfections work similarly. The point of the six perfections is to cultivate the understanding that there are no ultimately existing objects or subjects, however, this does not mean there are no subjects and objects at all (Sopa, 2008, p. 213). Rather, it is to cultivate the realization that "the subject and object of any action are relative, dependent, and like illusions" (Sopa, 2008, pp. 213-214). Nevertheless, as Buddha emphasized in the Sutra Gathering All the Threads, this does not mean that one should practice the perfection of wisdom only (Sopa, 2008, p. 204). The requirement of both the wisdom-side practices and the method-side practices will be explored further in chapter four.

The truth of suffering and the truth of the cause of suffering provide us with deepened insights into why being ignorant of the ultimate truth of emptiness and attaching to a dualistic mode of perception are the sources of sufferings. The truth of the cessation of suffering informs us that the key to the cessation of suffering lies in the cultivation and realization of the ultimate truth of emptiness, which signifies infinite transcendental possibilities and features a non-dualistic worldview. The truth of the path reveals the significant interrelationships between ethical conduct, meditative stabilization, and wisdom, and illuminates how each of the three trainings is indispensable to a spiritual pathway that will genuinely lead to positive, blissful life experiences and the achievement of various spiritual goals, may it be "a better rebirth in our next life, 
personal liberation from cyclic existence, or perfect buddhahood for the sake of all sentient beings" (Sopa, 2005, p. 4).

The above exploration of the four noble truths provides us with a glance at the essence of the spiritual path in Buddhism that not only deepens our understanding of the metaphor of the fourstage transitions depicted in Plato's allegory of the cave, but also, to an extent, gives answers to our question regarding the significance of the transitions of the essence of truth from one stage to another for human beings. Thus, the educational significance of the concepts of truth in Buddhism, including the two truths doctrine and the four noble truths, lies in that they make clear the existential significance of spiritual truths and spiritual practices for human beings that is intimately related to both the individual and collective experiences of genuine happiness and ultimate liberation. However, similar to the question of the extent of truthfulness of Plato's doctrine of truth, the educational significance of the concepts of truth in Buddhism need to be established upon the truthfulness of Buddhist doctrine of truth. For this purpose, in the following section, a dialogue between the concepts of truth in Buddhism and their corresponding or supportive phenomena, theories and philosophies in quantum physics is developed.

\subsection{A Dialogue between Buddhism and Quantum Physics}

As discussed previously, in the doctrine of Buddhism, consciousness, self and reality are inseparable, and the concepts of truth are established upon the doctrine of consciousness-only that maintains nothing exists except in the consciousness. For the purpose of verifying the truthfulness of the consciousness-only doctrine and Buddhist doctrine of truth, in this section, based on my identification of threads of continuity between the two systems of thought of 
Buddhism and quantum physics, I explore how we might understand the concepts of truth in Buddhism, including emptiness, dependent origination, the law of cause and effect of karma and the consciousness-only doctrine, from the perspective of quantum physics. The phenomena, theories and philosophies that will be examined include three parts: the quantum measurement problem, uncertainty and superstring theory; holographic principle; and quantum entanglement, the theory of It from Bit and participatory universe.

\subsubsection{The Quantum Measurement Problem, Uncertainty and Superstring Theory, and}

\section{Buddhism}

During the last hundred years, quantum mechanics is the most startling discoveries in physics that undermines the whole conceptual schema of classical physics (Greene, 2004, p. 177). According to Greene (2004), the concepts of space and time in classical physics, being established upon Newton's equations of motions, are absolute, rigid and immutable (pp. 7-8). However, in 1905, Einstein determined that space and time are not independent and absolute, but are enmeshed, relative, flexible and dynamic (Greene, 2004, p. 9). By the 1930s, propelled by experimental results, physicists were forced again to introduce a whole new conceptual schema known as quantum mechanics (Greene, 2004, p. 10). In contrast to classical physics, quantum theory portrays a distinct reality "in which things sometimes hover in a haze of being partly one way and partly another. Things become definite only when a suitable observation forces them to relinquish quantum possibilities and settle on a specific outcome" (Greene, 2004, p. 11). According to Copenhagen interpretation of quantum mechanics, it is not that a particle has a position and that we don't know it because we have not yet done the measurement. Rather, in contrast to what we would expect, a particle "simply does not have a definite position before the 
measurement is taken" (Greene, 2004, p. 94), it "exists in a nether state, a sum of all possible states, until a measurement is made" (Kaku, 1994, p. 260), and therefore, before measurement is made, the coexisting possibilities move collectively and behave like a wave. This is usually referred to as the quantum measurement problem. This phenomenon has been well illustrated in a variety of double-slit experiments (Greene, 2004, pp. 84-88) that culminated in 1974 when the Italian physicists Pier Giorgio Merli, Gian Franco Missiroli, and Giulio Pozzi successfully repeated Young's double-slit experiment using single electrons and showed that, while not being observed, even a single electron interferes with itself as predicted by quantum theory ${ }^{18}$ (Rosa, 2012). Niels Bohr summarized that everything "has both wavelike and particlelike aspects. They are complementary features" (Greene, 2004, p. 185).

Moreover, according to the Heisenberg uncertainty principle, quantum theory claims that "there are features of the world ... that cannot simultaneously have definite values" (Greene, 2004, p. 112). For example, a particle cannot simultaneously have definite a position and velocity, neither can it have a definite spin of clockwise or counterclockwise about more than one axis (Greene, 2004, p. 112). "Instead, particles hover in quantum limbo, in a fuzzy amorphous,

${ }^{18}$ In 2002, Young's double-slit experiment with single electrons was voted by readers of Physics World voted as "the most beautiful experiment in physics" of all time (Rosa, 2012). Rosa (2012) quoted Historian-philosopher Robert Crease that "the double-slit experiment with electrons possesses all of the aspects of beauty most frequently mentioned by readers. . . It is transformative, being able to convince even the most die-hard sceptics of the truth of quantum mechanics" (p. 180). 
probabilistic mixture of all possibilities; only when measured is one definite outcome selected from the many" (Greene, 2004, p. 112). This phenomenon echoes the doctrine of dependent origination and refutes the idea that particles have "their own way of existing without being posited through the force of consciousness" (Newland, 2009, p. 70) as discussed earlier. The mystic interrelationship between the observer's consciousness and the behavior of the observed electron becomes one of the most intriguing implications of this phenomenon. Since quantum theory is greatly at odds with our everyday experiences, at the time when quantum theory was first proposed by Niels Bohr and Werner Heisenberg, Einstein revolted against this concept and was fond of asking "Does the moon exist just because a mouse looks at it?" (Kaku, 1994, p. 260). However, according to Greene (2004), today, the majority of physicists agree that particle properties only "come into being when measurements force them to" (p. 121), and when "they are not being observed or interacting with the environment, particle properties have a nebulous, fuzzy existence characterized solely by a probability that one or another potentiality might be realized" (p. 121).

Apparently, quantum physics excludes absolutism and objectivism, and depicts a drastically different picture of reality than what is portrayed by classical physics. Nevertheless, for decades, there has been a permeating impression that quantum mechanics is only applicable in invisible microscopic realm (Verdal, 2011, p. 38). However, this assumption was overturned in 2010 when Aaron O'Connell created the world's first quantum machine and performed the first quantum measurement that is visible by naked eyes (Cho, 2010, p. 1604). The journal Science honored it as the Breakthrough of the Year of 2010, and commented that this machine "might lead to tests of our notion of reality" (Cho, 2010, p. 1604). This invention suggests that quantum 
mechanics is universally applicable to everything in both the microscopic and macroscopic realms. According to Greene (2004), if "quantum mechanics is a universal theory that applies without limitations to everything, the observed and the observer should be treated in exactly the same way" (p. 203). This equal treatment of the observer and the observed convincingly suggests the inseparability of consciousness, self and reality and a non-dualistic worldview. Furthermore, if quantum mechanics is applicable to macroscopic realm, then the seemingly absolute, substantial, essential and independent macroscopic material world, similar to the microscopic realm depicted by quantum theory, when not being observed, would also be merely "a nebulous, fuzzy existence characterized solely by a probability that one or another potentiality might be realized" (Greene, 2004, p. 121), and therefore, is in actuality empty of any absolute, substantial, essential and independent nature. This is exactly the meaning of emptiness.

The quantum measurement problem and the principle of uncertainty provide us with a scientific perspective for contemplating the doctrine of the truth of emptiness. Nevertheless, the true meaning of emptiness is more profound than we might have thought. According to superstring theory — a leading theory developed to unite general relativity and quantum mechanics - the particles (e.g. electrons, quarks, etc.) that are thought of as the smallest, indivisible constituents of matter, are not concrete dots at all (Greene, 2004, p. 17). Rather, it claims that, "every particle is composed of a tiny filament of energy, some hundred billion billion times smaller than a single atomic nucleus, $\ldots$ which is shaped like a tiny string" (Greene, 2004, pp. 17-18). And, much as different vibrational patterns of strings on a violin produce different musical notes, different vibrational patterns of the filaments of energy produce different particle properties (Greene, 2004, p. 18). Therefore, at the ultramicroscopic level, the universe described by superstring theory 
would be akin to a string symphony of pure energy vibrating matter into existence (Greene, 2004, p. 347). Moreover, for the fusion of general relativity and quantum mechanics to be mathematically sensible, superstring theory "requires nine spatial dimensions and one time dimension. And in a more robust incarnation of superstring theory known as M-theory, unification requires ten space dimensions and one time dimension" (Greene, 2004, p. 18). Superstring theory, thus, provides us with a novel framework for contemplating an elevendimensional space-time, to which the phenomenal world is referred as the basis of what are perceived in our daily life. From the perspective of superstring theory, the four-dimensional phenomenal world that we've so far glimpsed is but "a meager slice of reality" (Greene, 2004, p. 18), and is far from being substantial, absolute and permanent. Therefore, in his teaching of the emptiness of all phenomena, rather than denying the existence of the physical world of everyday life, what Buddha emphasized is that this is far from the ultimate reality (Choi, 2011, p. 90).

The doctrine of the ultimate truth of emptiness, when understood from the perspectives of the quantum measurement problem, the principle of uncertainty and superstring theory, becomes more sensible and conceivable and sensible. Other theories in quantum physics that also resonate with the concepts of truth in Buddhism are holographic principle and parallel universes. In the following, I explore how we might understand the central doctrine of consciousness-only, the concepts of dependent origination and the law of cause and effect of karma from the perspective of holographic principle and parallel universes. 


\subsubsection{Holographic Principle and Buddhism}

A hologram (holographic film) of an object is a piece of two-dimensional etched plastic negative produced by means of interference patterns of waves of two separate beams of a single laser light (Talbot, 2011, p. 14). When illuminated with appropriate laser light, a hologram will project a three-dimensional image by means of Fourier transforms, which are mathematics equations that are able to convert between three-dimensional images and waveform interference patterns (Greene, 2004, p. 482; Talbot, 2011, p. 27). In addition to the three-dimensionality of the projected image, another remarkable characteristic of holograms is the whole in every part property that every whatever small piece of fragment of a hologram contains all the information recorded in the whole. If a piece of hologram containing the image of an apple is cut into pieces and then illuminated by a laser, each one of these pieces will still be found to contain the entire image of the apple (Talbot, 2011, pp. 16-17). Evolving from David Bohm's holographic model of universe, which he called the holomovement (Bohm, 1980, pp. 190-197), and the parallel universe proposals, as well as "over thirty years of the theoretical studies on the quantum properties of black holes" (Greene, 2011, p. 8), the holographic principle envisions that "all we experience is nothing but a holographic projection of processes taking place on some distant surface that surrounds us" (Greene, 2011, p. 8).

As early as in the 1970s, based on a long-term contemplation and an inspiration kindled by hologram, quantum physicist David Bohm was convinced that the universe was a kind of giant, flowing hologram (Talbot, 2011, p. 46). For Bohm, "the tangible reality of our everyday lives is really a kind of illusion, like a holographic image" (Talbot, 2011, p. 46). Underlying this tangible aspect of reality, there is a deeper order of existence - "a vast and more primary level of 
reality that gives birth to all the objects and appearances of our physical world" (Talbot, 2011, p. 46) in much a similar way that a piece of hologram gives birth to a holographic image (Talbot, 2011, p. 46).

Bohm's idea of holographic universe explains many puzzles in quantum mechanics, including the effect consciousness seems to have on the subatomic world (Talbot, 2011, p. 49). He felt that "most physicists go about it the wrong way, by once again trying to fragment reality and saying that one separate thing, consciousness, interacts with another separate thing, a subatomic particle" (Talbot, 2011, p. 49). Bohm believed that it is meaningless to speak of the observing instrument and the observed object as interacting, because all such things are mere different aspects of an undivided wholeness, the holomovement (Bohm, 1980, p. 169; Talbot, 2011, p. 50). In addressing the issue of fragmentation between the observer and the observed, Bohm (1980) indicated that, "one of the most difficult and subtle points about this question is just to clarify what is to be meant by the relationship between the content of thought and the process of thinking which produces this content" (p. 23). By means of employing the metaphor of a turbulent mass of vortices in a stream, he explained that

the structure and distribution of vortices, which constitute a sort of content of the description of the movement, are not separate from the formative activity of the flowing stream, which creates, maintains, and ultimately dissolves the totality of vortex structures. . . Similarly, when we really grasp the truth of the one-ness of the thinking process that we are actually carrying out, and the content of thought that is the product of this process, then such insight will enable us to observe, to look, to learn about the whole movement of thought and thus to discover an action relevant to this whole, that will end 
the 'turbulence' of movement which is the essence of fragmentation in every phase of life. (Bohm, 1980, p. 24)

Bohm's metaphor of vortices in a stream well illuminates his point of how the observer and the observed, or the thinking process and its content, or consciousness and what is experienced, are mere different aspects of an undivided dynamic wholeness. His insights not only buttress the consciousness-only doctrine and the non-dualistic worldview, but also highlight the significance of the realization of the wholeness and interconnectedness of everything for guiding our actions and ending the fragmentation.

Later, in the early 1990s, based on the theoretical studies of information storage of black holes, the Nobel laureate Gerard't Hooft and Leonard Susskind started to envision a prototype of the holographic principle (Greene, 2004, p. 482). A consolidation of holographic principle came in 1997 when the Argentinian physicist Juan Maldacena made a dramatic breakthrough (Greene, 2004, p. 483). By applying superstring theory mathematically, he convincingly argued that, "everything taking place within the specified universe is a reflection of laws and processes acting themselves out on the boundary [surrounding this specified universe]" (Greene, 2011, p. 263). His results "realized explicitly the holographic principle, and in doing so provided the first mathematical example of Holographic Parallel Universes" (Greene, 2011, p. 263). Since "the holographic ideas have been subject to a great many stringent mathematical tests; having come through unscathed, they've been propelled into mainstream thought among physicists" (Greene, 2011, p. 269). In 2015, by means of calculating the value of entropy of entanglement, Arjun Bagchi, Rudranil Basu, Daniel Grumiller, and Max Riegler further theoretically confirmed the validity of the holographic principle (Vienna University of Technology, 2015). According to 
Greene (2011), there has been exciting evidence that the holographic ideas may well be able to be tested experimentally in the next few years (p. 263).

While holographic principle suggests that what we experience in daily life is but a reflection of a parallel process taking place in the boundary universe that surrounds us, "much as what we see in a holographic projection is determined by information encoded on a bounding piece of plastic" (Greene, 2004, p. 482), in reconfiguring our worldview, it is vital to bear in mind Bohm's caution against further fragmenting reality and saying that one separate thing interacts with another. Therefore, the eleven-dimensional universe depicted in superstring theory, the fourdimensional phenomenal world experienced in our daily life, the hologram-like source universe of information storing, processing and projecting, and the consciousness should be carefully considered as merely different aspects of an undivided wholeness, and therefore, inseparable.

Bohm's holographic paradigm also resonates with neuroscientist Karl Pribram's brain theory. By the 1970s, when Pribram has collected enough experimental evidence for his holographic brain theory, he met David Bohm and cooperated with him (Talbot, 2011, pp. 30-31). Their theories concluded that: "Our brains mathematically construct objective reality by interpreting frequencies that are ultimately projections from another dimension, a deeper order of existence that is beyond both space and time. The brain is a hologram enfolded in a holographic universe" (Talbot, 2011, p. 54). For Pribram, what we perceive as out there, including our own brains and bodies, are but "a vast ocean of wave and frequencies, and reality looks concrete to us only because our brains are able to take this holographic blur [of waveform interference patterns] and convert it into the sticks and stones and other familiar objects that make up our world" (Talbot, 
2011, p. 54). From this perspective, the seemingly objective world, which usually deemed as separate from our self, is but a filtered interpretation of our brain/consciousness out of one single undivided holographic universe, and the question regarding the two different aspects of realitythe aspect of what we perceive in our everyday life (the conventional aspect of reality) and the other aspect of the holographic blur of waveform interference patterns (the ultimate aspect of reality)—would be: “Which one is real and which is illusion?" (Talbot, 2011, p. 55).

The central concept of holographic principle is reified in Oxford philosopher Nick Bostrom's simple but curious philosophy that we are in a computer simulated universe (Greene, 2011, p. 288). As a theoretical physicist and string theorist, Brian Greene (2011) totally agreed with Bostrom's deduction and stated that "logic along can't ensure that we're not in a computer simulation" (p. 289), and that "after all, according to our belief, we're in one" (p. 289). In this computer simulation, a "sufficiently well-structured program would keep track of the mental states and intentions of its simulated inhabitants, and so would anticipate, and appropriately response to, any impending stargazing” (Greene, 2011, p. 287). At least, as Greene (2011) said, evidences for simulated worlds are grounds for rethinking the nature of our own reality (p. 293).

The holographic principle and computer-simulated universe provide us with a scientific framework for contemplating the central doctrine of consciousness-only that nothing exists except in the consciousness and Hsuan Tsang's analogy of a man in a dream. This scientific framework not only expands our understanding of the doctrine of dependent origination regarding how things cannot have independent ways of existence without the being posited through the force of consciousness, but also helps us realize the significance of consciousness in 
the creation of our own reality and how the division between inner self and external phenomena is merely illusionary in nature. In the West, the best-known philosopher that proponed a similar idealism is George Berkeley (Bulter, 2010, pp. 39-40; Siderits, 2007, p. 146). This is a sort of philosophy that not everyone will be persuaded to accept. An anecdote had reported that when Samuel Johnson heard of Berkeley's claim that matter is a figment of the mind's conjuring, he kicked a stone and said "I refute it thus!" (Greene, 2011, p. 298; Siderits, 2007, p. 146). Johnson's reaction is a representative refutation built upon an objectivist worldview. Nevertheless, from the perspective of holographic principle and Bostrom's computer simulated universe, Johnson's experiences, including his thoughts, body, speech, and the stone he kicked in what he thought of as an external objective world, are but abstraction and interpretation of his own consciousness in a computer simulated holographic universe that, in a sense, is akin to the experiences of a man in a dream. As Lusthaus (2002) stated, "even the notion that 'things exist external to my consciousness' is a notion conceived, affirmed, or denied in consciousness" (p. 5).

Moreover, given the whole in every part property of hologram, Bohm (1990) developed the notions of the enfolded or implicate order, and the unfolded or explicate order (p. 273). The essential feature of the enfolded or implicate order is that

the whole universe is in some way enfolded in everything and that each thing is enfolded in the whole. From this it follows that in some way, and to some degree everything enfolds or implicates everything, but in such a manner that under typical conditions of ordinary experience, there is a great deal of relative independence of things. The basic proposal is then that this enfoldment relationship is not merely passive or superficial. Rather, it is active and essential to what each thing is. It follows that each thing is 
internally related to the whole, and therefore, to everything else. The external relationships are then displayed in the unfolded or explicate order in which each thing is seen, as has already indeed been indicated, as relatively separate and extended, and related only externally to other things. The explicate order, which dominates ordinary experience as well as classical (Newtonian) physics, thus appears to stand by itself. But actually, it cannot be understood properly apart from its ground in the primary reality of the implicate order. (Bohm, 1990, p. 273)

Bohm's proposal of implicate order and explicate order reminds us of the two truths doctrine in Buddhism and demonstrates the profound meaning of dependent origination. In this holographic dependent arising relationship, everything actively implicates everything and the whole.

Therefore, the interdependency between things is much more complicated and immediate than a mere domino-effect-like one as perceived in our everyday life. This proposal also resonates with the ancient poetic metaphor of Indra's net ${ }^{19}$ for the universe taught by Buddha that animates the

${ }^{19}$ According to Avatamsaka Sutra, Indra's net is brought into existence by Hindu god Indra and is used to describe the interconnectedness and interpenetration of the universe (Mingyur, 2007, p. 174). At every connection of the Indra's infinite net, "hangs a magnificently polished and infinitely faceted jewel, which reflect in each of its facets all the facets of every other jewel in the net" (Mingyur, 2007, p. 174). Given that the net, the number of jewels and the facets of every jewel are all infinite, the number of reflections in each jewel is infinite as well (Mingyur, 2007, pp. 174-175). Also, "when any jewel in this infinite net is altered in any way, all of the other jewels in the net change too" (Mingyur, 2007, pp. 174-175). This ancient metaphor 
whole in every part concept and the mysterious connections between everything. Since the whole universe is enfolded or implicated in everything, whatever actions of mind, body and speech we take toward the others, in a holographic sense, must reflect in ourselves much like the reflections of the jewels on Indra's net. Philosophically speaking, the concept of implicit order suggests the likelihood of the law of the cause and effect of karma.

In addition to Bohm's concept of implicate order, the phenomenon of quantum entanglement and the theory of It from Bit also connotes the dependent originating nature of phenomenal world and the law of the cause and effect of karma. In the following, quantum entanglement and the theory of It from Bit and how they resonate with the concepts of truth in Buddhism are explored.

\subsubsection{Quantum Entanglement, Theory of It from Bit and participatory Universe, and}

\section{Buddhism}

Quantum entanglement is a bizarre state of interconnectedness between two particles (Greene, 2004, p. 116; Talbot, 2011, p. 36). According to various repeatable experiments, for a pair of appropriately prepared particles with common origin, no matter how far they are apart, if the measurement on certain property of one particle is performed at a precise moment, the other particle that is not measured immediately relinquishes the fuzzy state of quantum limbo and takes on identical or related property as if this measurement was performed directly on it (Greene, 2004, pp. 80, 116). According to Greene (2004), the phenomenon of quantum entanglement

animates the whole in every part concept of hologram and the mysterious connections between everything. 
challenges a basic property of space that "it separates and distinguishes one object from another" (p. 122), and shows that two things "can be separated by an enormous amount of space and yet not have a fully independent existence" (p. 122). While in 1935 Einstein, Podolsky and Rosen proposed a thought experiment, which is now referred to as the EPR paradox, intended to attack quantum theory by showing that when the distance between two particles was enlarged to an extent, "no 'reasonable definition' of reality would permit such faster-than-light interconnections to exist" (Talbot, 2011, p. 37), decades later, what they thought of as absurd really happened experimentally (Greene, 2004, p. 11). These experiments include Alain Aspect and his cooperators' work in the early 1980s, and a refined version of Aspect experiment carried out by Nicolas Gisin and his team in 1997 (Greene, 2004, pp. 113, 115; Theckedath, 1997, p. 64).

As Greene (2004) said, space "does not distinguish such entangled objects. Space cannot overcome their interconnection. Space, even a huge amount of space, does not weaken their quantum mechanical interdependence" (p. 122). This phenomenon reveals how two particles in microscopic realm that come from one origin are dependently arising and become the causes and conditions of each other. Furthermore, in 2011, an experimental research on entanglement between two separated naked-eye visible diamonds at room temperature confirmed that "entanglement can persist in the classical context of moving macroscopic solids in ambient conditions" (Lee et al., 2011, p. 1253).

While the phenomenon of quantum entanglement reveals the most astonishing example of dependent origination and suggests the likelihood of the existence of the law of the cause and effect of karma, in our everyday life, we rarely experience immediate quantum entanglement 
phenomenon. The theory of decoherence provides an explanation that it is because particles, despite being too small to have any significant effect of quantum entanglement on a big object, are able to continually nudge the probability wave of a big object, meaning they disturb the coherence of the probability wave by blurring its orderly sequence of crests and troughs, and melt the quantum probabilities into our familiar probabilities of everyday life (Greene, 2004, pp. 209, 210). Nevertheless, Greene (2004) pointed out that, "even though decoherence suppresses quantum interference,.. each of the potential outcomes embodied in a wavefunction still vies for realization. And so we still left wondering how one outcome 'wins"” (p. 212).

Speaking from the perspective of holographic principle, theoretical physicist John Wheeler, who coined and popularized the picturesque terms of black hole, wormhole, and gravitational radiation, etc. in modern physics (Narlikar, 2013, pp. 23-24), proposed that "things—-matter and radiation — should be viewed as secondary, as carriers of a more abstract and fundamental entity: information" (Greene, 2011, p. 239). Greene (2011) explained that, what Wheeler argued is that matter and radiation "should be viewed as the material manifestations of something more basic. He believed that information ... forms an irreducible kernel at the heart of reality” (p. 239). Greene continued, for Wheeler, "such information is instantiated in real particles, ... is something like an architect's drawings being realized as a skyscraper" (p. 239). Wheeler called his theory It from Bit and elucidated that the universe sprang into being because it was observed (Kaku, 2005, pp. 171-172). "This means that 'it' (matter in the universe) sprang into existence when information ('bit') of the universe was observed", and Wheeler called this universe the "participatory universe" (Kaku, 2005, p. 172). In this participatory universe, "the universe 
adapts to us in the same way that we adapt to the universe, that our very presence makes the universe possible" (Kaku, 2005, p. 172).

Akin to Wheeler's theory of It from Bit, in Buddhist doctrine of karma, each of our virtuous or non-virtuous action of body, speech, and mind upon the world would simultaneously deposit a corresponding karmic seed into the storehouse consciousness (Alaya) that carries the potential to ripen into corresponding pleasant or suffering type of results that is never inconsistent with the type of its seed (Sopa, 2005, pp. 20-22). Similar to the case that a tiny seed can grow a huge tree, a small inner karmic seed can possibly produce very great results (Sopa, 2005, pp. 22-23). In Buddha's teaching, the order in which various virtuous and non-virtuous karma seeds ripen is as follows:

(1) Whichever karma is weightiest will ripen first.

(2) If weights are equal, whatever karma is manifest at the time of death will ripen first.

(3) If this also is the same, whatever karma you have predominantly become habituated to will ripen first.

(4) If this also is the same, whatever karma you have done first will ripen earliest. (Tsong-kha-pa, 1402/2000, p. 242)

This order of the ripening of karmic seeds provides us with a glance at the mechanics underlying the law of the cause and effect of karma. Since Buddha's doctrine of karma is very profound and complicated, the other details of the rules will not be discussed here. Yet, by means of understanding the karmic seeds as information stored in storehouse consciousness or the database of the participatory universe that have the potential for springing into existence as real particles carrying such information, Wheeler's ideas of participatory universe and particles as 
carriers of information, along with Bostrom's computer simulated universe, quantum entanglement, holographic principle and Bohm's implicate order, constitute a well-expanded holographic computer-simulation model of participatory universe that always reflect the "what" in consciousness by virtue of following its own rules. This model is conducive to the speculation the likelihood of the law of the cause and effect of karma and the possible answers to Greene's question regarding how one potential outcome embodied in a wave-function wins and realizes in material realm.

From this perspective, in spite of the fact that we do not always experience immediate results of karma in our everyday life, each of our action of body, speech, and mind upon the world, due to the effect of entanglement, would simultaneously deposit corresponding information or karmic seeds into the database or storehouse consciousness. The probabilities of potentials of future happenings formed by accumulated information, like architect's drawings of a skyscraper, are therefore constantly altered by our actions upon and reactions to this holographic participatory universe and vies for realizing as some type of life experience. Although it is very difficult to verify the law of the cause and effect of karma by means of methods other than deep level of meditation, particularly when it involves multiple lives, the above conjecture serves as a basis for developing the confidence and certainty of the law of the cause and effect of karma for those who are willing to cultivate this belief.

In the above exploration, the phenomena, theories and philosophies of quantum physics greatly extend our understanding of the concepts of truth in Buddhism, including emptiness, dependent origination, the law of cause and effect of karma and the consciousness-only doctrine. In the 
following section, I probe into the implications of this dialogue between Buddhism and quantum physics for education and educational purposes.

\subsection{The Implications of This Dialogue for Education}

In the preceding section, by means of infusing quantum elements into the concepts of truth in Buddhism, the dialogue between Buddhism and quantum physics demystifies the religious language of emptiness, dependent origination, the law of cause and effect of karma, and the consciousness-only doctrine. The two branches of thought, to our surprise, rather than contradicting with each other, exhibit common threads of continuity and a startling tendency of convergence. Echoing with Heidegger's interpretation of Plato's allegory of the cave, both branches of thought uncover how the phenomenal world that we experience in everyday life is such a "deft master of disguise" (Greene, 2004, p. 22), which in actuality is merely "a meager slice of reality" (Greene, 2004, p. 18) and is empty of any absolute, essential, and independent nature. Both branches of thought suggest the inseparability of consciousness and inner self and external reality, and uncover the significance of consciousness in dominating life experiences. Both of them refute absolutism and objectivism, signify infinite possibilities, and uncover a profound dependent arising nature and the oneness of all phenomena. This convergence not only renews our comprehension of both branches of thought, deepens our understanding of the concepts of the transcendent and the non-dualistic worldview found in educational literature, but also increases our confidence in the truthfulness of both Plato's doctrine of truth and the concepts of truth in Buddhism. 
As discussed earlier, the holographic principle uncovers the fact that this phenomenal world we experience in our everyday life is but "a reflection of laws and processes acting themselves out on the boundary" (Greene, 2011, p. 263) in a way "much as what we see in a holographic projection is determined by information encoded on a bounding piece of plastic" (Greene, 2004, p. 482) and therefore is "but a faint inkling of a far richer reality that flickers beyond reach" (Greene, 2011, p. 238). Given the consistency between Plato's allegory of the cave and the holographic principle, Greene (2011) opened his book chapter on holographic principle by virtue of introducing this allegory and remarked that, "two millennia later, it seems that Plato's cave may be more than a metaphor" (p. 238). This increased confidence in the truthfulness of Plato's doctrine of truth and the concepts of truth in Buddhism provides us with a deepened and broadened conceptual ground for reconsidering the significance of spiritual truth and the relationship between truth and education found in previous review of educational literature. As Greene (2004) said, only when our understanding of the true nature of physical reality is deepened, a profound reconfiguration of our sense of our self and our experience of the universe emerges (p. 5), and this reconfiguration inevitably propels us into reconsideration of the essence and purpose of education.

For the purpose of attesting the value of understanding the true nature of universe to the appraisal of life's meaning and significance, Greene (2004) reasoned by analogy that, if evolution had proceeded differently and we had only the sense of touch, so everything we knew came only from the tactile impressions, or if human development stopped during early childhood, so our emotional and intellectual skills never progressed beyond those of a five-year-old, then our assessment of life would be thoroughly compromised (p. 4). When we regained the senses to see, 
hear, smell and taste, or the freedom to develop mental faculties beyond those of a five-year-old, our collective view of the meaning and significance of life would, of necessity, change profoundly (Greene, 2004, p. 4). In comparison with the true nature of consciousness, self and reality unveiled in the above dialogue between Buddhism and quantum physics, what we know from our rudimentary perceptions of everyday experience could virtually parallel to the mere tactile impressions or a five-year-old's viewpoint. From this perspective, the espousal of positivism and its associated absolutism and objectivism as well as the exclusion of spirituality from education could be tantamount to confine general human senses to mere touch or to restrain human development to no more than a five-year-old in comparison to the whole spectrum of human potentialities.

Greene's analogies as well as the dialogue between quantum physics and Buddhism reveal the significance of the realization of the true nature of human existence for recognizing the essence and purpose of education. As unveiled in the dialogue between Buddhism and quantum physics and in the perennial philosophy and Plato's allegory of the cave, for thousands of years, what the spiritual and religious traditions endeavor to achieve is to emancipate human beings from the imprisonment of the shadowy and deceiving phenomenal reality and, as Heidegger (1942/1962) said, to guide us to the most extremely unhidden or the Highest Idea of the upper world outside of the cave (p. 260) by means of delivering the generally unrecognized truth that there is something beyond the disguise of our everyday experience. From this perspective, the essence of spirituality is all about the ultimate truth of human existence that brings about ultimate liberation. However, over the past three hundred years since the progress of classical physics, the gradual neglecting and excluding of spirituality from curriculum and education has further 
confined human beings to the imprisonment of the phenomenal and shadowy aspect of reality. By means of deterring generations of human beings from turning around into their true nature, it hinders the transitions of humankind towards the ultimate truth of the most extremely unhidden, and consequently prevents genuine education from happening. This thoroughly compromised appraisal of human nature and life's value not only prevents us from leading a fulfilled and meaningful life, but also becomes the roots of various global crises. From this viewpoint, the revival of spirituality in education is never dispensable or optional, but imperative.

As shown in chapter two, the deliberation of the essence of education as fundamental concerns of “our Being as men” (Heidegger, 1942/1962, p. 257) can be traced back to Plato. By virtue of apprehending Plato's allegory of the cave as not only a metaphor for education but also a fourstage transitions of the essence of truth presumed or realized by an individual, Heidegger $(1942 / 1962)$ illuminated the essential relationship between education and the truth that underpins the significance of spiritual truth for education found in educational literature. The preceding exploration of the concepts of truth in Buddhism and the dialogue between Buddhism and quantum physics not only resolves our questions regarding the extent of truthfulness of Plato's doctrine of truth and the significance of the four-stage transitions of the essence of truth for human beings, but also points to the crucial and fundamental role of consciousness in dominating the possible transplanting of human into the region of one's essence in pure education, wherein "everything commonly known to man up to this time and the way it was known become different" (Heidegger, 1942/1962, p. 257). 
According to Heidegger (1942/1962), in Plato's own interpretation of this allegory, the things that are lying in the sunlight outside of the cave are "the image for what the real reality of beings consists in" (p. 254), and this is that "through which beings display themselves in their 'outward appearance" (p. 254). Yet, this "outward appearance" does not mean a mere aspect (Heidegger, 1942/1962, p. 254). Heidegger (1942/1962) indicated, it is "something of an extrusion through which each thing 'present' itself" (p. 254), and in Greek, it means "ideas" (p. 254). For Plato, if a person

did not have these ideas before his gaze as the respective "outward appearance" of things, living creature, men, number, and the gods, then he would never be able to perceive this or that particular things as a house, as a tree, or as a god. (Heidegger, 1942/1962, p. 254) Nevertheless, Heidegger (1942/1962) pointed out that, a person usually believes what he or she sees is exactly this house, that tree, and everything that is, and seldom suspects that "everything holding value for him in all its familiarity as the 'real' is always seen only in the light of 'ideas"' (p. 254). From Plato's perspective, what "is supposed to be alone and really real, the immediately visible, audible, comprehensible, and calculable, still steadily remains ... only the silhouette projected by the ideas, and consequently a shadow" (Heidegger, 1942/1962, p. 254), and it is this "reality" that "keeps man in its grasp day in and day out. He lives in a prison and leaves all 'ideas' behind him”' (Heidegger, 1942/1962, p. 254).

Heidegger's restatement of Plato's own interpretation of this allegory explored above resounds with not only the two truths and consciousness-only doctrine in Buddhism, but also John Wheeler's theory of It from Bit, which contends that things should be viewed as carriers and manifestation of something more basic — information - that forms the irreducible kernel at the 
heart of reality (Greene, 2011, p. 239). The "outward appearance" or “ideas" in Plato's interpretation of this allegory, thus, can well be understood as playing the role of the karmic seeds in Buddhism that have the potential of ripening into future live experiences, or the information carried by particles and radiation that is something akin to an architect's drawings waiting for being realized as a skyscraper. Heidegger (1942/1962) argued that, consciousness, properly speaking, has to do with the way outward appearance manifests itself and is preserved in the brightness of its steady appearance. . . Consciousness, properly speaking, applies to the [idea] ... The "idea" is the outward appearance which gives a perspective upon what is present. ... The "idea" does not just let something else (behind it) "make an appearance," it itself is what appears, and it depends upon itself alone for its appearing. ... The idea achieves presence.... Presence however is really the essence of Being. Being, then for Plato, has its real essence in its What. (pp. 261-262) Heidegger's clarification of idea and consciousness not only resonates with Bohm's contention of the oneness of the thinking process and its content (Bohm, 1980, pp. 23-24) and the consciousness-only doctrine in Buddhism, but also reaffirms the existential significance of the "What" that resides in consciousness, particularly the essence of truth presumed or realized by an individual. From this perspective, the concern of our Being as humans is in essence the concern of human consciousness, and the essence and purpose of education as the four-stage transitions of the essence of truth revealed in Heidegger's illumination of Plato's' allegory of the cave is in essence the transformation of consciousness from the grasping of the deceptive phenomenal everyday experiences toward the direct non-dualistic realization of the ultimate truth of emptiness, the personal ultimate liberation, and the highest spiritual goal of the liberation of all sentient beings from the suffering-laden shadowy phenomenal world. 
Following this realization of the transformation of consciousness as the essence and purpose of education that is well informed by Huebner's and other curriculum theorists' works, Heidegger's interpretation of Plato's allegory of the cave, Buddhism, and quantum physics, in the next chapter, I investigate into the Buddhist spiritual practices of consciousness transformation for educational use and explore how we might begin to understand curriculum as an experience of consciousness transformation. 


\section{Chapter 4: Curriculum as an Experience of Consciousness Transformation}

\subsection{Introduction}

In the preceding chapter, the dialogue between Buddhism and quantum physics expands our understanding of the nature of consciousness, self and reality, and increases our confidence in the truthfulness of Plato's doctrine of truth and the doctrine of truth in Buddhism that is in accordance with the core wisdoms common to various spiritual and religious traditions as exhibited in perennial philosophy. This expanded understanding and increased confidence provide us deepened insights into the essence and purpose of education as the transformation of consciousness toward the direct non-dualistic realization of the ultimate truth of self and reality, the ultimate personal liberation, and the highest spiritual goal of the liberation of all sentient beings from the imprisonment of the cyclic forms of existence in the suffering-laden shadowy phenomenal world. Following this realization, I ask: How might we further understand the concepts and process of consciousness transformation? What are the main barriers to be overcome? What are the characteristics of various stages of progress? What disciplines and practices are necessary in various stages? What are the features of these disciplines and practices? How might we facilitate the transformation of consciousness in educational contexts?

To seek answers to these questions and keeping the idea of a spiritual path with educational intent foremost in my attention, I now explore the main concepts and process of Buddhist spiritual path of consciousness transformation, including the main barriers to be overcome, the characteristics of various stages, the main spiritual disciplines and practices in various stages, and the core approach for attaining the goal of consciousness transformation. On the basis of 
this understanding, I then proceed to explore how educators might understand curriculum as an experience of consciousness transformation.

\subsection{The Concepts and Process of Consciousness Transformation in Buddhism}

In this section, drawing on the doctrine of Yogacara (the Consciousness-Only school of Buddhism), I explore the concepts and process of consciousness transformation in Buddhism to gain a panoramic view over a spiritual path for educational use.

\subsubsection{The Two Barriers to Consciousness Transformation}

As discussed in chapter three, from the Buddhist perspective, the right view (sammā-

dițthi/samyag-drsții) (see Footnote 4) of both the ultimate and conventional truths, meaning the correct seeing of emptiness and a proper understanding of the law of the cause and effect of karma, is the basis of various spiritual goals and all positive, happy, and blissful experiences. Nonetheless, owing to our ignorance of both truths and the habitual wrong view that firmly clings to the dichotomy of a subjective self (who takes or grasps) and an objective universe (what is taken or grasped) as absolute, essential and independent existence, we constantly deposit contaminated karmic seeds of afflictive and noetic barriers that carry the potential of ripening into various cyclic forms of existence and trapping us in the imprisonment of samsara (Hsuan Tsang, 659/1973, p. 671). In Yogacara doctrine, the karmic seeds of afflictive barriers and noetic barriers that originate respectively from the attachment to a subjective self and an objective universe as absolute, essential and independent existence are identified as the underlying causes of worldliness (Hsuan Tsang, 659/1973, p. 703). In other words, the attachment to the subject-object dichotomy is identified as the main characteristic of the shackled 
prisoners described in the first stage of Plato's allegory of the cave, and the afflictive barriers and noetic barriers that originate from this dualistic worldview are recognized as the main barriers to be overcome in the process of consciousness transformation. While the two barriers are not different in nature, their functions are distinct, and although afflictive barriers necessarily associate with noetic barriers as their basis, the reverse is not true. According to Hsuan Tsang (659/1973), an afflictive barrier perturbs and torments the bodies and minds of sentient beings and acts as a barrier to Nirvana, and a noetic barrier, with a false view of the external reality, along with doubt, ignorance, desire, hate, and conceit obscures the true nature of the known world and acts as a barrier to perfect transcendental wisdom (Bodhi) (p. 671). Yet, according to Hsuan Tsang, through the process of persistent cultivation and transformation of consciousness, the karmic seeds of these two barriers can be suppressed and then totally cut-off and cleared away, and when this is attained, two fruits of Buddhahood will be experienced (p. 705). One of the two fruits is Mahaparinirvana, also known as Buddha Nature, meaning the original states of consciousness that is not contaminated by the wrong views rooted in the ignorance of the ultimate and conventional truths (Hsuan Tsang, 659/1973, p. 759). The other one is Mahabodhi, which is the totality of the mental attributes associates with the perfection of four transcendental wisdoms, which are the uncontaminated functioning of Buddha Nature (Hsuan Tsang, 659/1973, p. 767) and will be explored in the following subsection. As Hsuan Tsang (659/1973), emphasized, the whole doctrine of consciousness-only "is established in order to enable sentient beings to experience these two fruits resulting from this process of 'revolution' or 'inner transformation"” (p. 705). 


\subsubsection{The Transformation of Consciousness into Four Transcendental Wisdoms}

In the doctrine of Yogacara, human consciousness is classified into eight consciousnesses: sight, sound, smell, taste, touch feeling, mind, thinking (Manas), and storage (Alaya) (Choi, 2011, p. vii). The process of the suppression and eradication of karmic seeds of the afflictive and noetic barriers is prescribed as a five-stage gradual path of consciousness transformation that transforms the mental attributes of the first five, the sixth, the Manas, and the Alaya consciousnesses into the perfection of four transcendental wisdoms, including the great mirror wisdom, the universal equality wisdom, the profound contemplation wisdom and the perfect achievement wisdom (Hsuan Tsang, 659/1973, pp. 665, 759, 767, 769). The great mirror wisdom is "entirely dissociated from all mental discrimination. Like a mirror, such wisdom reflects the absolute reality of all things as they are" (Choi, 2011, p. 91). The universal equality wisdom bears on both the ultimate and phenomenal aspects of reality (Hsuan Tsang, 659/1973, p. 777) and sees the identity of all phenomena and "the complete equality between its own self and other sentient beings" (Choi, 2011, p. 91). The profound contemplation wisdom "discerns in excellent ways the peculiar and common characteristics of all dharmas" (Choi, 2011, pp. 90-91). It cuts away all doubts, and can manifest itself in infinite activities without any hindrance and enable sentient beings to obtain blessings and joys (Choi, 2011, p. 91). The perfect achievement wisdom "manifests itself through the desire to promote the welfare and happiness of all sentient beings in a diversity of fictitious actions of the body, of the voice, and of the mind" (Choi, 2011, p. 90). This wisdom is regarded as important in this material world, for although this world is not the ultimate reality and there is no true and essential self in it, it cannot be ignored (Choi, 2011, p. 90). 
The perfection of the four transcendental wisdoms not only signifies the fulfillment of bodhicitta, (Sopa, 2008, pp. 6, 17, 99, 189), which is the aspiration to attain the highest spiritual goal for the liberation all sentient beings, but also represents the recovery of various spiritual qualities that are intrinsic in our Buddha Nature. By means of providing us with an overview of the spiritual qualities and achievement of a Buddha, these four wisdoms exhibit the transcendental human potentialities that are beyond our current forms of existence. The recognition of such transcending possibilities is conducive to both the deliberation and improvisation of curriculum as an experience of consciousness transformation. However, in contemplating the four transcendental wisdoms, it is important to bear in mind Lama Anagarika Govinda's reminder that, wisdom should not be comprehended as "merely intellectually formulated doctrine, proclaimed at a certain point in human history, but a movement which reveals its deepest nature in contact with different conditions and circumstances of human life and on every new level of human consciousness" (Lemkow, 1990, as cited in Miller, 1988/2008, p. 17). Also, as exhibited in the four transcendental wisdoms, "Buddhahood is not just a blank mind; it is a combination of many perfect things" (Sopa, 2008, p. 201). With a proper understanding of the dependent arising nature of all phenomena, including Buddhahood, we would be certain that such a complex of perfect spiritual qualities definitely requires multiple causes and multiple lifetimes' cultivation.

\subsubsection{The Five-Stage Gradual Path of Consciousness Transformation in Buddhism}

Akin to the four-stage transitions of the essence of truth in Plato's allegory of the cave, in the doctrine of Yogacara, the gradual ${ }^{20}$ spiritual path of consciousness transformation toward the

${ }^{20}$ The gradual and sudden paradigms in Buddhism have long been a source of debates in history 
(Faure, 1994, p. 41). In contrast to the five-stage gradual path in Yogacara, Zen Buddhism features the "sudden" teaching (Faure, 1994, p. 32). According to Lusthaus (2002), while in the Pali texts Buddha repeated that "awakening is consequent upon uncovering and removing the deep, underlying psycho-cognitive roots of avidya [ignorance or delusion]” (p. 108), some Theravadins argued that "if disentangling one's karmic condition involved the gradual activity of discovering and overcoming, piece by piece, one's karmic legacy, the task would be interminable, since each counter-karmic action is itself an action, and thus productive of further karma" (p. 108). The controversies of gradual/sudden and the modificatory/disruptive reemerged in China, Japan and Tibet (Lusthaus, 2002, p. 108; Sopa, 2008, pp. 195-199). The main cause of the debate in the eighth century Tibet was that, while the whole doctrine of Zen Buddhism is much profounder than the mere "sudden" aspect of teaching, it developed into an attractive Zen-like misconception holding that the thought-free meditation only is enough for attaining enlightenment, and that all other practices, such as meritorious practices and rigorous analysis, etc., are not worth doing (Sopa, 2008, pp. 198-200). According to Sopa (2008), King Trisong Detsen saw the danger of this view and resorted to a debate held at Samye Monastery (p. 198), and subsequently decided to follow the Indian Madhyamaka (the Middle Way) system, which formed the basis of Yogacara and maintained that, "the method to come to a direct realization of the truth is to first learn about it. Next one examines and analyzes what one has studied. Through inferential reasoning one gains an understanding that becomes more vivid through meditation" (p. 200).

Faure (1994) indicated that, "the protagonists of the debate were in fact speaking at cross- 
purposes" (p. 41), and as Paul Demieville once suggested, 'the 'sudden' and 'gradual' were universal categories" (p. 32) and "this antinomy is not only a psychological and methodological order, it applies to two conceptions of truth itself and actually spread to all planes of thought" (Demieville, 1949, p. 179, as cited in Faure, 1994, p. 32). Faure (1994) elucidated that "the philosophical framework of the controversy was provided by the Two Truths theory: sudden and gradual refer to whether awakening is regarded from the point of view of ultimate truth or of conventional truth" (pp. 32-33). Nevertheless, in practice, the positions of the protagonists were not so different_ “"both were 'sudden' . . . and both were to some degree 'gradual'” (Faure, 1994, p. 36). For example, while the founding patriarch of Japanese RinZai school Linji "himself came to Awakening in part by abandoning the modificatory model in favor of the disruptive model" (Lusthaus, 2002, p. 108), he also stressed that, "you must first fathom things yourself, purify yourself, polish yourself; then one day you will awaken" (Demieville, 1972, p. 116, as cited in Faure, 1994, p. 36). The significance of the need of both the gradual and sudden models that refer to the conventional truth and ultimate truth respectively was illustrated by Buddha in The Diamond Sutra by means of employing the metaphor of a raft and emphasizing that his doctrine of the dharma, like a raft_- "having fulfilled its function in bearing you to the other shore (Nirvana) — with its coincident qualities and ideas must inevitably be abandoned" (Gemmell, 1912, pp. 22-23, 97). This metaphor points to the concept of the middle way taught by Buddha and later restored by Nagarjuna. Rather than being a neutral or neutralized position, the middle way is achieved by simultaneously grasping the two truths and by the "refusal to reduce one level to the other or to reconcile them in a convenient hierarchy" (Faure, 1994, p. 37). 
perfection of four transcendental wisdoms is composed of five stages, including the stage of moral provisioning (the path of preparation), the stage of intensified efforts (the path of application), the stage of unimpeded penetrating understanding (the path of seeing), the stage of exercising cultivation (the path of meditation), and the stage of ultimate realization (the path of no more learning) (Choi, 2011, p. 91; Hsuan Tsang, 659/1973, p. 665). While the last three stages are identified as supra-mundane paths, the first two are usually referred to as worldly paths (Choi, 2011, p. 92), and therefore are of particular educational significance.

In the first stage, the stage of moral provisioning, also known as the path of preparation, the spiritual practitioners develop profound conceptual understanding of the whole doctrine of consciousness-only, including the two truths doctrine and the four noble truths explored earlier, the panoramic view of the whole spiritual path, the significance of the cultivation of bodhicitta, the nature of spiritual approach and practices, the obstacles eliminated by these spiritual practices, and the positive results brought about by these practices, etc. On one hand, for oneself, with a

While the sudden and gradual paradigms in essence are not so different, and for the more advanced practitioners, the sudden teaching serves well as a remedy for the over-reliance upon gradual and analytical activities, given the fact that this five-stage gradual path includes both the worldly path (with the emphasis on the method-side practices contingent on the conventional truth) and supra-mundane path (with the emphasis on the wisdom-side practice contingent on the ultimate truth), I consider this gradual path as of profound significance for the revival of spirituality in educational context. The details of the educational significance of this gradual path are explored in subsection 4.2.6. 
view to attaining the enlightenment, the spiritual practitioner "accumulates diverse and excellent 'moral provisions'” (Hsuan Tsang, 659/1973, p. 669). On the other hand, for the others, the practitioner "makes constant efforts to seek the deliverance of sentient beings" (Hsuan Tsang, 659/1973, p. 669). The significance of the accumulation of moral provisions is profound. In his kindness and skillfulness to make the accumulation of merit and moral provisions easier, Buddha condensed all negative actions of body, mind and speech into to ten non-virtues (Sopa, 2005, p. 45). The ten non-virtues are covetousness, malice, wrong view, lying, slander, harsh speech, senseless speech, killing, stealing, and sexual misconduct (Sopa, 2005, pp.45-46). The ten virtues are actions taken to oppose and prevent the ten non-virtues (Sopa, 2005, p. 45). As shown in previous exploration of the two truths and the truth of the path that is embodied in the practices of the three trainings and six perfections, rather than imposing meaningless restraints or control, after all, the goal of the Buddha "is to protect sentient beings, to free them from the cycle of misery, to lead them to the highest bliss" (Sopa, 2005, p. 43). According to Buddha, "just as the earth is the foundation of all things that exist upon the earth, practicing the ten virtuous actions is the foundation of all worldly and supermundane goals" (Sopa, 2005, p. 41). Relying on profound conceptual understanding of and deep faith in the whole consciousnessonly doctrine, the main practices in this stage are the six perfections (paramitas) (Hsuan Tsang, 659/1973, p. 675). As explored earlier, the six perfections are generosity, ethical discipline, patience, joyous perseverance, meditative stabilization, and wisdom (Sopa, 2008, p. 8). Although the practices of the six perfections are emphasized as the main practices in only the first stage of the five-stage gradual spiritual path of consciousness transformation, in the treatise Lamrim Chenmo (The Great Treatise on the Stages of the Path to Enlightenment) finished in 1402, following Buddha's teachings in the Perfection of the Wisdom and other sutras and the 
great bodhisattva Maitreya's six-fold exposition in the Ornament for the Mahayana Sutras, Tsongkhapa elucidated the sufficiency ${ }^{21}$ of the six perfections for fulfilling all of the individual sentient beings' temporary and ultimate spiritual goals (Sopa, 2008, p. 233; Tsong-kha-pa, 1402/2000, p. 17).

After the spiritual practitioner has well equipped himself with the spiritual provisions of meritsvirtues and transcendental wisdoms, he proceeds into the second stage — the stage of intensified efforts (the path of application) (Hsuan Tsang, 659/1973, p. 679). In this stage, aiming at entering the path of spiritual discernment, the practitioners learn to suppress and eradicate the conception of subject-object duality by making preparatory efforts conducing to decisive distinction (Hsuan Tsang, 659/1973, p. 679). These efforts are grounded on four reflections on the names, essences, self-nature and differences of things and ideas, as well as the four exact realizations that these four concepts do not exist apart from our consciousness and that the process of consciousness that knows them does not have absolute and independent existence neither (Hsuan Tsang, 659/1973, pp. 679, 681). The practices of this stage also include meditation on the four noble truths (Choi, 2011, p. 92). The perfection of this stage comes when the dualistic subject-object distinction vanishes and the non-discriminating transcendental

${ }^{21}$ Given that the teachings of Buddha are so vast and diverse, "Tsongkhapa's purpose in composing Lamrim Chenmo was to draw out the essence of all the Buddha's teaching and arrange them in a practical manual" (Sopa, 2004, p. 2). Tsongkhapa had received many personal instructions and guidance from Manjusri bodhisattva in visionary experiences (Culter, 2000, p. 10; Thurman, 1984, pp. 4-5). 
wisdom is attained. In other words, at that time, the practitioner attains the direct and nondualistic experience of emptiness. In this state, the practitioner no longer clings to the objective world, because "both the object to be apprehended and the act of apprehending by consciousness are absent" (Hsuan Tsang, 659/1973, p. 687). This means he experiences the ultimate reality of emptiness and oneness directly and enters into the third stage (Hsuan Tsang, 659/1973, p. 687). Given the worldly nature of the stage of moral provisioning (the path of preparation) and the stage of intensified efforts (the path of application), the main practices in the two stages are of great educational significance and will be revisited later.

In the third stage, the stage of unimpeded penetrating understanding, or the path of seeing, by developing the five spiritual faculties of faith, effort, mindfulness, concentration and wisdom to the utmost, the practitioners cure their doubt, laziness, heedlessness, distraction and ignorance, and perfect the true insights into the ultimate reality (Choi, 2011, p. 93). After attaining the perfection of true insights into the ultimate reality, the practitioners move into the fourth stage of exercising cultivation, also known as the path of meditation, and constantly cultivate the nondiscriminating wisdom (Choi, 2011, p. 93). Although the practitioners practice meditation right from the first stage, in this stage, the practitioners begin to "gain certain experiences and realizations that were not present previously" (Choi, 2011, p. 93). The perfection of this stage comes when the aforementioned four transcendental wisdoms are all achieved. From now on, the practitioners will enter into the fifth stage of ultimate realization, also known as the path of no more learning that equates the full enlightenment of Buddhahood (Choi, 2011, pp. 93-94). 


\subsubsection{The Union of Wisdom-Side and Method-Side Practices for Consciousness Transformation}

The above exploration of the five-stage gradual path of consciousness transformation makes clear that the profound conceptual understanding of and the deep faith in spiritual truths are crucial for the unshackling of the chains that confine the prisoners as depicted in Plato's allegory of the cave, and is able to release their sights from being captive to the mere shadows. Nevertheless, this is not yet real liberation. As shown in the second stage of Plato's allegory of the cave, the newly unchained prisoner in the cave would be perplexed and believe that the shadows he formerly saw to be more real and more unhidden than the objects now shown to him, and would try to turn back if he were forced to look at the fire-light itself (Heidegger, 1942/1962, pp. 252-253). Similarly, the mere conceptual understanding of the spiritual truths cannot genuinely emancipate the prisoners. Genuine transformation and real liberation require the union of wisdom and compassion for overcoming the habitual ways of thinking and doing entrenched in an absolutistic and objectivistic dualistic subject-object worldview. Wisdom is mainly attained through meditative insights (the accumulation of wisdom) and compassion is embodied in the methods of everyday spiritual practices motivated by bodhicitta (the accumulation of merit). Otherwise, even for those who have attained profound conceptual understanding of the whole consciousness-only doctrine, or have had profound experiences in meditation, the deeds component and view component could possibly remain mutually exclusive, and "never develop a long-lasting and very forceful certainty about both the view and deeds" (Tsong-kha-pa, 1402/2004, p. 96). As revealed in his profound self-inquiry, Sean Park (2014) recalled the difficulties he once encountered and said that, "unconsciously, I had reified my meditation practice into something that took me out of the world and away from deeper parts of 
myself . . . I thought I could meditate the pain away" (p. 29). Likewise, in a manuscript titled The Inner Experience, Thomas Merton recognized that, "contemplation is man's highest and most essential spiritual activity. It is his most creative and dynamic affirmation of his divine sonship ... Solitude is necessary for spiritual freedom" (as cited in Miller, 2007, p. 28).

According to Miller (2007), however, Merton also maintained that the spiritual freedom needs to be put back "to work in the service of a love in which there is no longer subjection or slavery. Mere withdrawal, without the return to freedom in action, would lead to a static and death-like inertia of the spirit” (p. 28) and would not lead to awakening at all. Huebner (1987/1999) also indicated that, for the majority today, the practice of the presence of God is limited to moments of prayer and worship (p. 388); but for Brother Lawrence, a barefoot lay brother in the 1600s, "times set aside for prayer were not different from the other times ... because his greatest business did not divert him from God" (as cited by Huebner, 1987/1999, p. 388).

The requirement of the union of wisdom-side practices (the accumulation of wisdom) and the method-side practices (the accumulation of merit) for consciousness transformation was emphasized by Buddha and numerous bodhisattvas, and was well summarized by Tsongkhapa (Tsong-kha-pa, 1402/2004, pp. 85-99). In his refutation of such discourses as "everything to do with method is not an actual path to buddhahood" (Tsong-kha-pa, 1402/2004, p. 96), Tsongkhapa clarified that, in Mahayana scriptures, buddhahood, also named as non-abiding nirvana, is the highest spiritual goal that does not abide in the two extremes-samsara (the attachment to the phenomenal aspect of reality) or the mere peace of nirvana (the attachment to the empty aspect of reality) (Sopa, 2008, p. 202). To avoid abiding in the extreme of samsara, one requires the practice of the accumulation of wisdom; to avoid abiding in nirvana, one needs 
the practice of the accumulation of merit (Sopa, 2008, p. 202). The accumulation of wisdom is aimed at cutting the root of samsara - the primary ignorance originating from an egotistic and dualistic view that grasp at an absolute and essential self as being independent of the universeby means of meditating on the deep realization of the ultimate truth of emptiness with no dual perception (Sopa, 2008, p. 203). However, "by itself this deep meditation on ultimate truth of emptiness does not lead to buddhahood; mere cessation of one's own ignorance cannot help others" (Sopa, 2008, p. 202). Without concern for other sentient beings, not only would the multiple causes for a complex of spiritual qualities of buddhahood be missing, after attaining nirvana, one might remain in the enjoyment of that state for eons and eons rather than progressing toward the buddhahood (Sopa, 2008, p. 202). Therefore, as revealed in the four transcendental wisdoms, the highest spiritual goal of buddhahood for the liberation of all sentient beings "is not just a mere negation or perfect cessation; it is also a combination of various positive qualities" (Sopa, 2008, p. 202) and requires also the accumulation of merit or the method-side practices - the practices based on love and compassion and motivated by bodhicitta, such as the six perfections - as "the causes for one to become a basis of enjoyment for all sentient beings" (Sopa, 2008, p. 203). This means if we want to take the responsibility for other sentient beings' liberation in addition to our own, we must train ourselves in the practices of bodhicitta along with wisdom (Sopa, 2008, p. 24).

As Buddha said, "wisdom not held by the method is bondage. Wisdom held by the method is liberation. Methods not held by wisdom are bondage. Methods held by wisdom are liberation" (Sopa, 2008, p. 204). However, this "does not mean that wisdom becomes compassion or that compassion becomes wisdom. Held means that, within the mental continuum, the two assist 
each other all the time" (Sopa, 2008, p. 204). For example, if one contemplates bodhicitta before practicing a meditation on emptiness, although no bodhicitta would be present in a meditating state of mind during the meditation session, the whole meditation is imbued with and empowered by the wish to attain enlightenment for the benefits of all sentient beings (Sopa, 2008, p. 215). This case instantiates the meaning of wisdom held by method (Sopa, 2008, p. 215). In turn, the openness, clarity and power brought about by the direct realization of emptiness attained in meditation can be carried over to infuse the method-side practices of generosity, ethical disciple, and so forth (Sopa, 2008, p. 215). In this way, method is held by wisdom. The question, therefore, is not anything to do with method is an actual path to buddhahood, but rather in how wisdom and method should be applied in a way that will lead to genuine liberation rather than more bondage and in what it really means by the union of the wisdom-side and method-side practices.

In the educational context, owing to the rejection of spiritual wisdom and the taken-for-granted attachment to the extreme of the shadowy phenomenal aspect of reality, the existential significance of the accumulation of wisdom is largely neglected and the means and ends of the accumulation of merit, in the absence of spiritual wisdom, are usually misconstrued. For instance, the moral and ethical doctrine, rather than being comprehended as pointing to a pathway for approaching and living the ultimate truth of human existence, is usually dogmatized, degraded, and risks being easily dismissed as mere a means of social control or personal reputation-building. More often than not, people either observe moral and ethical doctrine passively by virtue of blindly following such systems, or practice actively, yet in a way that nurtures only a dualistic and absolute sense of self and reality. In other words, in the absence of 
spiritual wisdom that knows emptiness and oneness of self and reality, the advocating of moral and ethical doctrine can be futile, and the method-side practices or the accumulation of merit alone can possibly create only more paranoia and fragmentation and result in more bondage rather than genuine transformation toward ultimate truth and genuine liberation. As Kumar (2013) argued, the nature of existential problems, such as fear, is that "they are always in the present; and when they are approached with a method [that is not held by wisdom], which employs the past, they are never comprehended in their totality" (p. 88). Without comprehending both the phenomenal and ultimate aspects of an existential situation of a specific individual in their totality in the present, a method - may it be moral doctrine, psychological analysis, strategies informed by behavior science, rational analysis, or even the six perfections, etc. - that misconceives the three spheres of agent, object, and recipient as with certain absolute, independent and essential attributes and existence in contrast to being dependently arising and signifying infinite possibilities, in Kumar's (2013) words, can at most “bring about a 'modification' in the existing psychological state, which does not qualify as real change" (p. 88). This is why Buddha would admonish us in the Three Heaps Sutra to "confess each of these: descending to the level of objective existence and giving gifts, observing ethical discipline because of a belief in the supremacy of ethics, etc." (Tsong-kha-pa, 1402/2004, p. 95). In this passage, Buddha cautioned us against "falling into objectifying" (Sopa, 2008, p. 217), and hinted that, "it is evil to practice any perfection motivated by a perverted view that holds the self to exist absolutely.... Any action, even the perfections [paramitas], is evil if it is done with this kind of misunderstanding" (Sopa, 2008, p. 217). It is evil in the sense that such objectifying practices only hinder us from penetrating and experiencing the ultimate nature of self and reality and, as a result, perpetuates the relentless cycle of suffering-laden samsaric experiences. 
Nonetheless, not falling into objectifying - generosity with no object or non-perceptual generosity, for example_- “does not mean not having a thought to give” (Sopa, 2008, p. 216). "The correct meaning of objectless or nonperceptual generosity is giving gifts without hypostasizing or superimposing the idea that something or someone exists in an ultimate real way" (Sopa, 2008, p. 216). In such objectless or non-perceptual generosity, the sharp subjectobject distinction and the preconceived notions give way, the truthful knowing occurs, the three spheres of agent, object, and recipient are equally perceived as being dependently arising and carrying infinite possibilities, each is part of the whole and each encompasses the magnificent whole. The concept of non-perceptual can also be understood from the perspective of what Krishnamurti referred to as "observe without observer or Ego" (Kumar, 2013, p. 86). In such pure observation, as Kumar (2013) explicated, “we meet life directly with each moment rather than through the screen of our past experiences ... which inhibits a clear perception of things as they are" (pp. 86-87).

The conception of objectless — with no object, non-perceptual — akin to the non-dualistic worldview, seems easy to understand, however, in practice, given our habitual ways of thinking and speaking that are prone to hypostatization, meaning "the process of reification or "thingifying': taking what is actually just a useful form of speech to refer to some real entity" (Siderits \& Katsura, 2013, p. 15), it can be easy for us to fall prey to the other extreme opposing the subject-object duality and hold that "there are no subjects and objects at all" (Sopa, 2008, p. 213). However, most importantly, cultivating toward a non-absolutistic and non-dualistic worldview is not at all a matter of holding views or opinions, but of "seeing things as they really are" (Walshe, 
2007). For the purpose of preventing us from falling into the conceptual proliferation that hypostatizes the aforementioned two extreme aspects of reality, Nagarjuna extracted Buddha's central teaching of dependent origination, which represents the correct middle path between the two extremes, into the famous eight negations: "there is neither cessation nor origination, neither annihilation nor the eternal, neither singularity nor plurality, neither the coming nor the going [of any dharma]" (Siderits \& Katsura, 2013, p. 13). This approach of negation points to not only the most significant feature of the union of wisdom and method but also the correct mindset of practicing the accumulation of wisdom and merits. The educational significance of this approach of negation is discussed in the next subsection.

\subsubsection{The Approach of Negation-The Core Approach to Consciousness Transformation}

As revealed in the preceding subsections, by means of pointing out explicitly that the origin of the karmic seeds of afflictive and noetic barriers that trap us in the imprisonment of the endless cyclic forms of existence is the absolutistic and objectivistic dualistic subject-object worldview that attaches to a subjective self and an objective world as absolute, essential, and independent existence, the Yogacarian doctrine of consciousness transformation provides us with profound empirical insights into the nature of spiritual path and spiritual practices for educational use.

In the dialogue between Buddhism and quantum physics, we have seen how the world that we experience in our everyday life is such a "deft master of disguise" (Greene, 2004, p. 22), we have also realized why the "overarching lesson that has emerged from scientific inquiry over the last century is that human experience is often a misleading guide to the true nature of reality" (Greene, 2004, p. 5), and why "assessing existence while failing to embrace the insights of 
modern physics would be like wrestling in the dark with an unknown opponent" (Greene, 2004, p. 5). By virtue of unmasking this "unknown opponent" as the absolutistic and objectivistic dualistic subject-object worldview that attaches to a subjective self and an objective world as absolute, essential and independent existence, the dialogue between Buddhism and quantum physics not only deepens and broadens our understanding of the concepts of truth and the relationship between truth and education, but also makes the spiritual practices of the five-stage gradual path of consciousness transformation sensible, graspable, practicable and achievable.

The spiritual practices prescribed in the five-stage gradual path of consciousness transformation, thus, can be understood as the efforts to the suppression and then the eradication of karmic seeds of the afflictive and noetic barriers that originate from an absolutistic and objectivistic dualistic subject-object worldview. As indicated in chapter three, even emptiness is itself empty; therefore, rather than advocating the positive pursuit of a hypostasized ideal of emptiness, the pedagogical foundation of this Yogacarian gradual path of consciousness transformation is grounded on the negation of the dualistic subject-object worldview that attach to a subjective self and an objective world as absolute, essential and independent existence. As discussed in chapter three, this is also a negation of the conception that holds "things having their own way of existing without being posited through the force of consciousness" (Newland, 2009, p. 70). However, as emphasized earlier, the negation of this absolutistic and objectivistic dualistic subject-object worldview is not to assume the other extreme of worldview and hold that there are no subjects and objects at all. Rather, it is seeing things as they really are by means of following the middle way approach of negation that grasps simultaneously the ultimate and phenomenal aspects of self 
and reality, and features the conception of objectlessness in the union of wisdom-side and method-side practices.

Grasping simultaneously the ultimate and phenomenal aspects of self and reality, this negative approach recognizes the ineffable and unfathomable grand nature of the original status of human consciousness that is sometimes referred to as the Buddha Nature, the Emptiness, the God, the Divine, the Otherness, the Atman, the Tao, the divine Reality, the Kingdom of God within, the Idea of the Good, the Idea of all ideas, or the Highest Idea by various religious and spiritual traditions, and can not possibly be fully grasped with the sensorial tools of the body and the analytical mind that is fragmentary both in nature and in effect, but only manifests itself when the attachment to the sharp subject-object dichotomy dissolves and the contaminated karmic seeds of afflictive and noetic barriers are suppressed or cleared away. By means of orienting the focus of practices on the suppression and then the eradication of the contaminated karmic seeds that originate from the attachment to the absolutistic and objectivistic dualistic subject-object worldview and on the union of the wisdom-side and method-side practices, this negative approach that is prescribed in Yogacara and informed by the middle way doctrine safeguards the practitioners from the deviation of conceptual proliferation and the pursuing of something ideally hypostatized by the ego as spiritual, and therefore prevents further inner fragmentation in consciousness from the very beginning of the path.

The essence of the approach of negation is well illustrated in Nagarjuna's famous eight negations. As discussed in last subsection, the eight negations well protect the practitioners from falling prey to the two extremes of nihilism and reificationism. As Kumar (2013) said, "the positive- 
be it love or non-violence - is not born through following [hypostatized] ideals [of love or nonviolence], which are opposite to the present state, but through negatively thinking and observing the present state of the mind" (p. 89). In other words, the positive manifests only through the negation of the afflictions originating from a dualistic subject-object perception that has caused the present unwanted state. He underscored that, "the negative approach is not reactionary in nature. It is not a mere replacement of one approach for another" (p. 89). He said, as Krishnamurti argued, if the negative approach is a mere reaction to the positive, then it would be merely the same thing in a different form (p. 90). Kumar elucidated this approach by drawing on Krishnamurti's discussion on love:

Is thought love? Does thought cultivate love? It is not pleasure, it is not desire, it is not remembrance, although they have their places. Then what is love? Is love jealousy? Is love a sense of possession, my wife, my husband, my girl—possession? Has love within it fear? It is none of these things, entirely wipe them all away, end them, putting them all in their right place - then love is. (as cited in Kumar, 2013, p. 89)

In other words, love as a given that is intrinsic in everything can never be genuinely attained through positive pursuits of hypostatized ideals, but only manifest itself when all of the contaminated clouds are dispelled. This elucidation deepens our understanding of not only the essence of the approach of negation but also the relationship between spirituality and truthful knowing and the dialectic between knowing and loving as explicated by Huebner and Palmer that are discussed in chapter two. Both of them criticized the dualistic subject-object worldview and the sharp distinction between the knower and the known. On the one hand, as shown in chapter two, Huebner (1985c/1999) indicated that the distortion of love occurs "when caring is for the self and knowing becomes an act of control, often an act of violence" (p. 349). Both 
Huebner's and Krishnamurti's insights instantiate how falling into objectifying or the subjectobject dichotomy becomes the origin of the afflictive and noetic barriers that not only contaminate and distort pure love, which is intrinsic in the original status of human consciousness, but also hinder truthful knowing. On the other hand, as discussed earlier, Palmer (1983/2003a) maintained that, "truthful knowing weds knower and the known.... We find truth by pledging our troth, and knowing becomes a reunion of separated beings whose primary bond is not of logic but of love" (p. 67). This dissolving of the distinction between the knower and the known, or the observer and the observed, echoes with the conception of objectlessness that unites wisdom and method, is one of the most significant features of the approach of negation. Given its epistemological and empirical significance for the genuine transformation of consciousness, this approach of negation is identified as the core approach in curriculum as an experience of consciousness transformation.

\subsubsection{The Implications}

Aiming for the eradication of the karmic seeds of the afflictive and noetic barriers that originate from an absolutistic and objectivistic subject-object worldview, the Yogacarian five-stage gradual spiritual path provides us with a panoramic view of the whole process of consciousness transformation into the perfection of the four transcendental wisdoms of the full enlightenment of Buddhahood. This panoramic view not only reveals the existential significance of the spiritual path of consciousness transformation for human beings, but also gives answers to our questions regarding the main barriers to be overcome on a spiritual path, the characteristics of various stages of progress, the main disciplines and practices and their interrelationships in various stages, and the core approach to consciousness transformation. In contrast to the 
misunderstanding about the spiritual path as entailing only the accumulation of wisdom by means of cultivating meditative stability and serenity, or to the misconceiving that moral suasion and ethical doctrine per se can bring about a genuine cure for current moral degradation and a resolution of various global crises, this gradual spiritual path illustrates the significance of following Buddha's teaching of the middle way that emphasizes the simultaneous grasping of the ultimate and phenomenal aspects of self and reality and features the approach of negation and the union of wisdom and method in practice.

On the basis of the realization of the essence and purpose of education as the transformation of consciousness attained in the review of educational literature and in the dialogue between Buddhism and quantum physics, the educational significance of this five-stage gradual spiritual path of consciousness transformation is threefold. Firstly, based on a profound conceptual understanding of the whole consciousness-only doctrine, including the concepts of truth, a panoramic view of the whole spiritual path, the cultivation of bodhicitta, the nature of spiritual approach and practices, the obstacles eliminated by these practices, and the positive results brought about by these practices, etc., this gradual path establishes, from the very first, a doctrine of the true nature of human existence, a vision of various spiritual goals, a selfless motivation, the recognition of the significance of the negative approach and the union of wisdom and method, etc. In this way, this gradual path well protects the practitioners from potential dangers and possible deviation from the very beginning of approaching various spiritual goals. In deliberating how we might facilitate the transformation of consciousness in educational context, such protection is of extreme significance. 
Secondly, by virtue of uniting the wisdom-side and method-side practices and including everyday experiences and phenomena as the entries for developing spiritual discernments and for overcoming the two barriers that originate from the dualistic subject-object worldview, the spiritual practices prescribed in this gradual path open up infinite possibilities in every moment and turn even the trivial everyday experiences into transcendental opportunities. Moreover, the requirement of the consistency between the view and deeds components of spiritual practices empowers the practitioners to experience a long-lasting and profound consciousness transformation along the path that, as discussed earlier, connotes the real happening of education.

Lastly, the panoramic view of this five-stage gradual path provides us with deepened hermeneutic insights into the essence, the language, and the pedagogical genius and expediency of the doctrines of various spiritual, religious and philosophical traditions, and how they resonate with each other. Such hermeneutic skills, as Huebner (1985c/1999) emphasized, are indispensable if we hope the veins of language about the spiritual within various religious and spiritual traditions can be well mined for educational use.

On the basis of the above exploration of the concept and process of consciousness transformation in Buddhism and the deliberation of its educational significance, along with the review of educational literature and the dialogue between Buddhism and quantum physics explored in the preceding two chapters, in the following, I proceed to investigate how we might understand curriculum as an experience of consciousness transformation by means of examining six key elements. 


\subsection{Curriculum as an Experience of Consciousness Transformation}

As shown previously, based on the review of educational literature and the dialogue between Buddhism and quantum physics, the essence and purpose of education that is revealed in Plato's allegory of the cave as the transitions of the essence of truth can be understood as in essence the transformation of consciousness toward the realization of the ultimate truth, the personal liberation, and the highest spiritual goal of the liberation of all sentient beings from the cyclic forms of existence in the suffering-laden shadowy phenomenal world. Propelled by this realization, earlier in this chapter, I explored Buddhist spiritual practices of consciousness transformation to gain deeper insights into how we might facilitate the transformation of consciousness in educational contexts.

In this section, I investigate how we might understand curriculum as an experience of consciousness transformation by means of examining six key elements. The six elements are: understanding the nature of consciousness, self and reality, learning to appreciate human temporality, cultivating impartiality and bodhicitta, becoming responsibly responsive, cultivating selflessness, and learning to embody a non-dualistic worldview.

\subsubsection{Understanding the Nature of Consciousness, Self and Reality}

Among the six key elements of curriculum as an experience of consciousness transformation, understanding the nature of consciousness, self and reality is of the first importance and is fundamental to the others. As indicated in the first stage of the five-stage gradual path of consciousness transformation, developing profound conceptual understanding of the whole doctrine of consciousness-only is the first and foremost step for progressing on this path. In the 
dialogue between Buddhism and quantum physics, we have also come to the realization that the doctrines of various spiritual and religious traditions are in essence all about the true nature of self and reality as well as the guidance on how we might attain the direct realization of it by virtue of both everyday and meditative spiritual practices. Without being well informed about the ultimate nature of self and reality that is contradictory to our everyday experiences, we can hardly penetrate the disguise of the shadowy phenomenal world and recognize the profound significance of spiritual wisdom and existential knowledge for human beings and for education. As Sopa (2008) said, we need to know "what we are doing and why we are doing it" (p. 17), "if one lacks knowledge or strong interest before beginning, one's practice will be shallow. If one's practice is weak the results will be feeble as well" (p. 232).

In his concern for human temporality, Huebner (1967/1999) also pointed out the significance of "probing the very nature of what it means to be a human being" (p. 135) for addressing the problems caused by the "dependency upon 'learning' as the major concept in curriculum thought" (p. 135) that were reflected in such expressions as "learning how to learn", or "how a person learns to be creative" (p. 134). Speaking from a theological perspective that sees humankind as transcendent being, Huebner (1967/1999) considered "learning how to learn" as a misleading question that stems from inadequate explanation of human characteristics, and asked: "Could it be that creativity is not learned, but an aspect of man's nature?" (p. 134). He maintained that, the adequate questions are what prevents creativity and how to explain fixation, rather than how to be creative or learn how to learn (p. 134). He was also concerned that by considering learning as implying the process of abstraction and generalization, "it yanks man out of his world and 
freezes him at a stage in his own biographic evolution" (Huebner, 1967/1999, p. 136). Huebner (1967/1999) indicated that, owing to a misapprehension of the nature of human existence, learning is assumed to be something that happens within the individual. Education is consequently conceived as doing something to an individual. This leads to the proposition that there is the individual and there is the world, and that the individual develops in such a way that he has power over the world or to act upon the world. Such thinking leads to consideration of the individual as something distinct. Obviously, this is not the case. The individual is not separated from the world, or apart from it—he is a part of it. The unit of study, as Heidegger, among others, points out, is a "being-in-the-world." Any system of thought dealing with human change as something that happens within the individual is likely to lead the educator astray. However, if a curricular language can be developed so that the educator looks at the individual or the situation together, not separately, then his powers of curricular design and educational responsibility might be increased. (pp. 138-136)

Huebner's insights illuminate how objectivism, despite not being convincing anymore, is institutionalized in our educational language and practices and in the ways we teach and learn through the power of hidden curriculum rooted in the lack of awareness of the true nature of human existence. The lack of existential knowledge and spiritual wisdom regarding the true nature of consciousness, self and reality not only prevents the genuine transformation of consciousness and real education from happening, I believe, is also the root cause of moral degradation, the depreciation of human existence, and various global crises. However, despite the fact that modern physics and other branches of science have pierced the disguise of the shadowy phenomenal world and indicated that it is far from the ultimate reality, educational 
scholars and decision-makers are hesitant to integrate a comprehensive interdisciplinary exploration of various human existential inquiries regarding the ultimate nature of consciousness, self and reality into school and university curriculum. While the underlying causes of this hesitation are complicated, one of the main obstacles might be the over-reliance on science and rational analysis in answering existential inquiries and issues.

In his concerns for the tendency of the over-reliance on scientific knowledge about human beings in education, Huebner (1959/1999) reminded us that "psychological or behavioral science is not the only channel of information about human beings available to educators" (p.2) and "behavioral scientists are not the only ones who speculate about and know men, women, and children" (p.2). He pointed out our curious position in education that we must run the schools and educate both the younger generations and ourselves anyhow, and "to do this job we need to use all available knowledge and more. We cannot postpone the educational task until we have the results of the 'scientific' knowledge" (p. 2). Moreover, he continued, "scientific validity is not the only kind of validity. In the existential situation in which we must plan for and act with boys and girls, we must bring all of our knowledge and creative powers to bear" (p. 2). Taking behavioral science as an example, Huebner (1959/1999) reminded us of our strange positions and stated that, although "the information coming through [behavioral science] is incomplete, charged with static, we nevertheless accept the picture we receive as the real representation. Yet during the next ten - twenty - or one hundred years that picture may change considerably" (p. 2). Moreover, such over-reliance on science and rationalism could also possibly develop into the attachment to scientific knowledge and lead to what David Smith (2000) called as frozen futurism, "in which what are expected to be revealed has been revealed" (p. 17). As a result, 
teaching is understood primarily as an act of implementation, with the curriculum as a settled commodity emerging from a settled anterior logic headed for a settled posterior conclusion. Teaching itself is reduced in the process to being nothing but a form of procedural manipulation in which the being of the teacher requires no true encounter with the being of the student, nor with curriculum. (p. 19)

In the absence of interest in genuine conversation and truthful knowing between the teachers, parents and the student for finding out the sources of the problem in a present situation, "a unilateral importation of externally derived behavior modification strategies . . . according to a predetermined criteria for future results" (p. 20) might be implemented mechanically or with love and care. Yet, even if it is implemented with love and care, "the future is frozen in an anticipatory set through which nothing ever really seems to change, although all of the language perpetually gives assurance that things are always changing" (Smith, 2000, p. 17), in actuality, there is "no change in the sense that it actually seems to make a difference in the way one lives" (Smith, 2000, p. 17). This kind of frozen futurism demonstrates how, in the absence of spiritual wisdom, such as emptiness or the transcendent that signifies infinite possibilities and the oneness of everything, the over-reliance on scientific knowledge can close up true conversation and form noetic barriers that inhibit truthful ways of knowing, being and living here and now, and hinder the "intricacies, the complexities and the living quality of clarity" (Krishnamurti \& Smith, 1996, pp. 201-202, as cited in Kumar, 2013, p. 88) from the student, parents and educators.

Such technical ethos developed from the language of scientific method and curriculum implementation becomes "a cultural version of instrumentalism - a way of life that is not fully bodily lived" (Aoki, 1991/2004, p. 369). Aoki (1991/2004) cautioned us that, "the danger in 
speaking this language is that we become the language we speak" (p. 369), and "in so becoming, we might become forgetful of how instrumental language disengages us from our bodies, making of us disembodied, dehumanized beings, indifferent to the nihilistic drying out of inspiritedness" (p. 369). As Huebner (1959/1999) indicated, the approach to the world through intellectual analysis "makes us more powerful by providing more control and prediction. But it may also lead to new enslavements - enslavement to the known, the abstract, and consequently to the past" (p. 8). Such enslavement to disembodied instrumentalism is also a concern to Aoki. Drawing on jazz trumpeter Bobby Shew, Aoki (1991/2004) suggested, "instead of 'curriculum implementation', how about 'curriculum improvisation'?” (p. 369). Curriculum improvisation "provokes in us a vitalizing possibility that causes our whole body to beat a new and different rhythm" (Aoki, 1991/2004, p. 369). As Bobby Shew insisted, for an instrument to cease to be an instrument, "the trumpet, music, and body must become as one in a living wholeness" (Aoki, 1991/2004, p. 368). In such moments, the subject-object separation is no longer present, and none is reduced to objects. Aoki (1991/2004) quoted Heidegger that, "objective meanings hide lived meanings. The later become silent and man becomes heedless of this silence" (p. 381). In this way, the oblivion of Being occurs, and this oblivion of Being "applies not only to the people objectified but also to the subject that objectifies. Usually unconsciously, the subject diminished itself to a half-life. An oppressor becomes oppressed by the half-lives he or she produces" (Aoki, 1991/2004, p. 381). From this perspective, scientific methods that objectify and fragment can at most give a half-answer to human existential inquires and issues.

Drawing on Krishnamurti, Kumar (2013) also pointed out that, "analysis and thinking — central features of intellectual pursuits—alone cannot solve human problems" (p. 77). However, given 
its extraordinary capacity for addressing scientific inquiries regarding the phenomenal world and for the accumulation and expansion of knowledge, consciously or unconsciously, rational analysis is gradually supposed to be an omnipotent means that, sooner or later, will give answers to various human existential questions. Nevertheless, as discussed earlier, the dissolving of the sharp subject-object distinction in either a meditative status or a everyday existential situation can not possibly be achieved by rational analysis alone, for analysis in itself, if not coupled with spiritual wisdom that knows emptiness, risks further fragmentation rather than the dissolving of the self-world dichotomy. As Kumar inferred, in the process of analysis and thinking, "is not 'the analyzer/observer/thinker/controller' also 'the analyzed/observed/thought/controlled'? If the very structure of thought is deeply conditioned, fragmented [by the dualistic subject-object worldview], and ridden with fear how can it understand and transform itself?" (pp. 77-78).

Michio Kaku (2005), theoretical physicist, also highlights the limitations of science and rational analysis in addressing existential issues. As Kaku (2005) illustrated, "if string theory is eventually experimentally confirmed as the theory of everything, then we must ask where the equations themselves came from. If the unified field theory is truly unique, ... then we must ask where this uniqueness came from" (p. 358). Since science can never answer such a question as "Why it is this?" in the very end of a series of the whys and wherefores, Kaku said, from a pure scientific viewpoint, he personally believed that the strongest argument for the existence of the God of Einstein or Spinoza might be teleology (p. 358). He reasoned that, "physicists who believe in this God believe that the universe is so beautiful and simple that its ultimate laws could not have been an accident" (p. 358). Nevertheless, Kaku further argued that, should one day the physicists succeed in discovering one ultimate equation from which all physical laws can 
be derived from, he would believe that this simply implies some sort of design, but "do not believe that this design gives personal meanings ${ }^{22}$ to humanity" (p. 358). He quoted theoretical physicist Alan Guth's words that,

it's okay to ask those questions [of the purpose of universe or the meaning of life], but one should not expect to get a wiser answer from a physicist. My own emotional feeling is that life has a purpose-ultimately, I'd guess that the purpose it has is the purpose that we've given it and not a purpose that came out of any cosmic design. (Croswell, 2002, as cited in Kaku, 2005, p. 359)

Kaku's illustration revealed the limitations of rational analysis and science per se in answering the existential inquiries regarding value and end, and exposed the difficulties caused by the complete exclusion of existential knowledge and spiritual wisdom from education.

As revealed in my earlier exploration, aiming for the suppression and then the eradication of karmic seeds of the afflictive and noetic barriers that originate from an absolutistic and objectivistic dualistic subject-object worldview, the approach of negation that grasps simultaneously the ultimate and phenomenal aspects of self and reality and features the conception of objectlessness in the union of wisdom-side and method-side practices is identified as the core approach in curriculum as an experience of consciousness transformation. On the contrary, the dominant approach of science that has been developed for ages is based on a

\footnotetext{
${ }^{22}$ According to Kaku (2005), "Einstein once confessed that he was powerless to give comfort to the hundreds of well-meaning individuals who wrote stacks of letters pleading with him to reveal the meaning of life" (pp. 358-359).
} 
dualistic subject-object worldview (Bohm, 1980, p. 19). Apparently, there exist fundamental differences in the modes of looking at the world and in the methodologies of exploring reality between the approach of negation and the approach of science. In scientific research, the dualistic way of looking, thinking and acting "tends very strongly to re-enforce the general fragmentary approach" in our society (Bohm, 1980, p. 19). Bohm (1980) indicated that, "in this way, people are led to feel that fragmentation is nothing but an expression of 'the way everything really is' and that anything else is impossible. So there is very little disposition to look for evidence to the contrary" (p. 19). In other words, people that are likened by Plato as strange sort of prisoner in an underground cave are led to reaffirm the fragmentary shadows on the wall of the cave as what the reality really is, rather than merely "a form of insight, i.e. a way of looking at the world" (Bohm, 1980, p. 4). In this manner, this prevailing scientific way of looking at the world becomes a fortified shackle that further prevents the transitions from one stage to another in the allegory of the cave, and therefore, hinders the real happening of education which, according to Heidegger (1942/1962), is "a shift in the definition of the essence of truth" (p. 251).

From this perspective, the hesitation in integrating a comprehensive interdisciplinary exploration of the human existential inquiries and the ultimate nature of consciousness, self and reality into school and university curriculum with the excuse that the spiritual truths and wisdoms have not yet been fully scientifically proven could be a meaningless and ultimately detrimental procrastination. In the following is a parable taught by Buddha that shows how this hesitation could be harmful. There was a bhiksu who was frustrated by fourteen difficult questions and went to Buddha to seek answers. The fourteen difficult questions were: Is the world eternal, or not, or both, or neither? Is the world finite, or not, or both, or neither? Is the self identical with 
the body, or not? Does the Buddha exist after death, or not, or both, or neither (Lamotte, 1949/2001, p. 711)? He pondered that, "If the Buddha will explain these fourteen difficult questions for me and satisfy my mind, I will remain his disciple; if he does not succeed in explaining them to me, I will seek another path" (Lamotte, 1949/2001, p. 711). Buddha knew what he was thinking about and told him that, "If I answered, you would not understand; at the time of death, you would have understood nothing and you would not be liberated from birth, old age, sickness and death" (Lamotte, 1949/2001, p. 711). Buddha continued that, like an ignorant person struck by a poisoned arrow, rather than allowing a physician to remove the arrow and apply an antidote immediately, this ignorant person insisted that he will not let the physician take out the arrow and apply antidote until he knows what the physician's name, family, age, etc. are, from which mountain the arrow came, what the arrow made of, and where the antidote comes from and what its name is (Lamotte, 1949/2001, p. 711). Buddha said to this bhiksu, "You are like him: the arrow of wrong views . . . dipped in the poison of thirst . . . has pierced your mind; I want to remove this arrow from you, my disciple; but you are unwilling to let me take it out, and you want to know if the world is eternal or non-eternal, finite or infinite, ... You will not find what you are looking for, but you will lose the life of wisdom . . ; you will die like an animal and fall into the shadows" (Lamotte, 1949/2001, p. 711). In educational context, the flat rejection of the spiritual truth and wisdom, which are prudently preserved and handed down by various religious and spiritual traditions, with the excuse that these spiritual doctrines have not yet been fully scientifically proven is, in a way, following the same logic as this bhiksu and risking similarly grave consequences. 
Huebner (1959/1999) also reminded us that, "in our concern to make the study of education scientific we have ignored other channels" (p. 2). He indicated that the study of the nature of being in the works of certain existentialists is one of the channels of "information about human being to which we as professional educators have not been attuned by the producers and users of educational knowledge. As university people we do an injustice by not making these notions available to the educator" (Huebner, 1959/1999, p. 3). From my perspective, the injustice we have done is much grosser than we might have thought. According to the foregoing deliberation over the limitations of science, rational analysis and moral systems, and with the renewed understanding of the spiritual truth and the essence and purpose of education attained in previous chapters, I am concerned that by means of excluding the existential knowledge and spiritual wisdom from curriculum, we have done injustice to numerous students by way of suggesting the incredibility and dispensability of the whole spiritual wisdom and the irreconcilability of various religious traditions in various forms of hidden curriculum, and thereby, perpetuate both the inner and external fragmentation and confliction, and hinder the genuine education from happening.

As discussed in the foregoing section, in the absence of spiritual wisdom that knows emptiness, moral suasion and ethical doctrine per se that work under the model of objectification cannot possibly bring about any real change in human consciousness, let alone the cure for current moral issues and the resolution of various global crises. Moreover, given the permeation of the market logic of contemporary globalization and the falling of public education into this logic, Smith (2000) concerned that it has brought about new levels of paranoia "along with an almost complete collapse of any older virtue of learning being valued for its own sake" (p. 13). Given the fact that genuine consciousness transformation that is crucial to our shared future requires the 
union of wisdom and method in practices, human beings need to be well informed about the existential knowledge and spiritual wisdom regarding the true nature of consciousness, self and reality from various perspectives so that the wisdom and method can possibly be held and imbued by each other. As Nisargadatta Maharaj said, your love towards others is the result of self-knowledge, not its cause. No virtue is genuine without knowledge of oneself. When you have certain knowledge that life itself flows through all that is, and that you are such life, you will love everything naturally and spontaneously... . But, when you see any thing as something separate from yourself, you cannot love it, because you are afraid of it. Alienation produces fear, and fear intensifies alienation. It is a vicious circle. Only self-knowledge can break that cycle. (Maharaj, as cited in Nava, 2001, p. 127)

Maharaj's insights illuminate why the shortage of existential knowledge and spiritual wisdom regarding the ultimate nature of consciousness, self and reality is the root cause of moral degradation, the depreciation of human existence, and various global crises. He also made explicit the vicious circle that the attachment to the alienating subject-object worldview becomes a source of fear that reinforces alienation. The emphasis that this vicious circle cannot possibly be broken down unless certain self-knowledge is attained also points to the futility of the sort of moral education with its existential roots removed. It is clear that, for Maharaj, self-knowledge does not refer to the psychologistic conceptions of knowledge of self that is established upon an objectifying mode of worldview. The method of psychological analysis, if not imbued with wisdom that knows emptiness, might result in only more bondage rather than genuine transformation and liberation. As Boler (1999) indicated, "the Socratic admonition to 'know thyself' may not led to self-transformation" (p. 177) and self-reflection, by itself, particularly as 
a narrow psychological process, "may result in no measurable change or good to others or oneself" (p. 177). This is true especially when the concept of the self is narrowly defined and remains entrenched in the absolutistic and objectivistic subject-object duality.

Earlier in this subsection, we have seen how the integration of existential knowledge and spiritual wisdom regarding the ultimate nature of consciousness, self and reality into school and university curriculum is never optional but is imperative. While the integration of the existential knowledge and spiritual wisdom into curriculum in a way that encompasses the vast diversity of religious, spiritual, philosophical, scientific, and various intellectual traditions surely involves formidable challenges and enormous efforts, in the face of various global crises, spiritual tensions, and the dominance of market logic of current globalization, I see no better and securer option than recovering the place of existential knowledge and spiritual wisdom in education to ensure a bright shared future that is grounded on mutual care and love, is genuinely open to infinite transcendental possibilities, and is genuinely sustainable in a noble and dignified way. With the belief in the truth force demonstrated by Gandhi and explicated by Gore that is explored in chapter one, I am convinced that "in every land, the truth—once known—has the power to set us free. Truth also has the power to unite us and bridge the distance between 'me' and 'we', creating the basis for common effort and shared responsibility" (Gore, 2008, p. 57), no matter how formidable this task might be.

Nevertheless, very significantly, the integration of existential knowledge and spiritual wisdom into curriculum for the transformation of consciousness is not just a matter of enlarging a stock of knowledge in curricular materials and a mere conceptual understanding of these materials. As 
discussed in last section, while a profound conceptual understanding of a comprehensive existential and spiritual doctrine is crucial for progress on a spiritual path, genuine transformation of consciousness and genuine attainment of self-knowledge entail also the union of the wisdom-side practices of meditative stabilization and serenity (the accumulation of wisdom) and the method-side practices based on love, compassion and bodhicitta in everyday existential conditions (the accumulation of merits). Only when wisdom is held by method and method is held by wisdom can genuine transformation of consciousness and real education possibly happen. This point is well explicated by Sopa. According to Sopa (2008), at first wisdom comes from extensive study—we learn from a teacher and from books. After we have learned about the goal and method to attain it, we analyze what we have studied. We establish our understanding by independent examination. Once we understand things through the first two techniques, we meditate on these topics. (p. 16) The wisdom and insights attained in meditation, as discussed in previous section, in turn, can be carried over to infuse the method-side everyday practices based on love, compassion and bodhicitta, and vice versa.

The crucial role of meditation in bringing about genuine transformation of consciousness and direct realization of the nature of consciousness, self and reality has been found in various experimental studies in neuroscience. For example, the results of the studies of brain scans conducted by Lutz, Greischar, Rawlings, Ricard, and Davidson (2004) have shown that "meditation on nonreferential compassion — a meditation practice based on the union of emptiness and compassion — produced a profound increase in what are often referred to as gamma waves" (Mingyur, 2007, p. 228). Gamma wave is a very high frequency of brain wave 
that reflects "an integration of information among a wide variety of brain regions" (Mingyur, 2007, p. 228). For neuroscientists, gamma waves represent "activity that occurs when various neurons communicate in a spontaneously synchronous manner across large areas of the brain" (Mingyur, 2007, p. 228). As one of the subjects of various empirical studies on meditation, including the aforementioned one, Mingyur Rinpoche himself demonstrated a staggering result, which showed that "during a meditation on compassion, [his] neural activity in a key center in the brain's system for happiness jumped by 700 to 800 percent" (Goleman, 2007, p. viii), while for ordinary subjects "who had just begun to meditate, the same area increased its activity by a mere 10 to 15 percent" (Goleman, 2007, p. viii). Speaking from his personal experience along with strong experimental evidences, Mingyur (2007) asserted that meditation on compassion fosters a broadening of insight into the nature of experience that stems from unchaining the habitual tendency of mind to distinguish between self and other, subject and object—a unification of the analytical and intuitive aspects of consciousness that is both extremely pleasurable and tremendously liberating. (p. 227) The personal experiences of Mingyur Rinpoche and the related experimental evidence convincingly demonstrate the mighty transformative power of meditation based on the union of wisdom and compassion for attaining the direct realization of the true nature of consciousness, self and reality that features the dissolving of the sharp distinction between self and other, subject and object. It is clear that the exclusion of existential knowledge and spiritual wisdom and the unilateral emphasis on rational analysis and scientific thinking in educational contexts have impeded both the conceptual understanding and the direct meditative realization of the true nature of consciousness, self and reality, and as a result, hinder the full development of human potential and real education from happening. The existential and educational significance of 
meditation and the union of the wisdom-side and method-side practices will be revisited later in the exploration of the others elements.

In the following, given that human temporality is one of the most significant features of human existence and human experiences, I probe into the significance of learning to appreciate human temporality for consciousness transformation.

\subsubsection{Learning to Appreciate Human Temporality}

Human temporality is one of the most significant features of human existence. However, as Greene (2004) indicated, "time is among the most familiar yet least understood concepts that humanity has ever encountered" (p. 127). It is so elusive that St. Augustine (354/1900) would confess: "What, then, is time? If no one ask of me, I know; if I wish to explain to him who asks, I know not" (p. 244). Even today, the subtle subject of time is far from fully grasped by science (Greene, 2004, p. 141). What is sure is that current scientific studies upon time, as shown in Greene's (2004) work (pp. 127-142), have exhibited various mind-boggling discrepancies between what are revealed in deep physical laws and what are experienced in our everyday life. This fact again demonstrates how human experience is often a misleading guide to the true nature of reality.

Considered from the two truths framework, while conventionally the objective concept of time provides us with a very handy tool and a very useful form of speech, ultimately speaking, time, in itself, is empty of any absolute, essential and independent nature but is dependently arising. As Huebner (1967/1999) indicated, “the very notion of time arises out of man's existence, which 
is an emergent" (p. 137). The dependent arising nature of time upon human existence or human consciousness is well demonstrated in Huebner's insights into the nature of future, past and present. Drawing on Heidegger, Huebner (1967/1999) indicated that the future is man facing himself in anticipation of his own potentiality for being. The past is finding himself already thrown into a world. It is the having-been which makes possible the projection of his potentiality. The present is the moment of vision when Dasein, finding itself thrown into a situation (the past), projects its own potentiality for being. (p. 137)

Human existence, thus, "is not simply given by his being in a given place, but by a present determined by a past and a future; thus offering possibilities for new ways of being in the anticipated future" (Huebner, 1967/1999, p. 135). For Huebner (1967/1999), "there is no such 'thing' as a past or a future" (p. 137). Past and future "exist only through man's existence as a temporal being. This means that human life is never fixed but is always emergent as the past and future become horizons of a present” (Huebner, 1967/1999, p. 137). Huebner's elucidation of the relationship between human and time not only increases our awareness of the dynamic and emerging nature of human existence and deepens our appreciation of the present that signifies infinite transcending possibilities, but also makes clear the inseparability of human being and the world that one finds oneself already in. As Huebner (1967/1999) said, human "temporality, or historicity, is not a characteristic of isolated man, but a characteristic of being-in-the-world" (p. 137). Given its resonances with the ultimate truth of emptiness, Huebner's concern for human temporality, thus, is in essence the concern for the ultimate nature of human existence that connotes infinite transcendental possibilities in the present and features the non-duality of being and world. 
In Buddhism, based on Buddha's profound transcendental perception of human nature, human temporality is considered from a prolonged framework of time that extends beyond both birth and death of the current life, and the dispelling of the wrong views about the past, the future and the present is fundamental to various spiritual progresses on the path of consciousness transformation. As Buddha stated in the Rice Seedling Sutra, when you properly understand dependent origination, it clears away wrong views about the past, the future, and the present. ... "Wrong views about the past" refers to denying that existence has a cause, or imputing an incompatible cause; ... "Wrong views about the future" refers to thinking that there is no future life after this life ends, that the causes you create in this life will have no results in the future. This is a kind of nihilism that leads to a "wrong views about the present." This is the belief that your present behavior does not matter because virtue and nonvirtue have no effect on future experience; you can do whatever you please because you will not suffer any consequences. (as cited in Sopa, 2005, p. 353)

A proper understanding of dependent origination also deepens our understanding of the theological description of human nature that

he [or she] participates in both the conditioned and unconditioned, or in necessity and freedom. Man [or Woman] is conditioned to the world; he [or she] participates in the world's structures of necessity. But given this patterning, fixation, and conditioning, he [or she] also participates in the unconditioned — in freedom, or (if you wish) in the continual creation of the world. (Huebner, 1967/1999, p. 135) 
On one hand, the twelve links of dependent origination discussed in chapter three reveals how our current samsaric form of existence is conditioned by the ripening of past karma seeds or information deposited in our consciousness. On the other hand, however, the dependent arising nature of all phenomena and the ultimate truth of emptiness that signifies infinite transcending possibilities reveal how we are unconditioned in respect of how we respond to the current experiences. From the perspectives of both Buddhism and theology, the opportunities of transcending our current forms of existence are always in the present that is determined by both a conditioned past and an unconditioned future.

Learning to appreciate human temporality, thus, is in essence learning to appreciate the present, which is "the foundation of reverence" (Huebner, 1985b/1999, p. 360). Drawing on Whitehead, who proposed "reverence as the other dimension of education that makes it religious" (Huebner, 1985b/1999, p. 360), Huebner (1985b/1999) maintained that, the foundation of reverence "is the perception that the present holds within itself . . eternity". In the present is the past and the future. In the present is the sum of all existence. ... In the traditions of Jewish and Christian faith communities, in the present dwells God—beyond comprehension, beyond knowing except for the glimmerings and the hints that shine forth in the acts of love, dwell in the awesome appearance of beauty and overwhelm us at the gift of life in birth and the loss of life in death. (p. 360) The perception that the present holds within itself eternity and that in the present dwells God or the grand source that overwhelms us at the gift of life in birth and the loss of life in death suggests the significance of living in the present with humility for approaching the direct nondualistic realization of emptiness. This perception also reminds us of our mortality, and human 
mortality, if revered and faced up to, is able to nurture the appreciation of the present and open the door to the grand ultimate nature of human existence.

In contemplating the question about how one should live, Heidegger addressed on the concept of authenticity and its relationship with death. For Heidegger, the anxiety in the face of death, "if faced up to, can open the door to an authentic existence" (Dreyfus \& Wrathall, 2005, p. 8), and can liberate "one from possibilities which 'count for nothing', and lets one become free-for those which are authentic" (Heidegger, as cited in Dreyfus \& Wrathall, 2005, p. 8). Death, for Heidegger, is "the possibility of the impossibility of every way of comporting oneself toward anything, of every way of existing" (Dreyfus \& Wrathall, 2005, p. 8). According to Dreyfus and Wrathall (2005), from Heidegger's perspective, "the way we relate to death is a fundamental kind of dealing in the world, one that affects the character of the way things show up at a very basic level" (p. 8). The certainty of death, thus, is not an empirical one, "but instead certain because it is the basis for disclosing ourselves to us. That is, our experience of every-thing is an experience in the light of the fact that we are mortal and temporal beings" (Dreyfus \& Wrathall, 2005, p. 8). While, of course, there are various ways of trying to deal with death, an authentic being towards death means taking death as a possibility — that means, not thinking about it or dwelling on it, but rather taking it up in the way it shapes all our particular actions and relations.... That is, we are ready for the world in light of the fact that each decision has consequences, and will someday culminate in our not being able to get by any longer. This, in turn, makes it possible for me to live my life as my own. (Dreyfus \& Wrathall, 2005, p. 8) 
However, Dreyfus and Wrathall (2005) indicated that, according to Heidegger, Dasein, which he referred to as the peculiar human way of existence that is always already existing in a world, often "disguises from itself — primarily by taking up societal norms as if they somehow revealed the ultimate truth about how one should live" (p. 7) to the extent that it becomes "all too easy never to take a stand for oneself" (p. 7), and this aspect of conformism is called by Heidegger as inauthenticity. Thus, for Dasein, "in its very being, that being is an issue for it" (Heidegger, 1962, as cited in Dreyfus \& Wrathall, 2005, p. 8). According to Dreyfus and Wrathall's (2005) reading of Heidegger, this issue can be understood in terms of moods, which "are often dismissed as merely subjective colorings of our experience of the world" (p. 5); however, Heidegger insisted that, "moods actually reveal something important about the fundamental structure of the world and our way of being in it" (p. 5). In other words, moods reveal one's realization of the nature of self and reality. Heidegger also maintained that while it is clear that moods are not objective properties of entities within the world, it is also clear that moods in fact are not merely subjective either. A boring lecture really is boring, a violent person really is frightening. This shows that the subjectiveobjective distinction fails to capture the interdependence of our being with the world and the entities around us. In addition, moods in fact make it possible for us to encounter entities within the world by determining how those entities will matter to us. (Dreyfus \& Wrathall, 2005, p. 5)

Echoing with Buddha's teaching of dependent origination that grasps simultaneously the ultimate and phenomenal aspects of self and reality, Heidegger made clear that the subject-object dichotomy only hinders us from realizing the dependent arising nature of self and reality, from living in light of our true nature as an authentic being-in-the-world, and from realizing new 
meanings and new possibilities. Moods, therefore, reveal one's worldview and disclose how the presumed or realized "truth" grasped by an individual regarding the nature of human existence influences one's relationship to the world, and reveal how one might take up death as a possibility for reshaping one's actions and relations. For Heidegger, authentic Dasein does not surrender itself to the public interpretation of the self, although it depends on it (Dreyfus \& Wrathall, 2008, pp. 7-8). Furthermore, authentic Dasein "is open to the particular needs of the situation. Having recognized the fact that its being is at issue, it responds appropriately to the particular situation before it" (Dreyfus \& Wrathall, 2008, p. 8). Therefore, in authenticity, Dasein recognizes its being-in-the-world, challenges the public interpretation of the self, takes up the public understanding of its world and makes it its own by projecting on its own possibilities (Dreyfus \& Wrathall, 2008, p. 8), and such sort of possibilities, in Heidegger's sense, “is a way of dealing with things that shows them as the things they are" (Dreyfus \& Wrathall, 2008, p. 6).

Given its resonances with the ultimate nature of human existence explored in earlier discussion, Heidegger's insights into death and the authentic Dasein provide educators a new perspective for contemplating how one might learn to appreciate human temporality and mortality and might live and educate in light of the true nature of human existence. In educational context, there have been numerous obstacles that hinder Dasein from facing one's temporality and mortality, from realizing one's authentic existence as a being-in-the-world, and from living in a way that deals with things that shows them as they really are. Such obstacles originate partly from the disadvantages intrinsic in knowledge. As Huebner (1962/1999) indicated, "the negative aspects of knowledge arise from the imposition of a symbolic curtain or screen between the person and reality" (p. 38). While this symbolic curtain does empower human in his encounter with and 
exploration of reality, it is the very same curtain that may blind a person to what really is (Huebner, 1962/1999, p. 38). Huebner (1962/1999) quoted Cassirer that, "no longer can man confront reality immediately; he cannot see it, as it were, face to face" (p. 38). Given this screening quality of knowledge, human "is apt to forget that reality is not seen 'as it is,' but through a man-made screen which filters out certain information and organizes the rest into patterns which exist not necessarily in the world" (p. 38). In other words, in the absence of spiritual wisdom that knows emptiness, we are apt to forget that knowledge and various methods it serves are empty of any absolute, essential and independent nature, and exist in dependence upon conceptual designation. Yet, this disadvantage of knowledge can be overcome, as Huebner (1962/1999) suggested, when the human "uses knowledge with humility and tempers it with doubt, willing and eager to entertain other ways of knowing that which is beheld" (p. 39).

In educational contexts, as a result of the upholding of objective knowledge that serves various scientific methods and the neglecting of spiritual wisdom, this screening and objectifying quality of knowledge also hinders human beings from seeing death as it is, and in turn, hinder humankind from living with authenticity. Thompson (2015) has indicated that all of us will die and it is a fact like no other (p. 274). "It's not just that everyone of us will die; it's that I, myself, am going to die" (Thompson, 2015, p. 274). Yet, despite this certainty, we don't believe that it can happen to us (Thompson, 2015, p. 274). Thompson (2015) also pointed out that, "modern Western society, like no other society in human history, reinforces our blindness to the inevitability of our own death" (p. 274) by means of countless ways. One peculiar and powerful way, as Thompson pointed out, is that biomedicine usually "talks about death as if it were essentially an objective and impersonal event instead of a subjective and personal one" 
(Thompson, 2015, p. 274). A purely biomedical perspective of death "consists in the breakdown of the functions of the living body along with the disappearance of all outer signs of consciousness" (Thompson, 2015, p. 274). Missing from this biomedical perspective, Thompson (2015) underscored, "is the subjective experience of this breakdown and the significance of the inevitable fact of one's own death. Biomedicine hides the inner experience of dying and the existential meaning of death" (Thompson, 2015, p. 274). In sharp contrast, according to Thompson (2015), "the Indian and Tibetan yogic traditions claim to provide detailed accounts of the transformations of consciousness during the dying process" (p. 275), and Tibetan Buddhism also "offers a rich contemplative perspective on death, including meditations to prepare for death and to practice as one dies. This kind of experiential view of dying and death is missing from the biomedical perspective" (p. 275). Various experiential view of dying and death can also be found in the records of various religious and spiritual traditions (e.g. the records of successful practitioners in the Pure Land school ${ }^{23}$ of Buddhism, the guidance on dying and the bardo

${ }^{23}$ Successful practitioners of the Pure Land Buddhism usually know (mostly being informed by Amitabha Buddha or Pure Land bodhisattvas) the exact time of their death and prepare it in advance. At the moment of death, the dying practitioner would inform those people who are on the scene of the advent of the Three Saints of the West (Amitabha Buddha, bodhisattvas Avalokiteśvara and Mahāsthāmaprāpta) who are going to escort this dying person to Amitabha Buddha's Pure Land. After passing away, the face expression of the dead usually looks very peaceful, and their body would remain very soft and flexible. 
experiences $^{24}$, meaning the intermediate state between death and the next rebirth, in Tibetan Buddhism) and in the burgeoning research of near death experiences (e.g. the works thinkers such as Raymond Moody and Bruce Greyson) and the research of reincarnation in the last few decades. In Buddhism, such an experiential view of death is categorized as the extremely remote or extremely obscure phenomena that cannot be known through neither direct perception nor through inference, but are known only through the testimony of a third person (Thompson, 2015, p. 288). Yet, such experiential accounts as "the records of those who have been transformed, or have experienced transcending moments" (Huebner, 1985c/1999, p. 346) are of great educational significance. In Huebner's (1985c/1999) words explored in chapter two, they are "ways to know others, and consequently also ways to know one's self" (p. 347), in this manner, "they provide ways to think and talk about one's self, with others, from birth to death. They provide possibilities, to be chosen or rejected" (p. 347). For the purpose of educating toward the truth and of facilitating the transformation of consciousness, such experiential views of death should well be mined by educators.

Learning to appreciate human temporality, therefore, is learning to appreciate the ultimate nature of human existence as unveiled in the dialogue between Buddhism and quantum physics, and learning to appreciate the present that connotes infinite transcending possibilities of becoming an

${ }^{24}$ Compiled and edited by Evans-Wentz (1927/2000), The Tibetan Book of the Dead: Or The After-Death Experiences on the Bardo Plane, According to Lama Kazi Dawa-Samdup's English Rendering is one of the best-known English translations of the experiential teaching on death in Tibetan Buddhist literature. 
authentic existence. This requires one to liberate oneself from those count for nothing based on the reverence for human mortality and on the right seeing of death as it is. With the appreciation of human temporality, we recognize the significance of learning to take the responsibility for one's decisions and respond appropriately to the world.

As suggested in the stage of intensified efforts, the second stage of the five-stage gradual path of consciousness transformation, learning to take the responsibility for one's decision and respond appropriately to the world requires a vision to enter the path of spiritual discernment by making efforts to cultivate the non-dualistic worldview that is conducive to decisive distinction. The vision to enter the path of spiritual discernment necessitates the cultivation of righteous mindset and motivation that is able to guide and support us through the path. With this realization, before investigating into how we might learn to take the responsibility for one's decision and respond appropriately to the world, in the next subsection, I explore the cultivating of impartiality and bodhicitta that is crucial for developing significant spiritual discernment.

\subsubsection{Cultivating Impartiality and Bodhicitta}

Among the four transcendental wisdoms explored earlier, the perfection of universal equality wisdom that bears on both the ultimate and phenomenal aspects of reality and sees the identity of all phenomena and the equality between its own self and other sentient beings is one of the four mental attributes of Buddhahood that represent the fulfillment of bodhicitta, which is the aspiration to attain the highest spiritual goal of the omniscience of enlightenment for the liberation of all sentient beings. Such non-discriminating transcendental wisdom is "equally divorced from the aspects of subject and object. ... Both aspects constitute discrimination, being 
the sophistic manifestation of the mind which clings to something as its object" (Hsuan Tsang, 659/1973, p. 687). While the dissolving of the subject-object dichotomy is crucial for the transformation of consciousness toward the ultimate spiritual truth, given that "our dualistic perspective of 'self' and 'other' didn't develop overnight, we can't expect to overcome it all at once” (Mingyur, 2007, pp. 176-177). As Sopa (2008) said, “our minds are like wild elephants drunk with self-centered egoism. If anything looks like it might harm us we try to destroy it" (p. 42). In the long run, such attempts that originate from the ignorance of the ultimate truth of emptiness create only more problems and suffering experiences rather than positive, happy and blissful ones. However, this elephant can be tamed gradually, and one day "we can reverse our habitual selfish inclinations and develop universal compassion free from partiality" (p. 12) by means of the incessant cultivation of bodhicitta.

As the principal motivation for attaining the highest enlightenment, bodhicitta arises from the superior thought, which is a special kind of love and compassion. As Sopa (2008) indicated: superior love is taking responsibility for the happiness of all others. Superior compassion is thinking "I will take responsibility for eliminating the suffering of other beings." This is far greater than kindly thinking, "How nice it would be if others were happy and free from misery." Once we decide to take the responsibility to free others from misery and lead them to bliss, we see that attaining enlightenment is the only way to do $\mathrm{it}^{25}$ (p. 43).

${ }^{25}$ According to Sopa (2008), the accumulation of wisdom is meditation on the deep realization of the truth with no dual perception. ... When one arises from meditation on emptiness, one keeps in mind 
At first glance, the aspiration of bodhicitta looks daunting and seems impossible, but if we begin from the cultivation of superior love devoting to bringing others positive things such as happiness and superior compassion focusing on freeing others from negative circumstances by means of applying the antidote to partiality, it will become more practicable. The significance of recognizing the equality of all sentient beings is in that, "if we do not take the antidote to partiality_being attached to some, hating others and ignoring the rest—our compassion and love will be discriminatory" (Sopa, 2008, p. 63), and "if we try to generate compassion before mastering equanimity [meaning impartiality] the result will not be the great universal compassion" (Sopa, 2008, p. 63). In other words, without recognizing the equality of all sentient beings and cultivating the mind in impartiality, we can never develop proper spiritual discernment that is conducive to the attainment of various spiritual goals. Nevertheless, the cultivation of impartial love and compassion does not mean that we do not take any counteractions to the oppressors. Rather, with the sympathy for their ignorance of the true nature of human existence and the concern about the grave consequences of their commitment of the

the understanding that the nature of things is illusory and empty of substantive existence, and engages in various activities to accumulate merit. Practiced together in this way, wisdom and method will result in buddhahood. (p. 203)

Usually, bodhisattvas engage in both practices over many lifetimes, sometimes for eons (Sopa, 2008, p. 203). Only when one attains buddhahood, one can practice the accumulation of wisdom and the accumulation of merit simultaneously (Sopa, 2008, p. 64) and achieve the perfection of four transcendental wisdoms. 
non-virtues, we learn to take ethical counteractions with proper union of method and wisdom out of compassion rather than anger or hatred.

One basic way to get rid of partiality is to consider "why sentient beings are equal from their side and why there is no reason for us to discriminate from our side" (Sopa, 2008, p. 64). From their side, all sentient beings, just like ourselves, "whether they are our friends or enemies, equally want to have happiness. None of them want any problems, disagreement, or suffering; on this basis there is no difference between them. If we think about it deeply we will realize that they are equal" (Sopa, 2008, pp. 64-65). From our side, within the broad framework of time, we have been born innumerable times high or low in the six realms ${ }^{26}$, and have had various relationships with each sentient being (Sopa, 2008, p. 65). Each of them has once been our best friend and our worst enemy, "so to which ones should we be attached? Which of them should we hate? There is no way to make this distinction objectively" (Sopa, 2008, p. 65). Another way of getting rid of partiality is to contemplate on the ultimate truth of emptiness and the dependent arising nature of all phenomena. Although there always exist phenomenal differences between sentient beings, ultimately speaking, all sentient beings, no matter who or what they are at a given time, are all temporal and impermanent manifestation based on various causes and conditions, and therefore, are equally empty of any absolute, essential, fixed, and independent nature, and are equally participating in the unconditioned in the present that signifies infinite transcending possibilities.

\footnotetext{
${ }^{26}$ Six realms refer to six directions of reincarnation or six states of existence, including hell, hungry ghost, animal, asura (malevolent nature spirits), human existence, deva (heavenly existence).
} 
After developing the superior thoughts of love and compassion towards all sentient beings without partiality, one can then train the mind to develop bodhicitta - the aspiration to attain the highest spiritual goal of the omniscience of enlightenment for the liberation all sentient beings. Bodhicitta can be understood from various perspectives. Usually, it is understood from two aspects: absolute bodhicitta and relative bodhicitta. "Absolute bodhicitta is a spontaneous recognition $^{27}$ that all sentient beings, regardless of how they act or appear, are already completely enlightened" (Mingyur, 2007, p. 177). When the state of absolute bodhicitta is achieved, "there is no distinction between sentient beings; every living creature is understood as a perfect manifestation of Buddha nature” (Mingyur, 2007, p. 190). However, as Mingyur (2007) indicated, since very few people are capable of attaining this state right away and most of us are still caught up in regarding other sentient beings from a dualistic perspective, we need to begin from developing relative bodhicitta, which involves two aspects - aspiration and application (pp. 188-189). According to Mingyur (2007), with impartial love and compassion as the basis, "aspiration bodhicitta involves cultivating the heartfelt desire to raise all sentient beings to the

${ }^{27}$ From Buddhist perspective, sentient being's spontaneous cognition of things differs according to their karma. One radical example is that, for a cup of liquid that appears to be cool clean water to a human, it appears to be pus and blood to a hungry ghost, and appears to be nectar to a god (Cabezón, 1992, p. 335). With the liquid substance as the material cause and the hungry ghost's evil karma as the dominant cause, the cup of liquid arises as pus and blood; similarly, with a god's own karma as dominant cause, the cup of liquid arises as nectar for the god (Cabezón, 1992, p. 336). 
level at which they recognize their Buddha nature" (p. 190), and thinking that "I wish to attain complete awakening in order to help all sentient beings attain the same state" (p. 190); application bodhicitta is actually taking actions to accomplish this aspiration (p.190). The practices of relative bodhicitta, such as the six perfections, cultivates within us an open mindset that allows the dualistic perspective of self and other to dissolve, and thereby, allows the wisdom and power to help others and ourselves to grow (Mingyur, 2007, p. 190). In spite of the fact that the cultivation of relative bodhicitta is still working within the framework of duality, it is grounded on the approach of negation that features the simultaneous perception of both the ultimate and phenomenal aspects of reality. It is the realization that every sentient being is already a perfect manifestation of the Buddha nature, the God, or the Divine that is intrinsic in everyone and that all sentient beings and phenomena are impermanent, dependently arising in accordance with the underlying law of the cause and effect of karma, and therefore, are empty of any absolute, independent and fixed nature. Such middle way perception provides us with a substantial philosophical ground for deliberating the significance of the axiom of equality for education.

In a talk on ignorant schoolmasters, Jacques Rancière (2010) indicated that "the most important quality of a schoolmaster is the virtue of ignorance" (p. 1). Yet, by ignorance, he meant being ignorant of the "explanatory logic that presents inequality axiomatically" (Rancière, 2010, p. 5). According to Rancière (2010), in this explanatory logic, "one must start from inequality in order to reduce it" (p. 4) and "the way to reduce inequality is to conform to it by making it an object of knowledge" (p. 4). In his reading of Joseph Jacotot, Rancière (2010) indicated that, with inequality as the presupposition, the goal of an equality-to-come that comprises simply the 
unequal equality, in turn, will only "drive a system that produces and reproduces inequality" (p. 5). Therefore, the explanatory logic of the axiom of inequality, for Rancière (2010), "is a social logic in which the social order is presented and reproduced" (p. 6), and such logic was named as stultification (p. 5).

Rather than being an ignorant person who is thrilled by playing teacher, an ignorant schoolmaster is a teacher "who shows us that the so-called 'transmission of knowledge' consists in fact of two intertwined relations that are important to dissociate: a relation of will to will and a relation of intelligence to intelligence" (Rancière, 2010, p. 2). However, he emphasized that it is not "the desire to undermine the relation of educational authority in order that one intelligence might enlighten another more effectively" (p. 2) that "is the principle of numerous antiauthoritarian pedagogies whose model is the maieutic ${ }^{28}$ of the Socratic pedagogue" (p. 2). Rather, he underscored that the ignorant schoolmaster "knows the double gambit of the maieutic.

${ }^{28}$ Maieutics, also known as Socratic method, method of elenchus, or elenctic method. It is a form of cooperative argumentative dialogue between individuals, based on asking and answering questions to stimulate critical thinking and to draw out ideas and underlying presumptions. It is a dialectical method, often involving a discussion in which the defense of one point of view is questioned; one participant may lead another to contradict themselves in some way, thus weakening the defender's point. This method is introduced by Socrates in Plato's Theaetetus as midwifery (maieutics) because it is employed to bring out definitions implicit in the interlocutors' beliefs, or to help them further their understanding. ("Socratic Method," n.d.) 
Under the disguise of creating a capacity, the maieutic aims, in fact, to demonstrate an incapacity" (p. 2), and "the 'liberalist' maieutic is just a sophisticated variation of ordinary pedagogical practice, which entrusts to the teacher's intelligence the ability to bridge the gap separating the ignorant person from knowledge" (p. 2).

In contrast, an ignorant schoolmaster exercises an authority_-a will that sets the ignorant person down a path, that is to say to instigate a capacity already possessed" (Rancière, 2010, pp. 2-3). For ignorant schoolmasters, equality is "an axiom to be verified. It relates the states of inequality in the teacher-student relation not to the promise of an equality-to-come that will never come, but to the reality of a basic equality" (Rancière, 2010, p. 5). Rancière (2010) argued that, "equality, in general, is not an end to be attained. It is a point of departure, a presupposition to be verified by sequences of specific acts” (p. 9). Significantly, equality and inequality, for Rancière, are not two states, but two opinions, meaning two distinct axioms by which education can operate (pp. 4-5). An ignorant schoolmaster who refuses the knowledge of inequality "addresses him or herself to the ignorant person not from the point of view of the person's ignorance but of the person's knowledge" (Rancière, 2010, p. 5). For Rancière (2010), "the obstacle stopping the abilities of the ignorant one is not his or her ignorance, but the consent to inequality" (p. 5), and what can suspend this submission to inequality is not teacher's knowledge, "but the teacher's will. The emancipatory teacher's call forbids the supposed ignorant one the satisfaction of what is known, the satisfaction of admitting that one is incapable of knowing more" (p. 6). The emancipatory teacher "forces the student to prove his or her capacity, to continue the intellectual journey the same way it began" (Rancière, 2010, p. 6). In other words, emancipatory teachers recognize the Buddha nature, or the dwelling God, or the transcendent intrinsic equally in 
everyone despite the phenomenal and temporal differences in their manifestations at a given time. With the heartfelt desire to raise all their students to the level at which they recognize their Buddha nature or God within, emancipatory teachers embody their spiritual wisdom and their impartial love and compassion in their will and authority that open new possibilities, instigate the transcending of the current forms of existence, and give assurances that life will be enhanced and can be whole again in the face of the lure of the transcendent that might look threatening. With an open mindset that knows the ultimate equality of all sentient beings and allows the dualistic and discriminating perspectives to dissolve, emancipatory teachers also make possible genuine conversation and truthful knowing. As Rancière (2010) described, an emancipatory teacher "is first of all a person who speaks to another, who tell stories and returns the authority of knowledge to the poetic condition of all spoken interaction" (p. 6). For Rancière, the logic that operates under the presupposition of equality deserves the name of intellectual emancipation (Rancière, 2010, p. 6).

The distinction between stultification and intellectual emancipation, i.e. the logics that presume inequality and equality respectively, however, is not a distinction between methods of instruction but one of philosophy (Rancière, 2010, p. 6). From the perspective of the two truths doctrine, the major philosophical distinction between the two logics is that the logic that presumes inequality refers to the mere phenomenal aspect of self and reality, while the logic that presumes equality as a point of departure follows the middle way approach and grasps simultaneously both the ultimate and phenomenal aspects of self and reality. For Rancière (2010), this distinction "concerns an idea of intelligence that guides the very conception of intellectual training" (p. 6). Rather than affirming any specific virtue for those who do not know, Rancière (2010) maintained 
that the axiom of equality of intelligences "simply affirms that there is only one sort of intelligence at work in all intellectual training" (p. 6) and "it concerns the very conception of the relation between equality and inequality" (p. 6) that is in question. What is questioned is the logic of the equalization of inequality of a society that puts "into harmony its productive forces, its institutions, and its beliefs, making them act according to a singular regime of rationality" (Rancière, 2010, p. 7). The problem comes in that such explanatory logic of rationality, akin to our earlier discussion on the limitation of rational analysis, is characterized by infinite regress"an explanation is usually accompanied by an explanation of that explanation" (Rancière, 2010, p. 3). According to Rancière, Jacotot summed up that "if explanation [of inequality] is in principle infinite, it is because its primary function is to infinitize the very distance it proposes to reduce" (p. 3). People's education, thus, becomes "an 'explanation' of society; it is a working allegory of the way that inequality is reproduced by 'making visible' equality" (Rancière, 2010, p. 8). Furthermore, by means of embracing such knowledge of inequality—-knowledge about why those who are left behind are left behind" (Rancière, 2010, p. 13) -accumulated from the explanatory logic of rationality, both educators and students risk falling prey to a hidden social bond that features the over-reliance on rational analysis and scientific knowledge based on the subject-object dichotomy that, as discussed earlier, usually hinder us from confronting reality directly and from seeing reality as it is, and can hardly enable genuine conversation and true comprehension of a specific existential situation in their totality at a present that in actuality connotes infinite transcendental possibilities. 
On the contrary, emancipatory teachers refuse to blindly take up the knowledge of inequality and the explanatory logic of societal norms that presumes inequality as a point of departure. As Huebner (1985c/1999) maintained, all knowing requires openness, this means

present forms of knowledge, which relate the person to the vast otherness in the world and which hold together past, present, and future, must be acknowledged as limited, fallible, insufficient. To have new forms emerge, old forms must give way to relationship: love takes priority over knowledge. (p. 350)

However, without taking the antidote to partiality, our love will be discriminatory. One of the subtlest forms of partiality reveals in taking the axiom of inequality for granted and accepting the knowledge and explanatory logic of inequality without hesitation. What distinguishes emancipatory teachers from the others, therefore, is that by means of recognizing the ultimate equality of all sentient beings, they prioritize impartial love rather than the explanatory knowledge of inequality. From Buddhist perspectives, emancipatory teachers are emancipatory because they respect both the ultimate and phenomenal aspects of self and reality, open to new possibilities, and take actions based on truthful knowing from a non-objectifying perspective and on proper spiritual discernment informed by the ultimate truth rather than on the mere explanatory knowledge of societal norms. Being imbued with spiritual wisdom that knows emptiness and the ultimate equality of all sentient beings, emancipatory teachers' methods and intelligence become emancipatory. With the union of wisdom and method, not only their own lives demonstrate living in accordance with the true nature of human existence, their impartial love and will to instigate the capacity already possessed by their students also become a call for their students to recognize their full potential and live with authenticity. 
In the above, I explore how the universal equality wisdom as well as the absolute and relative bodhicitta might provide us with deepened insights for contemplating the impact of the subtle philosophical differences between the axiom of equality and inequality held by teachers. This exploration not only demonstrates the significance of impartiality and bodhicitta for education but also suggests the crucial role teacher plays in facilitating the transformation of consciousness. Truly, as Huebner's (1993/1999) observed, “it is futile to hope that teachers can be aware of the spiritual in education unless they maintain some form of spiritual discipline" (p. 415). In the following, I probe into another aspect of the educational significance of bodhicitta as the motivation of teaching, learning and knowing in contrast with market logic.

As the essence of the Mahayana spiritual path, bodhicitta is the most powerful virtue since it dispels our great enemy—-selfishness (Sopa, 2008, pp. 25-29) and guides us directly to the highest spiritual goal of the omniscience of enlightenment for the liberation of all sentient beings. As the core motivation of the method-side practices, such as the six perfections, bodhicitta not only prevents the practitioners from falling into the habitual tendency of objectifying, but also transforms the ordinary everyday routine into meaningful practices and transcendental opportunities. As Sopa (2008) said, like an alchemical elixir that turns iron into gold, bodhicitta "transforms every activity so that it is for the benefit of other sentient beings. With bodhicitta, everything we do- - even eating or sleeping-becomes a virtue" (p. 32) because we need to take care of this body so that we can attain enlightenment for the benefit of other sentient beings (p. 32). Therefore, "when bodhisattvas eat or sleep their motivation is to keep up their strength so they can attain their goal of helping other sentient beings" (Sopa, 2008, p. 32). 
In educational context, bodhicitta, akin to what Einstein (1930/1954) called "the cosmic religious feeling" (p. 39), when accompanied with spiritual wisdom that knows emptiness, can be the strongest and noblest motive for engaging in various modes of teaching, learning and knowing, and can transform every activity into the cause of blissful experiences and spiritual progresses for oneself and all the others. In contrast to the formulaic logic of the market and the language of global competitiveness that instigate the social and educational planning with the sheer desire to win, the motivation of bodhicitta places knowledge back into the eternal cycle of openness, love and hope, and returns dignity, value, meaning and purpose back to human beings. Revisiting Huebner's (1985c/1999) words explored in chapter two, "every mode of knowing is also a mode of being in relationship. It is a relationship of mutual care and love" (p. 349), yet, the distortion of this relationship of mutual care and love occurs when "caring is for the self and knowing becomes an act of control, often an act of violence" (Huebner, 1985c/1999, p. 349). The sheer desire to win, as a prevailing form of the distortion of the relationship of mutual care and love entrenched in the sharp subject-object dichotomy, has led to the "hypercompetitiveness in the social realm" (Smith, 2000, p. 18) with the "heightened social paranoia and the turning of friends into enemies" (p. 18) that can hardly bring about true conversation and truthful knowing. Being ignorant of the true nature of human existence and being blinded by the rhetoric of global competitiveness for securing one's own happiness, we fall prey to the deviation of conceptual proliferation and reification, and begin to pursue something ideally hypostatized by the ego as "happiness". Yet, as shown in earlier exploration of the approach of negation, the positive, such as happiness, can never be attained through the pursuit of ideally hypostatized objects, e.g. people, fame or wealth, etc., under a dualistic mode and through a sheer desire to win, but only manifests itself through the negation of the afflictions originating from the dualistic subject- 
object perception, and through living in accordance with our true nature as an authentic being-inthe-world. As Adam Smith said,

if we placed our happiness in winning the stake, we place it in what depended upon causes beyond our power and out of our direction. We necessarily exposed ourselves to perpetual fear and uneasiness, and frequently to grievous and mortifying disappointments. If we placed it in playing well, in playing fairly, in playing wisely and skillfully, in the propriety of our own conduct, in short, we placed it in what, by proper discipline, education, and attention, might altogether be in our own power, and under our own direction. Our happiness was perfectly secure and beyond the reach of fortune. (Smith, 1759/2000, as cited by Ahmed, 2010, p. 208)

Smith's words make clear that the formulaic logic of the market and the language of global competitiveness that instigate the social and educational planning with the sheer desire to win only expose human beings to perpetual fear and uneasiness rather than happiness. While Smith's argument was addressing on only personal happiness, it is clear that, if we place our happiness in playing well, in playing fairly, in playing wisely and skillfully, in the propriety of our own conduct out of the motivation of bodhicitta and imbue it with wisdom that knows emptiness, we secure not only our own happiness and ultimate liberation but also those of all sentient beings.

In today's educational landscape, while objectivism is not upheld anymore, as explored earlier, Palmer (1983/2003a) reminded us that it is institutionalized in our educational practices, in our ways of teaching and learning (p. 65), and obviously, also in our motivation of teaching and learning. Huebner (1993/1999) also pointed out that, our problem is that "the schools are not places where the moral and spiritual life is lived with any kind of intentionality" (p. 415). The 
motivation instigated by the sheer desire to win, seems for me, partly explains "how the spiritual and moral is being denied in everything" (Huebner, 1993/1999, 414) and how objectivism is institutionalized. Smith (2000) cautioned us that, as the central logic of contemporary globalization, market logic "is not adequate for ensuring a future that is truly open and capable of sustaining human fellowship in any decent sense. It is a logic that requires a profound deconstruction" (p. 25). In the face of various global crises, I am convinced that with its alchemical-elixir-like transformative power, the altruistic motivation of bodhicitta provides us an alternative logic for educational planning, teaching, learning and studying, and for sustaining human life in a noble and dignified sense.

In this subsection, for the purpose of cultivating a righteous mindset and motivation for entering the path of spiritual discernment that is conducive to decisive distinction and to learning to take the responsibility for one's decision and to respond appropriately to the world, I explore the educational significance of the cultivating of impartiality and bodhicitta that is able to guide and support us through the path. On the basis of the understanding of the true nature of consciousness, self and reality, the appreciation of human temporality, and the impartial and altruistic motivation of bodhicitta, in the next subsection, I explore how we might cultivate the spiritual discernment that is conducive to decisive distinction and become responsibly responsive.

\subsubsection{Becoming Responsibly Responsive}

In this subsection, I explore the concept of being responsibly responsive and its relationship with the dilemma of change or non-change and then examine how we might become responsibly responsive from three different perspectives. Firstly, drawing on the practices of four reflections 
and four exact realizations, I examine the role of language in dominating our worldview and how the habitual force of hypostatization and reification might cause us to forget the symbolic function of language and to mistake what is just a useful way of speech for reality as it really is, and hinder us from seeing things as they really are which is the moral basis for becoming responsibly responsive. Secondly, I explore the educational significance of the injunctions of the four noble truths for overcoming the stultifying effects of passivity brought about by pain and for waking us up to our responsibility as temporal being-in-the-world. Thirdly, drawing on Lusthaus's (2002) analysis of the quandary of human change and changelessness and its relationship with the appropriational circuit between grasper and grasped, I show that becoming responsibly responsive is first of all an inner work by means of exploring how the sharp selfworld dichotomy may nurture our attachment to the outward pursuit of hypostatized happiness, and as a result, blind us to infinite possibilities and hinder us from becoming truly responsibly responsive.

In chapter three, through the dialogue between Buddhism and quantum physics, we came to the realization that the concern of our being as humans is in essence the concern of human consciousness, and the essence and purpose of education as the four-stage transitions of the essence of truth revealed in Heidegger's explication of Plato's allegory of the cave is in essence the transformation of consciousness from the grasping of the deceptive phenomenal everyday experiences toward the direct non-dualistic realization of the ultimate truth of emptiness, the ultimate personal liberation, and the highest spiritual goal of the liberation of all sentient beings from the suffering-laden shadowy phenomenal world. The real happening of education, thus, always entails the examining, overcoming, transforming, reforming, shifting and transcending of 
the presently assumed "truth" grasped by an individual. This means education is all about change. Yet, it is not change in an arbitrary way. In Huebner's (1966/1999) words, “it isn't simply change that is wanted, it's something else" (p. 118).

In his concern for human temporality, Huebner (1967/1999) underscored that "man is a transcendent being, i.e. he has the capacity to transcend what he is to become something he is not. In religious languages this is his nature, for he is a creator" (pp. 134-135). He indicated that since the transcending ability is intrinsic in human nature, as educators, the appropriate question we should ask is not how to explain change, but how to explain non-change (Huebner, $1967 / 1999$, p. 134), or "what gets in the way of the great journey - the journey of the self or soul" (Huebner, 1993/1999, p. 405). Huebner (1966/1999) also observed that, for the majority of educators, maybe both ideas of change and non-change are not desired; the educators are interested in something in between - a balance (p. 119). As Lusthaus (2002) indicated, "radical change disrupts what we are used to, while routine deadens our senses" (p.3), "either extreme harbors dangers" (p.3). Huebner (1966/1999) also expressed his concerns for the terms "change" and "innovation" (p. 118). While he emphasized that "by all means schools should have innovations and a climate should be fostered in which innovations can come to the surface; for these are the sources of renewal" (p. 118), he was discomforted by the notion of novelty and the meaning of innovation that is somewhat distinct from evolution and from history (pp. 118-119). He indicated that

evolution takes place not by simply introducing something new, but also through respect for the historicity of a given situation [or individual]. . . . Newness can be introduced, or an old situation brought up to date, but the new in a short time can become the old. It is 
the continuous process of keeping something alive and viable that should concern educators. (Huebner, 1966/1999, p. 119)

Huebner (1966/1999), thus, proposed that perhaps "a more adequate term to describe that which is needed in schools today is neither 'change' nor 'innovation', but 'responsiveness"' (p. 119), meaning a person's ability to respond. One important form of a person's response is "his understanding of himself in the moment of vision, as he projects his own possibility for being in terms of 'having been"' (p. 138). However, given that responsiveness can be anything at either sides of or in between the change-permanence continuum, Huebner stressed that what is desirable is being responsibly responsive (p. 119).

Huebner's (1966/1999) use of the word "responsibly" is "in the sense of being aware of one's obligations as an historical and temporal being for the continual creation of the world and in the sense of being accountable for one's acts" (p. 120). Huebner (1966/1999) elucidated that, since each decision we make is in a particular time and place,

those who share that time and place rightfully hold him responsible for the consequences of his decisions. However, his decision is a factor in the continual emergence or evolution of that situation as it exists through time, thus his accountability extends into the past and into the future. To be responsibly responsive, then, is to be aware of the history and destiny of the given situation and to be answerable for the consequences of any responses made. (p. 120)

Huebner made clear that each of us is responsible for not only one's own destiny but also our shared future on earth. On the basis of the renewed realization of the nature of human existence attained in the dialogue between Buddhism and quantum physics, we see that to be truly aware of 
the history and destiny of a given situation and to be answerable for the consequences of any responses made requires us to cultivate a proper spiritual discernment grounded on a righteous mindset and an altruistic motivation of bodhicitta along with the recognition of human nature as a dependent arising being-in-the-world that signifies infinite transcending possibilities in the present as well as the willingness to allow the self-world dichotomy to dissolve and to see things as they truly are. Becoming responsibly responsive, therefore, is the cultivating of spiritual discernment in making decisions grounded on the understanding of the nature of consciousness, self and reality, the appreciation of human temporality, and the impartial and altruistic motivation of bodhicitta.

Compared to the five-stage gradual path of consciousness transformation, learning to become responsibly responsive is parallel to the second stage - the stage of intensified efforts or the path of application. In this stage, as discussed earlier, with the aim to entering the path of spiritual discernment, the practitioner learns to suppress and eradicate the conception of subject-object or self-world dichotomy by means of making preparatory efforts conducing to decisive distinction (Hsuan Tsang, 659/1973, p. 679). These preparatory efforts are based on four reflections on the names, essences, self-nature and differences of things and ideas, as well as the four exact realizations that these four concepts do not exist apart from our consciousness and that the process of consciousness that knows them does not have absolute and independent existence neither (Hsuan Tsang, 659/1973, pp. 679, 681). In this stage, the practices also include meditating on the four noble truths (Choi, 2011, p. 92). 
The practices of the four reflections and the four exact realizations for cultivating the nondualistic worldview call our attention to the role of language in dominating our worldview and various aspects of life. In Bohm's (1980) inquiry about the role of language structure in bringing about fragmentation in thought, he noted that "though language is only one of the important factors involved in this tendency, it is clearly of key importance in thought, in communication and in the organization of human society in general" (p. 35). Similar to the contemplation of the four reflections and the four exact realizations regarding the names, essences, self-nature and differences of things and ideas, in this inquiry, Bohm (1980) examined the pervasive structure of sentence, subject-verb-object, which tends "to divide things into separate entities, such entities being conceived of as essentially fixed and static in their nature" (p. 37). Being conditioned by the force of habit, we usually fall unwittingly into the fragmentary mode, focus exclusively on the content under discussion and neglect the symbolic function of language, and mistake the fragment implied in language as "actual breaks in "what is"” (Bohm, 1980, p. 40). Yet, as revealed in the dialogue between Buddhism and quantum physics, this is far from the way everything really is. As explored earlier, from Bohm's (1980) perspective, the relationship between the content of thought and the process of thinking which produces this content is similar to the relationship between a turbulent mass of vortices and the flowing stream "which creates, maintains, and ultimately dissolves the totality of vortex structures" (p. 24). Thus, akin to the vortices in a flowing stream, the "apparently static and separately existent things [along with their names, essences, self-nature and differences in our consciousness] are seen as [only] relatively invariant states of continuing movement" (Bohm, 1980, p. 38) and in actuality do not exist apart from our consciousness, and the process of consciousness that knows them does not have absolute and independent existence neither. 
Suggesting that we should allow the verb rather than the noun to play a primary role in language, Bohm (1980) intended to end the aforementioned fragmentation because "the verb describes actions and movements, which flow into each other and merge, without sharp separations or break" (p. 37). Bohm concerned that, when people are guided by a fragmentary subject-object worldview, in the long run, they risk trying in their actions only "to break themselves and the world into pieces" (p. 20). Such attempt is "to extend the analysis of the world into separate parts beyond the domain in which to do this is appropriate, it is in effect an attempt to divide what is really indivisible" (Bohm, 1980, p. 20). The logic of such an attempt, when used in reverse direction, will then lead us also to try to unite what is not in actuality unitable, e.g. forming a group of people, may it be political, economic, or religious, etc., in society (Bohm, 1980, p. 20). Bohm (1980) explicated that, rather than uniting people, the very act of forming a group "tends to create a sense of separation of the members from the rest of the world" (p. 20). This is because that unity or oneness has already been the true nature of consciousness, self and reality, and the positive pursuit of unity as a reaction to fragmentation is but the same thing with fragmentation in different form that can never bring about true unity. Echoing with the approach of negation, Bohm (1980) underscored that "true unity in the individual and between man and nature, as well as between man and man, can arise only in a form of action that does not attempt to fragment the whole of reality" (p. 20). The problem of fragmentation, therefore, is in that, it "is in essence a confusion around the question of difference and sameness (or one-ness)" (Bohm, 1980, p. 21). Bohm (1980) concerned that since "the clear perception of these categories is necessary in every phase of life" (p. 21), "to be confused about what is different and what is not, is to be confused about everything" (p. 21). When the mind is caught up in such confusion, it 
will be futile "to try to impose some fixed kind of integrating or unifying 'holistic' principle on our self-world view" (Bohm, 1980, p. 21). From this perspective, the positive and active advocating of holistic education could be futile if people remain caught by such confusion about difference and oneness that usually debated at cross purposes depending on which aspect of reality - the phenomenal or the ultimate aspect of reality —is referred to. This fact points to the educational significance of the middle way doctrine that emphasizes the simultaneous grasping of the ultimate and phenomenal aspects of self and reality and features the approach of negation for clearing away the confusion around the question of difference and oneness that is crucial for cultivating a proper spiritual discernment and becoming responsibly responsive.

For Bohm (1980), "any form of fixed self-world view implies that we are no longer treating our theories as insights or ways of looking, but, rather, as 'absolutely true knowledge of things as they really are"' (p. 21). Such misperception is well illustrated by the noted Zen metaphor: to take the finger pointing at the moon for the moon. However, the fact is that "our theories are not 'descriptions of reality as it is' but, rather, ever-changing forms of insight, which can point to or indicate a reality that is implicit and not describable or specifiable in its totality" (Bohm, 1980, pp. 21-22). As mentioned earlier, the cultivation of the non-dualistic worldview and spiritual discernment is not at all a matter of holding views or opinions, but of seeing things as they really are. Bohm's insights remind us of our earlier discussion on our habitual way of thinking and speaking that are prone to hypostatization - "the process of reification or 'thing-ifying': taking what is actually just a useful form of speech to refer to some real entity" (Siderits \& Katsura, 2013, p. 15). Huebner (1963/1999) has been concerned about the blind acceptance and reification of language in educational context and indicated that, "if the user reifies the concepts, 
then language obscures the world rather than opens it" (p. 79). Kumar (2013) also indicated that, 'thought reduces existential things into words through 'verbalization' and 'naming' and thus stops their comprehension" (p. 78). For Kumar (2013), while "language and words are necessary to communicate things to others, ... when verbalization happens mechanically, it acts as a barrier between awareness and feelings" (p. 78). For the purpose of preventing mechanical verbalization or naming, Krishnamurti suggests "pure observation that involves neither translating the state of being into words nor judging it with pre-determined ideals, but rather observing it with full attention" (Kumar, 2013, p. 79). Kumar (2013) underscored that although "intellect and language are very important, there is a level of our existence, which can only be experienced and understood in the state of "pure observation"' (Kumar, 2013, p. 79). In such pure observation, the symbolic curtain that divide the observer and the observed gives way, "the description is not the described. The word is not the thing" (Krishnamurti, 1999a, as cited in Kumar, 2013, pp. 79-80). Things, thus, are allowed to open themselves up and to be perceived as they really are. Only when things are perceived as they really are, we see "the specifics of human lives" (Phelan, 2001, p. 52) rather than the mere "general forms" (Phelan, 2001, p. 52) as presented in objective knowledge, and this is the moral basis that enables us to respond to the lived existential situations appropriately and responsibly.

The above exploration demonstrates how the four reflections on the names, essences, self-nature and differences of things and ideas and the four exact realizations of their true nature might prevent us from falling unwittingly to the habitual force of hypostatization, verbalization, or naming that only fortifies the absolutistic and dualistic subject-object worldview, and from being confused by words and language and mistaking what is only a useful form of speech or a way of 
looking for descriptions of reality as it truly is. Such contemplation is conducive to not only the suppression and eradication of our taken-for-granted dualistic subject-object worldview, but also the cultivation of spiritual discernment that is indispensible for becoming responsibly responsive.

In addition to the four reflections and the four exact realizations, meditation on the four noble truths is also vital practice in the stage of intensified efforts for entering the path of spiritual discernment. As mentioned in chapter three, the four noble truths consist of the truth of suffering, the truth of the cause of suffering, the truth of cessation and the truth of the path (Sopa, 2005). Rather than being intended as mere creeds or beliefs, they are taught as "active and performatively differentiated injunctions" (Sedgwick, 2003, p. 170). As bodhisattva Maitreya metaphorically summed up in the following stanza:

The illness should be recognized, its cause removed,

Health should be attained, the remedy should be applied.

Like that, suffering, its cause, its cessation, and the path

Should be recognized, eliminated, attained, and practiced. (Sopa, 2005, p. 196)

As discussed in chapter three, by placing the truth of suffering as the first of the four noble truths, Buddha pointed to the significance of recognizing the suffering nature of samsara. The point is that even though we realize that we are in prison of cyclic forms of existence or experience, if we do not perceive it as a problem, we won't have any incentive to get out of it, instead, we are used to it and attached to it (Sopa, 2005, p. 192). However, the mere recognition of the suffering is not enough. Sopa (2005) cautioned that, "if you do not properly understand the causes of bondage in cyclic existence, you will miss the essential points of the path. You will head off the wrong direction, mistaking for the path to liberation activities that only lead to more suffering" 
(p. 197). In Buddha's teaching, the samsaric suffering is caused by various forms of contaminated or unvirtuous karma produced by inner afflictions rooted in ignorance, meaning being ignorant of the emptiness of self and reality, and distorts the basically open experience of awareness into dualistic distinctions between self and other (Mingyur, 2007, p. 117; Sopa, 2005, pp. 195, 296, 326). For the cessation of suffering, the truth of the path that is embodied in the three trainings and the six perfections provides us with a path that unites both the method-side and wisdom-side practices in everyday life to actually eliminate the causes of suffering and attain the liberation from the cyclic forms of experience and existence.

The educational significance of the injunctions of the four noble truths can be found in Ahmed's (2010) research. In an exploration on happiness, Ahmed (2010) quoted feminist Rosi Braidotti that, "taking suffering into account is the starting point; the real aim of the process, however, is the quest for ways of overcoming the stultifying effects of passivity, brought about by pain" (Braidotti, 2006, as cited in Ahmed, 2010, p. 215). Ahmed (2010) refused the idea that our access to the cause of pain is random. Taking Audre Lorde's story for instance, Ahmed (2010) stated that Lorde's mother "says to her that the woman who spits is spitting into the wind not spitting to her, a black child, as a way of protecting the child from the pain of racism” (p. 215), Ahmed commented that "it is a desire for protection that is understandable — but it fails to protect" (p. 215). She wrote, as Lorde showed us, "the very idea that violence is random is what stop us from seeing what is at stake in an encounter" (Ahmed, 2010, p. 215), and "we should not be protected from what hurts. We have to work and struggle not so much to feel hurt but to notice what causes hurt, which means unlearning what we have learned not to noticed" (Ahmed, 2010, pp. 215-216). However, as Maxine Greene noted, "relatively few people are ... courageous 
enough actually to 'see"' (as cited in Boler, 1999, p. 176), and unlearning what we have learned not to notice is not always easy as "to recover can be to re-cover, to cover over the cause of pain and suffering" (Ahmed, 2010, p. 216). Ahmed (2010), thus, argued that, the desire to move beyond suffering in reconciliation, the very will to 'be over it' by asking others to 'get over it,' means that those who persist in their unhappiness become causes of the unhappiness of many. Their suffering becomes transformed into our collective disappointment that we cannot simply put such histories behind us. (p. 216) Paradoxically, it is also "those who have already cracked a bit, those who have suffered pain and injury, who are better placed to take the lead in the process of ethical transformation" (Braidotti, 2006, as cited in Ahmed, 2010, p. 216). Since each of us suffers one way or another, Ahmed's argument wakes us up to our responsibilities as temporal and historical beings-in-the-world and makes clear why to be responsibly responsive "is to be aware of the history and destiny of the given situation and to be answerable for the consequences of any responses made" (Huebner, 1966/1999, p. 120). By means of taking our own suffering as a starting point and unlearning what we have learned not to notice - meaning to be courageous enough to actually see things as they really are - we learn to cultivate proper spiritual discernment and become aware of the history and destiny of a given situation that are conducing to the recognition of the root causes of sufferings and to the decision-making and action-taking that will truly lead to the cessation of suffering. This is how observing the injunctions of the four noble truths could help us become responsibly responsive and become answerable for the consequences of any responses made. 
In the above discussion, the quandary of "to recover or to re-cover" also brings us back to the dilemma of change or non-change. Exploring human change and changelessness from the perspective of identity, Lusthaus (2002) indicated that,

we project our theories onto our experience in the form of atman and dharmas [subjective self and objective world] in order to maintain an appropriational circuit. We appropriate because we desire, and desire stems from a sense of lack... According to Buddhism what we fundamentally lack is a "self," and our frantic search and grasping for "things" is at once a sign of our sense of this lack — a way of asking, suppressing or diverting the painful awareness of that lack—and a desperate attempt to fill the void with an acquirable “identity," a self which one owns—one's own self. ... One clings to those identities as an expression of a deep-seated desire for permanence, stability, as a shielding from death. These identities ... are the theories each of us lives by, the grounding orientations through and by which we experience the world as we do. (p. 2)

However, any kind of theories about our selves, as revealed in earlier discussion, rather than being descriptions of who or what we really are, are but ever-changing forms of insight that point to merely certain aspects of our whole existence which is not describable or specifiable in its totality. These theories or identities about our selves, as shown in chapter three, have arisen from causes and conditions and are in actuality empty of any absolute, essential, and independent nature, thus, "no matter how seamlessly we seem to project our desires and anxieties, eventually our experience itself challenges us. Everything is impermanent, and whatever is living must inevitably succumb to sickness, old age and/or death" (Lusthaus, 2002, p. 2). As a result, we are caught in the incoherence of two mutually exclusive drives: "we want to change, become otherwise, improve ourselves, and, on the other hand, we want to maintain our-selves as 
unalterable, immutable, immortal. We want difference and identity to coincide" (Lusthaus, 2002, p. 3). Lusthaus (2002) further analyzed that the quandary between the two extremes of change and changelessness, however, do not reflect objective circumstances, but rather reveal our interpretive enterprise: To fail to cognize changes with acceptance due to our expectations and frustrations on the one hand, and to fail to see the uniqueness of each and every moment on the other. Caught between these extremes of our own devising (parikalpita), we suppress our dissatisfactions, only to reproject them into one set of circumstances after another (samsara). For Yogacara, the appropriational circuit running between grasper and grasped signifies that we are locked inside the narcissism of our own habits (karma). Rather than seeing, hearing, smelling, tasting, touching, and thinking our relation to the world in the manner it becomes [as it really is] (yathabhutam, tathata), we perpetually grasp at our own reflections, mistaking the images (pratibimba) in our self-constructed mirror for what is other than ourself. Ironically, in order that our projected images and ideas become graspable and appropriatable, we have to dispossess them, i.e., disown and disavow them as our own projections. If we recognized them as already ours, pursuing them further would be redundant. Only by pretending that they are not ours, can we appropriate them. (pp. 3-4)

Lusthaus's analysis of this quandary provides new insights into the questions regarding how to explain non-change, or "what gets in the way of the great journey - the journey of the self or soul" (Huebner, 1993/1999, p. 405), and reveals how the quandary of change or non-change that hinders us from transcending our current form of existence and from becoming responsibly responsive is basically an interpretative enterprise deep seated in the dualistic subject-object 
worldview that attaches to the self as an absolute fixed existence that is independent of the world.

While on the biological level the distinction between self and others is essential for the survival of our physical bodies, when it is generalized into areas that have nothing to do with basic survival, problems begin (Mingyur, 2007, p. 119). As discussed in chapter three, by means of locking ourselves into the dualistic mode of perception, we become unable "to recognize the infinite potential, clarity, and power of our own mind" (Mingyur, 2007, p. 117), and "begin looking [outwardly] at other people, material objects, and so on, as potential sources of happiness and unhappiness" (Mingyur, 2007, p. 117). Relying exclusively on external sources to give us happiness, gradually, "we lose the ability to distinguish between the bare experience of happiness and whatever objects temporarily make us happy” (Mingyur, 2007, p. 119). As a result of this confusion, life becomes an endless struggle to pursue and defend happiness. However, as revealed in the dialogue between Buddhism and quantum physics, in contrast to our everyday experiences of the deceiving phenomenal world, "the truth is that all the causes of our problems are inside ourselves, in the qualities of our own minds" (Sopa, 2005, p. 2). By means of pretending, either consciously or unconsciously, that the external reality has nothing to do with us, like the shackled prisoners in Plato's allegory of the cave, we see no relationship between our self and the world and what create the shadows, mistake the mere shadows on the wall as the sources of our happiness and unhappiness, and as a result, mistake activities that only lead to more sufferings for the means to happiness.

Such mistaken view and the overly generalized distinction between the self and the others, in Buddhism, is known as attachment or desire (Mingyur, 2007, p. 119) with "craving" as the 
general form of attachment and "grasping" as a more intense form (Sopa, 2005, pp. 332-333). According to Mingyur (2007), akin to addiction, attachment is "a compulsive dependency on external objects or experiences to manufacture an illusion of wholeness" (p. 119), and it becomes more intense over time (p. 119). Like "drinking salt water from an ocean. The more we drink, the thirstier we get" (Mingyur, 2007, p. 119). As shown in Adam Smith's analysis explored earlier, by placing our happiness in winning the stake, we expose ourselves to perpetual fear and uneasiness. Mingyur (2007) also indicated that "every strong attachment generates an equally powerful fear that we'll either fail to get what we want or lose whatever we've already gained" (Mingyur, 2007, p. 121). In other words, our attachment and selfish desire- the blind outward pursuing, grasping and defending of hypostatized happiness rooted in the ignorance of the ultimate truth of emptiness - rather than bringing about happy and blissful experiences and leading to ultimate liberation, only perpetuates our fear and uneasiness, imprisons us in the cyclic forms of suffering experiences, and blinds us to infinite possibilities. Yet, as Ahmed (2010) said, if we do not assume that happiness is what we must defend, if we start questioning the happiness we are defending, then we can ask other questions about life, about what we want about life, or what we want life to become. Possibilities have to be recognized as possibilities to become possible. (p. 218)

The recognition of possibilities as possibilities is vital for becoming responsibly responsive particularly in the moment of vision. Ahmed made clear to recognize possibilities other than defending our own happiness as possibilities requires us to overcome our craving and grasping rooted in the ignorance of the true nature of human existence, to stop the outward pursuit and defense of reified objects of happiness, and to recognize the infinite potential, clarity and transformative power intrinsic in our consciousness. Otherwise, even though we are willing to 
take our own suffering as a departing point and willing to take both the personal and historical responsibilities for the continual creation of the world and to be answerable for the consequences of any responses made, if we mistake the causes of suffering and sources of happiness as simply external, we are bond to lose the spiritual discernment and head off the wrong direction, and as a result can hardly become truly responsibly responsive. Becoming responsibly responsive, thus, is first of all, an inner work of overcoming the habitual force of craving and grasping and the sharp subject-object dichotomy based on a proper understanding of the true nature of consciousness, self and reality in the self-world dialectic.

In the above discussion, we see how becoming responsibly responsive is closely related to the cultivating of selflessness. In the following, I proceed to investigate deeper into the concepts of self and selflessness and explore the conception, approach, and educational significance of cultivating selflessness.

\subsubsection{Cultivating Selflessness}

In earlier exploration of the concepts and process of consciousness transformation in Buddhism, the afflictive barriers and noetic barriers are identified as the main barriers to be overcome in the process of consciousness transformation. Since the afflictive barriers and noetic barriers refer to barriers originating respectively from the attachment to a subjective self and an objective universe as absolute, essential and independent existence, cultivating selflessness and learning to embody a non-dualistic worldview are crucial for the transformation of consciousness. While cultivating selflessness and learning to embody a non-dualistic worldview are not different in essence and are mutual inclusive and supportive, and both require the union of wisdom-side 
practices based on wisdom that knows emptiness (the accumulation of wisdom) and method side-practices based on compassion, love and bodhicitta (the accumulation of merits) that are embodied in the six perfections (generosity, ethical discipline, patience, joyous perseverance, meditative stabilization, and wisdom), with emphasis on the view component, in this subsection, I draw on the wisdom-side practices, including the perfections of wisdom and meditative stabilization, and investigate into the concepts of self and selflessness and explore how we might cultivate selflessness in educational context.

Following the two truths and the middle way doctrine taught by Buddha, in chapter three, I explore the preliminary concepts of the empty and dependent arising nature of self and reality. Rather than denying the existence of the self, what the emptiness of self denies is an absolute, essential, and independent substantial self. Drawing on the middle way doctrine explicated by Nargajuna, Thompson (2015) introduced an enactive understanding of the self (p. 324). Echoing with Huebner's (1967/1999) elucidation of human temporality that emphasized the dynamic and emerging nature of human existence, Thompson (2015) considered the everyday self as a subject of experience and an agent of action and maintained that the self is a dependently arisen series of events; in other words, the self is an enacted process (p. 323). For Thompson (2015), "the self isn't a thing or an entity at all; it is brought forth or enacted in the process of living" (p. 324). This means that "the self is a process of 'I-ing', a process that enacts an 'I' and in which the 'I' is no different from the I-ing process itself, rather like the way dancing is a process that enacts a dance” (Thompson, 2015, p. 325). He quoted Stephen Batchelor that, "you are unique not because you possess an essential metaphysical quality that differs from the essential metaphysical qualities of everyone else, but because you have emerged from a unique and 
unrepeatable set of conditions" (as cited in Thompson, 2015, p. 323). In the same vein, Newland (2009) indicated that "our uniqueness arises from our distinctive, ever-shifting, and infinite array of connections with other things. We are unique . . but we do not own our uniqueness. We have no intrinsic core. We owe our uniqueness to all of our conditions" (p. 96).

Nonetheless, the problem is that we seldom experience our self as an emerging and dependently arising process. Habitually, we "experience our self as if it were a unified agent that functions as the executive controller of what we think and do, and that has a permanent inner essence distinct from our changing mental and physical characteristics" (Thompson, 2015, p. 324). This fundamental cognitive error "to mistake something that's dependent and contingent - and hence 'empty' of substantiality_-for something that's independently existent”' (Thompson, 2015, p. 324), for Nargajuna, is similar to take the illusory images in a dream as independently real objects of perception with its own inner essence (Thompson, 2015, p. 324). This ancient metaphor, as revealed in chapter three, is now well supported by the holographic computersimulation model of participatory universe. Yet, Thompson (2015) cautioned that this analogy does not mean that there is no self at all or that any sense of self is mistaken (p. 324). As he indicated, "after all, dreams exist as genuine experiential phenomena, yet they lack the independent being that we take them to have when we do not realize we're dreaming" (Thompson, 2015, p. 324). Similarly, our sense of self does exist as genuine experiential phenomena although they lack the absolute, independent and substantial essence that we take them to have. Even in the deep and direct penetrating experiential realization of the emptiness of self, akin to "becoming lucid in a dream or waking up from a dream - the subject of experience still exists but is no longer deluded about its nature" (Thompson, 2015, p. 324). The direct 
experience of "No-Self" or selflessness is well described by Austin (2009). As he clarified, the phrase No-Self

does not mean that the person stops witnessing ... It means that witnessing happens with none of the old intrusive, Self-conscious I-Me-Mine standing in the way. It means that no former veils of Self obscure or distort everything in that outside environment. Once these old concepts drop off, the anonymous observer is finally graced by the glimpse of an unimaginally "objective vision." This fresh reality sees clearly into the eternal perfection of "all things as THEY really are." Coming out of this state of oneness, the person finally grasps the error inherent in the old Self/other mode of dual perception. (p.

Austin made clear the meaning of No-Self, selflessness, or the emptiness of self and the transformative power of the direct non-dualistic experience of emptiness and oneness in recognizing the erroneousness of the self-other dichotomy. Cultivating selflessness, therefore, is cultivating toward the direct realization of the ultimate nature of human existence without being obscured by the erroneous cognition of an egoistic self entrenched in the dualistic self/other perception. The direct experience of emptiness, according to the five-stage gradual path of consciousness transformation, signifies the perfection of the first two stages, the mundane path. On this basis, the practitioners then develop further spiritual faculties and attain deeper meditative experience. However, as discussed earlier, since most of us remain caught in a dualistic mode of perception and can hardly attain this state all at once, at the very beginning, cultivating selflessness in educational context requires the approach of negation and the union of method-side and wisdom-side practices grounded on a proper conceptual understanding of the emptiness of self. 
Conceptually, the meaning of emptiness, as explored in chapter three, is also coterminous with dependent origination that involves three levels of meaning: the causal, the whole/part dependence, and the conceptual dependence (Newland, 2009, pp. 69-70; Thompson, 2015, p. 330). The causal level of dependence reveals how a phenomenon is dependent on causes and conditions for its existence and ceasing to existence (Thompson, 2015, p. 330). The whole/part dependence refers to how the part and whole of a phenomenon co-arise and depends on each other for existence (Thompson, 2015, p. 330). The conceptual level of dependence- - the subtlest level of dependent origination, according to the sub-school of Madhyanaka called Prasangika Madhyamaka, refers to that "the identity of something as a single whole depends on how we conceptualize it and refer to it with a term" (Thompson, 2015, pp. 330-331). This means the identity of something also depends on the scale of observation (Thompson, 2015, p. 331). Taking the cell as a metaphor for the self, Thompson (2015) illustrated that "the cell has no intrinsic identity independent of a conceptual schema and scale of observation that individuate it as a unit" (Thompson, 2015, p. 331). When observed from different conceptual and observational perspective, the cell either dissolves into self-organized dance of smaller molecules or loses the observational validity (Thompson, 2015, p. 331). Employing the concepts of a selfspecifying system, Thompson (2015) further illustrated that the identity of the interlocking network as one self-specifying system depends on how we cognitively frame things, that is, on our decision to focus on those conditioning relations that mutually specify each other in a recursive way. Depending on our interests or explanatory purposes, we could decide to frame things differently by focusing on other conditioning relations. What we mark off as a system depends on our cognitive frame of 
reference and the concepts we have available. (p. 331)

However, as noted in chapter three, "this doesn't mean that nothing exists apart from our words or concepts" (Thompson, 2015, p. 331). According to Prasangika Madhyamaka, the full statement of conceptual dependence is that "whatever is dependently arisen depends for its existence on a basis of designation, a designating cognition, and a term used to designate it" (Thompson, 2015, p. 332). Utilizing this formulation of dependent arising as conceptual ingredient, which Thompson (2015) referred to as a self-designating system-“one that conceptually designates itself as a self and where changing body-mind states serve as the basis of designation" (p. 332), Thompson developed the I-making system—-"one that has a sense of itself as an I who endures through time as a thinker of thoughts and a doer of deeds" (p. 332). The three levels of meanings of dependent origination and Thompson's illustration of the concept of self as an enacted I-ing process and the theory of I-making system provides us not only deepened insights into how our sense of self arises dependently, but also a consolidated conceptual ground for perceiving the deviation of our sense of self and for contemplating how we might cultivate selflessness or the emptiness of self in educational context.

According to Thompson (2015), the way our everyday sense of self appears does involve an illusion, however, it is not the case that there is no self at all or that the appearance of the self is merely an illusion. Rather, "the illusion —or delusion—is taking the self to have an independent existence, like taking the mirror image to be really in the mirror" (Thompson, 2015, p. 365). To undo this illusion, meaning to cultivate selflessness or the emptiness of self, doesn't mean destroying the appearance of the self; it means not being taken in by the appearance of the self and holding the belief that the self has an independent existence while that appearance is still 
there and performing its routine I-making function (Thompson, 2015, pp. 365-366). Thompson (2015) emphasized that, it is "this ignorant and deep-seated belief, not the appearance of the self as such, habitually deludes us into thinking, feeling, and acting as if the self were independent" (p. 365). From the perspective of conceptual dependence, our attachment to our body-mind aggregations as our self that is independent of the world is in actuality an attachment to the conceptual schema and scale of observation that neglect the relationships between the self and world and confine the observation to a small scale. The cultivating of selflessness, thus, also requires us to break the boundary of the scale of observation and to include our relationships to the world into our conceptual schema of our self. Such realization helps us understand Huebner's (1987/1999) statement that “we are our relationships. Our so-called personalities and habits of language and thinking are the fabric of yesterday - the way we are in relationship with the people of our past" (p. 390). As Smith (2000) indicated, "claim an Identity, whether racial, tribal, or gendered, and quickly it can be seen how it emerges through a web of relationships" (p. 23). Pitt (2000) also indicated that, "the personal is constituted within a web of relations that includes relation of time (how the past works on the present) and relations with others, knowledge and authority" (p. 69). However, this "is not to ignore the obvious fact that we each have an explicit (but transient) physical self or to pretend that it doesn't exist” (Austine, 1991, p. 79). Rather, it is a shift of scale of observation and conceptual schema to include our fabric of relationships and to experience our self as a being-in-the-world from an expanded scale of observation. As Japanese Zen Master Dōgen said: “To study your own self is to forget yourself. To forget yourself is to have the objective world prevail in you" (as cited in Austin, 1991, p. 79).

However, in practice, given the habitual force of our ignorance entrenched in a dualistic 
perception and the elusive nature of our sense of self, more conceptual tools are required for recognizing and overcoming our illusion and attachment. The slippery nature of our secret self is well delineated by Pitt (2000) with the metaphor of hide and seek. For the purpose of scrutinizing the subtle aspects of our deluded implicit self, Austin (1991) developed a descriptive system by means of separating the sensitive implicit self into three different operational components with $I, M e$, and Mine as their operative words (p. 79). To have a glance at these descriptions, let us begin with the $I$. According to Austin (1991), "the $I$ is, and acts. No one of us can appreciate how big our own $I$ is. Other persons know" (p. 80). Austin described that, "this almighty I is virtually perfect. It is also vain. It monograms and polishes its self-image. Can it ever, even rarely, fall into error? No. It makes excuses and shifts the blame” (p. 81). Besides, in the repertoire of our $I$, there are also many masks, or personas (Austin, 1991, p. 81). According to Austin (1991), each rigid mask took many decades to construct or to conceal. The roles our persona assume stemmed not only from parents, siblings, friends and teachers but increasingly from media personalities. Collectively, they now form the mosaic of our personal identity, our self image. We shift from one role model to another depending on the circumstances. We also adopted the attitudes of each persona. These shape how each 'role model I' should behave. ... Each of us has an agenda of highly personal biases which distort what we perceive and shape what we then think is true. (p. 81) Then, the pronoun $M e$, according to Austin (1991), stands for our self as an object that like to be praised and is bothered by all the "bad" event that threat to harm, to expose, or to embarrass, and is "on the receiving end of every self-inflicted, psychic wound generated by the inappropriate activities of its two other partners, the I and the Mine" (p. 81). Austin call it the vulnerable Me. 
Lastly, "the adjective, Mine, stands for our grasping, greedy, possessive self" (Austin, 1991, p.

81). It represents our attachment, and akin to our discussion on attachment in the preceding subsection, Austin (1991) described that it clutches out and clings, and "is self-indentured, because whatever is possessed, possesses. The more it gets, the less satisfied it is, and the more it covets. But the more it possesses, the more it stands to lose" (p. 82). Similar to Lusthaus's (2002) analysis of the appropriational circuit between grasper and grasped explored earlier, Austin (1991) indicated that "our Mine starts out in deceptively simple fashion. It proceeds from the basic premise of the self/other split in perception. But this then implies that anything around the core of Mine, including my thoughts and opinions, must be defended" (p. 82). Usually, not until late in the direct experience of emptiness "does one realize how pervasive was this insidious, intrusive, grasping process. Then, astonished, the experiant discovers the extent of the Mine” (Austin, 1991, p. 83).

The above brief of the selfish I-Me-Mine complex not only provides us clues to how our deluded implicit and egoistic self works, particularly in our fabric of relationships, but also gives us traits in what it is to be negated by the approach of negation. However, again, this does not mean that all of our I-Me-Mine thoughts should be denied. Rather, the overcoming of our selfish $I-M e-$ Mine complex means not being taken in by the selfish I-Me-Mine complex and holding that the self has an independent and essential existence. For Austin (1991), the overcoming of one's selfish I-Me-Mine complex "involves reaching down through one's own efforts to pull out its prolific roots. It means abdicating the sovereign $I$, abandoning the ramparts defending the $M e$, and abolishing the enslavement to the Mine" (p. 83). In Huebner's (1991/1999) words, it is “a dying to oneself that we may find ourselves" (p. 397), and for Huebner, this is education. For 
Winnicott, as Pitt (2000) indicated, this is development. Quoting Adam Philip, Pitt (2000) stated that, for Winnicott, development is "a growing capacity to tolerate the continual and increasingly sophisticated illusionment-disillusionment-re-illusionment process throughout the life-cycle" (p. 68). This process can well be understood from the nature of "the Christian experience: creation, fall, and recreation; from 'greatness' to 'wretchedness' to 'renewal' and transformation" (Huebner, 1985a/1999, p. 317). The increasingly sophisticated cycles of illusionmentdisillusionment-re-illusionment illustrate the process of the overcoming of our I-Me-Mine complex and the cultivating of selflessness toward the ultimate truth of human existence. As Smith (2000) indicated, "truth calls me to human maturity" (p. 21). To facilitate this process, scrutinizing the fabric of our relationships is crucial. As Huebner (1987/1999) pointed out, the agenda for religious education "is one of scrutinizing the fabric of relationships that we have, those of intimacy and those of community, and of asking how God is present or absent in those relationships" (p. 392). For Huebner, God is Love, unfathomable and ineffable. By means of understanding God as the ultimate nature of human existence that is identical with the nondualistic uncontaminated original state of human consciousness wherein love is a given, the scrutinizing of the fabric of our relationships and the awareness of the emerging of our dualistic selfish I-Me-Mine complex help us recognize how God or love is absent in these relationships and provides us opportunities of not being taken in by such complex and of pulling out its prolific roots that are essential for facilitating the cycles of illusionment-disillusionment-reillusionment and for transcending our current forms of existence.

The above exploration of the concepts of self and selflessness provides us deepened insights into how the perfection of wisdom that knows emptiness facilitate the cultivating of selflessness. 
Given the significance of meditative stabilization as another essential wisdom-side practices for consciousness transformation, in the following, I explore how meditative stabilization can be conducive to the cultivating of selflessness.

The relationship between meditative stabilization and the cultivating of selflessness is well demonstrated by Thompson (2015) by means of introducing the concept of self-projection, which refers to the perspective switch of the mental projection of oneself into an alternative situation of either personal past or imaged future that usually includes both the first-person and third-person perspectives of the mental representation of one's self (p. 348). According to Thompson, in a kind of self-projection known as mental time travel, "every memory or expectation you encounter normally represents itself as yours, as belonging to you, where you feel as if you're one and the same self who endures through time as the subject of these experiences" (p. 348). Self-projection, thus, "exemplifies the sense of self that consists in the feeling of being a distinct individual with a unique personal identity and a protracted existence in time" (p. 348). Neuroscientist Antonio Damasio called this sense of self as the autobiographic self, and phenomenologists call it the narrative self (Thompson, 2015, p. 348). Thompson (2015) indicated that, self-projection, meaning the autobiographical or narrative sense of self, depends on a network of brain areas that overlaps closely with the default network of the brain, and when the default network is active during resting or passive situation, spontaneous self-projection thoughts, or mind wandering, are at their peak (pp. 348-349). During meditation, such mind wandering along with the self-related thoughts and emotions arise spontaneously, yet, according to Thompson, at the moment you notice it, "you have the opportunity to disengage from identifying with the contents of these thoughts — specifically, from identifying with the mentally 
imaged "I" who is the central character-and to shift your attention to the thoughts simply as thoughts" (pp. 349-350). Moreover, with repeated experience of the dynamics between being taken in by self-related thinking occurs in mind wandering and waking up to what our mind is doing, not only the frequency of the arising of self-related thoughts lessens, we also "feel the difference between identifying with the content of a self-related thought—with the "I" as you mentally represent it—and identifying that a thought is occurring while experiencing the larger field of awareness in which it arises" (p. 350).

Referring to various researches, Thompson (2015) pointed out that negative moods lead to mind wandering and when the mind is wandering, people are less happy than when they are focusing on what they are doing (p. 350). Given the close association between mind wandering, the default network, and self-projection network of brain, this finding suggests that during the period of self-projection or self-related processing, including the selfish I-Me-Mine complex, people are less happy than when they are living here and now. Moreover, given such association, "it's not surprising that focused attention and open awareness forms of meditation, which involve stabilizing awareness while developing meta-awareness of ongoing mental activities, affect the brain's default network" (Thompson, 2015, p. 350), and therefore, affect the network of selfrelated processing and the autobiographical or narrative sense of self. This means, such meditation helps us transcend our conditioned default mode of self-projection.

Another research conducted by Judson Brewer and his colleagues at Yale University revealed that, compared to the novices, the experienced meditators reported less mind wandering and the main nodes of their default network were less active during the meditation periods across three 
types of meditation (Thompson, 2015, p. 353). Moreover, when their default network is activated, experienced meditators co-activate different brain regions (Thompson, 2015, p. 353). This implies that they might be more likely to recognize new possibilities than the novices or non-meditators. This study also suggested that the mental processes supported by the default network, including mind wandering and self-related processing, "may be more accessible to monitoring and control in experienced meditators than in novice meditators" (Thompson, 2015, p. 353). The increased accessibility to monitoring and control of self-related processing suggests that the cultivating of selflessness is easier for experienced meditators than for novice meditators or non-meditators.

In one other study, Norman Farb and Adam Anderson of the University of Toronto uncovered "the relationship between mindfulness practice and the neural systems underlying two different modes of self-experience - present-moment awareness of the body versus the narrative or autobiographical sense of self" (Thompson, 2015, p. 355). Their findings suggested that with the kind of training in present-centered awareness provided by mindfulness practices, such as MBSR (Mindfulness-based Stress Reduction), it's easier for us to disengage from our narrative self, e.g. worrisome rumination about our selves in memory or prospection, or mentally elaborated stories with attachment to certain mental representation of ourselves, etc., and we are also more likely to adopt an experiential focus, meaning present-centered embodied awareness that anchors our attention to our bodily being in the here and now (Thompson, 2015, pp. 354-355). This means mindfulness training is also conducive to the cultivating of selflessness. Moreover, a quasiexperimental study evaluating the effectiveness of the Mindfulness Education (ME) conducted by Schonert-Reichl and Lawlor (2010) also showed significant improvements in teacher-rated 
social and emotional competence and positive emotion of optimism for both pre- and early adolescents, and improvement in general self-concept for early adolescents.

The findings of the above studies revealed the interrelationships of meditation, self-related processing and positive emotion and provide us substantial evidences regarding how meditative practices can be conducive to the cultivating of selflessness, and therefore, consciousness transformation, particularly when meditative practices are motivated by bodhicitta and grounded on wisdom that knows the emptiness of self and reality. Given its positive influences on social and emotional competence and its existential significance for cultivating selflessness and for attaining various spiritual goals, in curriculum as an experience of consciousness transformation, meditative practices are indispensable. In the following subsection, based on the deepen realization regarding the concepts of self and selflessness and how we might cultivate selflessness in educational context, I investigate into the educational significance of learning to embody a non-dualistic worldview.

\subsubsection{Learning to Embody a Non-Dualistic Worldview}

As indicated in the preceding subsection, cultivating selflessness and learning to embody a nondualistic worldview are mutual inclusive and supportive and both require the union of wisdomside and method side practices. In this subsection, with accent on the deed component, I explore the method-side practices to gain insights into how we might learn to embody a non-dualistic worldview for consciousness transformation in educational context. 
In earlier exploration of the concepts and process of consciousness transformation, we have seen the significance of the cultivation and embodiment of a non-dualistic worldview for the suppression and eradication of contaminated karmic seeds of afflict barriers and noetic barriers that hinder the transformation of consciousness. As revealed earlier, while the wisdom-side practices for consciousness transformation are vital for the cultivating of selflessness and a nondualistic worldview and for preventing us from abiding the extreme of the phenomenal aspect of reality (samsara), for the purposes of avoiding the inconsistency between the view component and deeds component in our practices and preventing us from abiding the other extreme of the ultimate aspect of reality (nirvana), we need also the method-side practices or the accumulation of merits that aim for the embodiment of a non-dualistic worldview in everyday existential situations motivated by compassion, love and bodhicitta.

While there are countless methods for embodying a non-dualistic worldview and achieving various spiritual goals, in The Great Treatise, Tsong-kha-pa (1402/2004) convincingly demonstrated that the six perfections, along with their order, are the best way of categorizing these methods (pp. 103-111). This categorization serves well as a concise framework for understanding and applying various methods in Buddhism and in various religious and spiritual traditions. Also, according to Tsong-kha-pa (1402/2004), the order of the six perfections reflects the arising, the inferior and superior, and the coarse and subtle of these perfections: each of the perfections produce or influence the arising of the subsequent one, and is inferior, easier and coarser than that follows (p. 111). He explicated the order of the arising of the six perfections that 
when you have a generosity that is disinterested in and unattached to resources, you take up ethical discipline. When you have an ethical discipline, which restrains you from wrongdoing, you become patient with those who harm you. When you have patience wherein you do not become dispirited with hardship, the conditions for rejecting virtue are few, so you are able to persevere joyously. Once you persevere day and night, you will produce the meditative concentration that facilitates the application of your attention to virtuous objects of meditation. When your mind is in meditative equipoise, you will know reality exactly. (Tsong-kha-pa, 1402/2004, p. 111)

However, it is important to bear in mind that, as indicated in chapter three, in the explanation and application of the six perfections, each of the six perfections is a complex combination of methods and wisdom and each supports and is part of the others; therefore, the order of the six perfections, rather than suggesting that one should practice the six perfections one by one accordingly, is to provide the practitioners, particularly the novice practitioners, a focus of proficiency in each stage of practicing the dynamic and recursive matrix of the six perfections and a sensible order of focus for making consolidated progresses that will lead to genuine transformation of consciousness. The order of the six perfections, thus, is of great significance and has important implications for the design of curriculum as an experience of consciousness transformation.

For the purpose of demonstrating how each of the six perfections should be practiced with the six perfections present, Tsong-kha-pa (1402/2004) took the generosity of giving the teachings as an example and elucidated that 
when you are giving the teachings, for instance, it is extremely powerful if you practice all six perfections. You have ethical discipline when you restraint yourself from the consideration from Śrāvakas and pratyekabuddhas [meaning dedicating the merit of generosity for only one's own emancipation or happiness]; patience when you bear any hardship while you aspire to the qualities of omniscience and when you are patient with abuse from others; joyous perseverance when you yearn for the ever-greater increase of your generosity; meditative stabilization when you dedicate to complete enlightenment the virtue that you cultivate with one-pointed attention unmixed with Hīnayāna considerations [meaning considering one's own liberation only]; and wisdom when you know that the giver, gift, and recipient are like magician's illusion. (p. 121)

This example instantiates how each of the six perfections supports and is part of the others, and exemplifies how in educational context, the first four perfections can be handy and powerful conceptual tools for examining our motivation and implementation of teaching, learning, studying and decision-making, and preventing us from being taken in by our I-Me-Mine complex rooted in dual perception within the fabric of our relationships, and thus, provide us opportunities of transcending and redefining our sense of self, as, in Huebner's words, we are our relationships. In this way, the first four perfections that aim for embodying a non-dualistic worldview can possibly open formerly unseen possibilities, recover value and dignity, facilitate mutual love and reverence, enact genuine conversation and truthful knowing, return the spiritual significance and existential meanings to everyday teaching, learning, studying, and decision-making in educational circumstance, and dispel the formulaic logic of the market and the language of global competitiveness that permeate educational landscape. 
The six perfections, when understood from the perspective of three trainings (ethical conduct, meditative stabilization, and wisdom), the perfections of generosity, ethical discipline, and patience stand as the precondition, the nature, and the aid of the training in ethical conduct respectively, and the perfection of joyous perseverance is included in each of the three trainings (Tsong-kha-pa, 1402/2004, p. 109). Since both trainings in meditative stabilization and in wisdom rely on the firm foundation of the training in ethical conduct, the first four perfections constitute the preconditions for the perfections of meditative stabilization and wisdom (Tsongkha-pa, 1402/2004, p. 110). The order and interrelationships among the six perfections explored above not only helps us recognize the significance of the first four perfections as training in ethical conduct and how they relate to the other two perfections, but also reminds us of the issues arising with the popularity of meditative practices in educational context that are not necessarily grounded on a substantial training of ethical conduct and guided by wisdom that knows emptiness. In the absence of the training in ethical conduct, i.e. the first four perfections or the method-side practices in everyday existential situations motivated by compassion, love and bodhicitta, the training in meditative stabilization loses its ground; in the absence of the training in wisdom that knows the emptiness and oneness of self and reality, meditative stabilization risks being deprived of its existential significance and being trivialized by instrumentalists as merely another tool for enhancing their competitiveness or for nurturing their superiority that, as a form of objectifying practices, only perpetuates the suffering-laden samsaric experiences. Preventing such potential danger should be a continuous concern to educators, particularly to the curriculum theorists who recognize the significance of spirituality for education.

According to Tsong-kha-pa (1402/2004), in Buddhism, generosity "is an intention accompanying 
bodhisattvas' disinterested non-attachment to all their possessions and their body, and motivated by this, the physical and verbal actions of giving the things to be given" (p. 114), and there are three types of generosity corresponding to three sorts of gifts: the gifts of teachings, fearlessness, and material gifts; ethical discipline "is an attitude of abstention that turns your mind away from harming others and from the sources of such harm" (p. 143), and the coarsest factors that are incompatible with ethical discipline are the ten non-virtues that include covetousness, malice, wrong view, lying, slander, harsh speech, senseless speech, killing, stealing, and sexual misconduct (Sopa, 2005, pp.45-46); patience is "(1) disregarding harm done to you, (2) accepting the suffering arising in your mind-stream, and (3) being certain about the [Dharma] teachings and firmly maintaining belief in them" (p. 152); joyous perseverance is "a flawless state of mind that is enthusiastic about accumulating virtue and working for the welfare of living beings, together with the physical, verbal, and mental activity such a state of mind motivates" ( $p$. 182). While the transformative power of the first four perfections relies on a proper understanding of the details of the teaching of the six perfections, given that this detailed teaching is not our current focus, in the following, only points that are of particular educational significance are selected for discussion. First of all, rather than being intended as dogmatic moral tenets to be observed under dual perception that sees the world as outside and independent of us, the first four perfections are practices that are in accordance with a non-dualistic worldview that sees the "objective" world as an essential part of our own existence. The meaning of the first four perfections as training in ethical conduct for embodying a non-dualistic worldview can well be understood through Smith's (2000) explication of the word "discipline", which he referred to as the act of following a task to its true end, a kind of obedience to the call of truth as it 
speaks out to me from the task at hand. When I respond in a way true to the thing itself, I find my estrangement from it slowly melt away such that I become one with it, and it with me, and something new is brought into the world from out of us both. (pp. 24-25) As he indicated, in pedagogical situations, the labor of overcoming our primal sense of estrangement from the world, meaning the self-world duality, is best understood through the practice of discipline (p. 24). For Smith, "Self implies Other. If there is to be truth in the world, it will be only truth as shared, something between us. Such is the foundation for ethics in the age of globalization" (p. 23). Smith's words revealed the ethical and pedagogical significance of the first four perfections as a kind of obedience to the call of truth as it speaks out to me here and now that brings about the dissolving of self-other dichotomy and the reborn of self.

The first four perfections as training in ethical conduct and as a kind of obedience to the call of the truth of oneness can also be understood through the concept of witnessing. According to Boler (1999), in contrast to spectating that "permits a gaping distance between self and other" (p. 184), witnessing "is a process in which we do not have the luxury of seeing a static truth or fixed certainty. As a medium of perception, witnessing is a dynamic process, and cannot capture meaning as conclusion" (p. 186). In other words, in positioning our self as a witness, we recognize the non-duality of self and world and the transcending nature of human existence, and respond to the world in ways correspond with this realization. The concept of witnessing is similar to Bowers's theory of ecological intelligence that abandons "the Cartesian representation of the individuals as spectator of an external world", and considers the individual as "an interactive member of the larger and more complex ... culture/environment relationship" (as cited in Riley-Taylor, 2002, p. 15). Both the concepts of witnessing and ecological intelligence 
emphasize "the relational embeddedness of individuals" (Riley-Taylor, 2002, p. 15). Boler indicated that ethical questions do exist in spectating. Ethical issues arise when someone is suffering, yet we choose to keep a comfortable safe distance without doing anything. Such issues point to ethical complexities and the need to go beyond the moral binary of guilt vs. innocence, which, as Boler said, "severely constrains educational possibilities" (p. 186). For Boler (1999),

spectating vs. witnessing provides a useful tool for learning how positionalities shift and slip in complex, unpredictable, and precarious ways. Through learning to see how and when one spectates or bears witness it become possible, at least provisionally, to inhabit a more ambiguous sense of self not reduced to either guilt or innocence. In this process one acknowledges profound interconnections with others. (p. 187)

Becoming aware of our positioning as spectator or witness, thus, is conducive not only to learning to go beyond moral binaries and cultivate morality as responding in a way true to the thing itself with non-dual perception, but also to learning to embody a non-dualistic worldview. In the positioning of witnessing, we stop watching the world from an outsider perspective, learn to overcome what Huebner called the subject-object attitude, and we transform the sense of human estrangement from the world that usually distorts the others with the paranoia of narcissistic and egoistic I-Me-Mine complex. By means of adopting the subject-subject attitude from an insider perspective, in witnessing, we include our relationships to the world into our sense of our self and become aware of how in these interrelationships, you and me co-arise concurrently and interdependently not as separate identities but as a dyad that bring about new transcending possibilities. In this kind of self-world dialectic, there is no longer "other" to compete with, to fight against, or to grab from, but an equal to love and give with generosity, 
ethical discipline, patience, and joyous perseverance based on meditative insights and wisdom that knows emptiness.

In practicing the first four perfections, it is important to notice that the completion of the first four perfections are referring to the fulfillment of the mental aspect of the perfections rather than the physical and verbal aspects, such as completely removing sentient beings' poverty by giving gifts, or perfectly establishing sentient beings in a state free of all harm, etc. It is also very important to bear in mind that we should not practice the perfections with arrogance. Taking the perfection of generosity for example, Tsong-kha-pa (1402/2004) reminded us that "you do not despise the person who asks for something, you do not compete with others, and after you give something, you do not conceitedly think, 'I am so generous; no one else can do like this'” (p. 125). Drawing on a sutra, Tsong-kha-pa (1402/2004) explained that when ordinary beings make gift, observe ethical discipline, or maintain patience, etc., they get angry with, lose faith in, or speak disparagingly of those who do the opposite, and as a result of such contaminated karma rooted in dualistic perception, they obstruct their own practices of the six perfections and can possibly fall into miserable realms (p.125). In the absence of impartial love and compassion, it is easy for us to fall into such pitfalls and forget that the oppressors are themselves the oppressed by their own ignorant conducts. In educational context, if we want to facilitate genuine transformation of consciousness, avoiding such pitfalls in both our discourse and practice is extremely important.

In this subsection, drawing on the method-side practices of the six perfections motivated by compassion, love and bodhicitta, I explore the significant educational implications of the first 
four perfections for learning to embody a non-dualistic worldview as an attempt to transform everyday educational planning, teaching, learning, and studying into opportunities for consciousness transformation and to return spiritual and existential significance back to everyday life in educational circumstance.

The above six key elements, together, provide us an overview of curriculum as an experience of consciousness transformation. Despite being explored separately, as we have seen, they are mutual inclusive and indivisible. Rather than being intended as a comprehensive theory, the six key elements constitute a possible framework for contemplating how curriculum might be an experience of consciousness transformation. The implication and further questions are explored in the next chapter. 


\section{Chapter 5: Conclusion and Implications}

\subsection{Brief Summary, Conclusion and Implications}

In this study, with deep concern over the inappropriate reliance on classical science in place of spiritual wisdoms in education that has become the cause of the radical commercialization of human values and the root of various global crises, I aim at imbuing curriculum with spiritual wisdoms by drawing mainly on the work of curriculum scholar Dwayne Huebner and I explore how we might understand curriculum as an experience of consciousness transformation.

Over several decades, while there has been growing appreciation of the spiritual on the educational landscape, the concepts of spirituality found in educational literature remain largely vague and elusive. Questions regarding what the spiritual is all about and the meaning of 'being on a spiritual path' remain unanswered. While Huebner's phenomenological and theological discourses have eloquently ruled out absolutism and objectivism, which I recognize as the main epistemologies that hinder two of the most significant aspects of spiritual truth - the openness to the transcendent and the non-dualistic worldview_-given the longstanding reliance of educational enterprises upon scientific traditions and the fact that curriculum development or the systematic tradition of curriculum, which is largely in keeping with Ralph Tyler's framework, is far from dead but thriving despite being consistently criticized (Null, 2008), I see the imperative to scrutinize spiritual wisdoms from a scientific perspective and to resolve the prevailing myth of the incompatibility between spiritual wisdoms and scientific ways of thinking. 
Given my religious background, by means of conducting a dialogue between Buddhism and quantum physics, I illustrate a dramatic convergence and compatibility of the two branches of thought regarding the nature of consciousness, self and reality, particularly the resonances between the Buddhist concepts of the two truths (the ultimate truth of emptiness and the conventional truth of daily phenomenal world) and the two distinct realities depicted respectively by quantum physics and classical physics. This convergence provides insight into the essence of spirituality as all about piercing the deceptive shadowy phenomenal reality that is but a holographic projection of a computer-simulated model of universe, and all about attaining the realization of the ultimate nature of consciousness, self and reality that bring about ultimate liberation. This deepened understanding of the true nature of consciousness, self and reality also helps us apprehend the four-stage transition of the essence of truth presumed or realized by an individual that, for Heidegger, is the essence and purpose of education, as in essence the transformation of consciousness.

For the purpose of gaining a panoramic view over the whole spiritual path for educational use, and of preventing various potential dangers and deviation of spiritual practices, in addition to Huebner's work, I draw on the five-stage gradual path of consciousness transformation into four transcendental wisdoms as prescribed in the consciousness-only school of Buddhism and explore how we might understand curriculum as an experience of consciousness transformation from the perspectives of six key elements: understanding the nature of consciousness, self and reality, learning to appreciate human temporality, cultivating impartiality and bodhicitta, becoming responsibly responsive, cultivating selflessness, and learning to embody a non-dualistic worldview. 
In retrospect over this journey, my joy of experiencing the hermeneutic power of different language and symbol categories for the same phenomena or situations is immense. This joyousness deepens my appreciation of Huebner's reminder that the compartmentalization of human thought into religious, philosophical, and scientific sections, without attempting consciously to compare and evaluate the differing language and symbol categories for the same phenomena or situations, cannot be justified. Such comparison and evaluation does not imply that one thought or language system must predominate over the others, for each has its own values. But the values can only be realized if their respective powers and limitations can be identified. (Huebner, 1963/1999, p. 91)

During this journey, on one hand, I deeply appreciate the way Huebner's phenomenological and theological discourses deepen my understanding of Buddhism and the implications of quantum physics; on the other hand, as my understanding of Buddhism and quantum physics increases, different layers of meanings of Huebner's discourses emerge. I also enjoy the dialogue between Buddhism and quantum physics that not only informs each other, but also brings new light into educational thinking. However, in his reflection on the Tower of Babel, the symbol of confounded speech, Huebner (1985a/1999) reminded us that as more and more people seem capable of understanding people of other cultures, other types of strangers and foreigners appear on the scene. The scattering process appears to be constitutive of human kind. As we become unified in some aspects, we become scattered in others. (p. 312) 
It seems for me that the attempt to unify people in any aspect is itself an act of fragmenting or scattering, as, recalling Bohm's (1980) words, it tends only "to create a sense of separation of the members from the rest of the world" (p. 20). With this awareness in mind, although this study employs various languages, including educational, philosophical, religious, and scientific, for understanding the same spiritual phenomena or situations, the intention of this study, rather than attempting to unify these languages and thoughts, is to unlock the shackles that prevent human kind from penetrating the disguise of the shadowy phenomenal world and to bring in new image and new possibilities to the educational landscape based on the recognition of the profound significance of spiritual wisdom and existential knowledge for human beings and for education.

In his work on education and spirituality, Huebner (1993/1999) asked that if one dwells faithfully in the world, meaning if one whose imagination acknowledge the "moreness", "what images of education, specifically curriculum, are possible?" (p. 403). For Huebner (1993/1999), "different images of the same landscape enable us to see different possibilities, different relationships, and perhaps enable us to imagine new phenomena in that educational landscape" (p. 404). He indicated that he spoke as one who tries to dwell as a Christian because it is his religious tradition, and because he is more familiar with its many qualities, quirks, and its language (Huebner, 1993/1999, p. 403). He invited "those in other traditions ... to attempt the same, thereby enriching the ensuing conversation" (Huebner, 1993/1999, p. 403). As a response to Huebner's invitation, this study makes such an attempt. As an effort to imbue curriculum with spiritual wisdoms, understanding curriculum as an experience of consciousness transformation requires the transformation of consciousness in educational decision-makers, educators and researchers in the first place. Besides, since the integration of the existential knowledge and 
spiritual wisdom into curriculum in a way that encompasses the vast diversity of religious, spiritual, philosophical, scientific and other intellectual traditions, the task outlined by Huebner involves formidable challenges and enormous effort; a shared sense of responsibility is required.

\subsection{Limitations of This Study and Questions for Further Inquiry}

In the following, several limitations of this study are recognized. Firstly, while I am convinced that the other religious traditions are bound to have ample resources, knowledge, and wisdoms that can be conducive to this study, given my unfamiliarity with the other religious traditions, the concepts and process of consciousness transformation employed for exploring curriculum as an experience of consciousness transformation are mainly drawn from Buddhist literature. Besides, in order to maintain the focus of this thesis, the environment design, the teachers' role, the bodymind connection, the biographical journey, the aesthetic and the artistic, and the details of the six perfections are not included or well discussed in this study despite their conceptual and pedagogical significance. Their significance for the transformation of consciousness can possibly be the topics of future research.

In this study, the Middle Way (Madhyamaka) system of thought taught by Buddha and supported by quantum physics has played a critical role in illuminating the significant spiritual approach of negation and in preventing the spiritual practices from falling into the extreme of phenomenal aspect of reality or slipping into the other extreme of the ultimate aspect of reality. Given the strong clarifying power of the Middle Way interpretation of the two truths doctrine in reconciling or resolving the spiritual quandaries and paradoxes, such as emptiness vs. existence, selflessness vs. self, non-duality vs. duality, quantum reality vs. classic reality, meditative serenity vs. 
analytical discernment, subject-subject attitude vs. subject-object attitude, etc., and given the fact that the debates between the existential tradition of curriculum and the systematic tradition of curriculum usually refer to different aspects of reality and speaking at cross purposes, I am convinced that if we hope to imbue curriculum, particularly the currently thriving systematic tradition of curriculum, with spiritual wisdoms, our efforts must include reconciling the existential and systematic traditions of curriculum theories and giving each of them its due place in the field of curriculum studies within the Middle Way two truths framework. With the hope of extending my MA inquiry to a more comprehensive study of Dwayne Huebner's works on curriculum studies and to reconcile the existential and systematic traditions of curriculum thoughts, my questions for further inquiry are: How might the Middle Way interpretation of the two truths doctrine inform our educational thinking? How might we understand the theories underlying Dwayne Huebner's works and systematic traditions of curriculum within the Middle Way two truths framework? How might we reconcile the existential and systematic traditions of curriculum theorists? How might we balance the weights of spirituality and science in education? 


\section{References}

Alexander, H. A. (2003). Education as spiritual critique: Dwayne Huebner's lure of the transcendent. Journal of Curriculum Studies, 35(2), 231-245.

Aoki, T. T. (2004). Sonare and videre: A story, three echoes and a lingering note. In W. F. Pinar \& R. L. Irwin (Eds.), Curriculum in a new key: The collected works of Ted T. Aoki (pp. 367-376). New York, NY: Routledge. (Original work published 1991)

Aoki, T. T. (2004). Taiko drums and sushi, perogies and sauerkraut: Mirroring a half-life in multicultural curriculum. In W. F. Pinar \& R. L. Irwin (Eds.), Curriculum in a new key: The collected works of Ted T. Aoki (pp. 377-388). New York, NY: Routledge. (Original work published 1991)

Beck, C. (1986). Education for spirituality. Interchange, 17(2), 148-156.

Bohm, D. (1980). Wholeness and the implicate order. New York, NY: Rooteledge.

Bohm, D. (1990). A new theory of the relationship of mind and matter. Philosophical Psychology, 3(2), 271-286.

Boler, M. (1999). A pedagogy of discomfort: Witnessing and the politics of anger and fear. In Feeling power: Emotions and education (pp. 175-203). New York, NY: Routledge.

Bryman, A. (2004). Fallacy of objectivism. In M. S. Lewis-Beck, A. Bryman, \& T. F. Liao (Eds.), Encyclopedia of social science research methods (p. 377). Thousand Oaks, CA: Sage Publications.

Cabezón, J. I. (1992). A dose of emptiness: An annotated translation of the sTong thun chen mo of mKhas grub dGe legs dpal bzang. Albany, NY: State University of New York Press.

Chang, G. C. C. (1983). A treasury of Mahāyāna Sūtras: Selections from the Mahāratnakūta Sūtra. Pennsylvania, PA: The Pennsylvania State University. 
Cho, A. (2010). The first quantum machine. Science, 330(6011), 1604.

Choi, D. (2011). Mechanism of consciousness during life, dream and after-death. Bloomington, IM: Author house.

Culter, J. W. C. (2000). Editor's preface. In The Lamrim Chenmo Translation Committee (Trans.), The great treatise on the stages of the path to enlightenment, Volume Two (pp. 9-11). Ithaca, NY: Snow Lion Publications.

Dreyfus, H., \& Wrathall, M. (2005). Martin Heidegger: An introduction to his thought, work, and life. In H. Dreyfus \& M. Wrathall (Eds.), A companion to Heidegger (pp. 1-15). Malden, MA: Wiley-Blackwell.

Einstein, A. (1954). Religion and science. In S. Bargmann (Trans.), Ideas and opinion by Albert Einstein (pp. 36-54). New York: Crown. (Reprinted from The New York Time Magazine, 1930, November 9, pp. 1-4)

Evans-Wentz, W. Y. (2000). The Tibetan book of the dead: Or the after-death experiences on the bardo plane, according to Lama Kazi Dawa-Samdup's English Rendering. NY: Oxford University Press. (Original work published 1927)

Faure, B. (1994). The rhetoric of immediacy: A cultural critique of Chan/Zen Buddhism. Princeton University Press.

Fenwick, T. J. (2001). Critical questions for pedagogical engagement of spirituality. Adult Learning, 12(3), 10-12.

Forbes, S. H. (1996). Values in holistic education. Paper presented at the Third Annual Conference on Education, Spirituality and the Whole Child at the Roehampton Institute, London. Retrieved from http://www.holistic-education.net/articles/values.pdf 
Forman, R. K.C. (2011). An emerging new model for consciousness: The consciousness field model. In H. Walach, S. Schmidt, \& W. B. Jonas (Eds.), Neuroscience, Consciousness and Spirituality (pp. 207-288). Springer Netherlands.

Fuller, P. (2005). The notion of ditthi in Theraväda Buddhism. New York, NY: RoutledgeCurzon. Gemmell, W. (1912). The diamond sutra (Chin-Kang-Ching): Or prajna-paramita, translated from the Chinese with an introduction and notes. London: Kegan Paul, Trench, Trübner.

Gold, J. C. (2015), Vasubandhu. In Edward N. Zalta (Ed.), The Stanford encyclopedia of philosophy (Summer 2015 Edition). Retrieved from http://plato.stanford.edu/archives/sum2015/entries/vasubandhu/

Gore, A. (2008). Finding the moral resolve to solve the crisis of global climate change. Vital Speeches of the Day, 74(2), 55-58.

Greene, B. (2004). The fabric of the cosmos: Space, time, and the texture of reality. New York, NY: Alfred A. Knopf.

Greene, B. (2011). The hidden reality. New York, NY: Alfred A. Knopf.

Greyson, B. (2010). Implications of near-death experiences for a postmaterialist psychology. Psychology of Religion and Spirituality, 2(1), 37-45.

Hodge, D. R., \& Derezotes, D. S. (2008). Postmodernism and spirituality: Some pedagogical implications for teaching content on spirituality. Journal of Social Work Education, 44(1), $103-123$.

Heidegger, M. (1962). Plato's 'doctrine of truth' (J. Barlow, Trans.). In B. William \& D. A. Henry (Eds.), Philosophy in the twentieth century vol. 3 (pp. 251-270). New York, NY: Random House. (Original work published 1942) 
Heidegger, M. (1998). Plato's doctrine of truth (T. Sheehan, Trans.). In W. McNeill (Ed.), Martin Heidegger: Pathmarks (pp. 155-182). Cambridge, UK: Cambridge University Press. (Original work published 1942)

Hsuan Tsang (1973). Ch'eng wei-shi lun: The doctrine of mere-consciousness (T. Wei, Trans.). Hong Kong, China: The Ch'eng Wei-shih Lun Publication Committee. (Original work published 659). Retrieved from http://www.dhalbi.org/dhalbi/html t/authors/author main.php?p id=8

Huebner, D. E. (1999). The capacity for wonder and education. In V. Hillis (Ed.), The lure of the transcendent: Collected essays by Dwayne E. Huebner (pp. 1-9). New York, NY: Routledge. (Reprinted from paper presented at the All College Lecture Series, by D. E. Huebner, Summer, 1959)

Huebner, D. E. (1999). Knowledge: An instrument of man. In V. Hillis (Ed.), The lure of the transcendent: Collected essays by Dwayne E. Huebner (pp. 36-43). New York, NY: Routledge. (Reprinted from unpublished manuscript, by D. E. Huebner, 1962) Huebner, D. E. (1999). New modes of man's relationship to man. In V. Hillis (Ed.), The lure of the transcendent: Collected essays by Dwayne E. Huebner (pp. 74-93). New York, NY: Routledge. (Reprinted from New insights and the curriculum, pp. 144-164, by A. Frazier, Ed., 1963, Washington, DC: ASCD)

Huebner, D. E. (1999). Facilitating change as the responsibility of the Supervisor. In V. Hillis (Ed.), The lure of the transcendent: Collected essays by Dwayne E. Huebner (pp. 118130). New York, NY: Routledge. (Reprinted from paper delivered at The Changing Role of the Supervisor, Annual Supervisors' Conference, Florida, by D. E. Huebner, 1966) 
Huebner, D. E. (1999). Curriculum as concern for man's temporality. In V. Hillis (Ed.), The lure of the transcendent: Collected essays by Dwayne E. Huebner (pp. 131-142). New York, NY: Routledge. (Reprinted from Theory into Practice, 1967, 6(4), 172-179)

Huebner, D. E. (1999). Babel: A reflection on confounded speech. In V. Hillis (Ed.), The lure of the transcendent: Collected essays by Dwayne E. Huebner (pp. 312-320). New York, NY: Routledge. (Reprinted from Reflection, 1985a, 82(2), 9-13)

Huebner, D. E. (1999). Religious metaphors in the language of education. In V. Hillis (Ed.), The lure of the transcendent: Collected essays by Dwayne E. Huebner (pp. 358-368). New York, NY: Routledge. (Reprinted from Religious Education, 1985b, 80(3), 460-472. Also from Phenomenology + Pedagogy, 1985b, 2(2))

Huebner, D. E. (1999). Spirituality and knowing. In V. Hillis (Ed.), The lure of the transcendent: Collected essays by Dwayne E. Huebner (pp. 340-352). New York, NY: Routledge. (Reprinted from Learning and teaching the ways of knowing, The 84th yearbook of the National Society for the Study of Education, Part II, pp. 159-173, by E. Eisner, Ed., 1985c, Chicago, IL: NSSE, distributed by University of Chicago Press)

Huebner, D. E. (1999). Practicing the presence of God. In V. Hillis (Ed.), The lure of the transcendent: Collected essays by Dwayne E. Huebner (pp. 388-395). New York, NY: Routledge. (Reprinted from Religious Education, 1987, 82(4), 569-577)

Huebner, D. E. (1999). Educational activity and prophetic criticism. In V. Hillis (Ed.), The lure of the transcendent: Collected essays by Dwayne E. Huebner (pp. 396-400). New York, NY: Routledge. (Reprinted from New Haven: Yale University, The Divinity School, 1991) Huebner, D. E. (1999). Education and spirituality. In V. Hillis (Ed.), The lure of the transcendent: Collected essays by Dwayne E. Huebner (pp. 401-416). New York, NY: Routledge. 
(Reprinted from paper presented to the Seminar on Spirituality and Curriculum, Loyola University, New Orleans, by D. E. Huebner, 1993. Also from JCT, 1995, 11(2), 13-34) Iannone, R. V., \& Obenauf, P.A. (1999). Toward spirituality in curriculum and teaching. Education, 119(4), 737-743.

Johnson, G. (2014, January 22). Get a degree in mindfulness at Simon Fraser University. The Georgia Straight. Retrieved from: http://www.straight.com/life/571946/get-degreemindfulness-simon-fraser-university

Kaku, M. (1994). Hyperspace: A scientific odyssey through parallel universes, time warps, and the tenth dimension. Oxford: Oxford University Press.

Kaku, M. (2005). Parallel worlds: A journey through creation, higher dimmensions, and the future of the cosmos. New York, NY: Random House.

Kochumuttom, T. A. (1989). A buddhist doctrine of experience. A new translation and interpretation of the works of Vasubandhu, the Yogacarin. Delhi: Motilal Banarsidass.

Koetting, J. R., \& Combs, M. (2005). Spirituality and curriculum: The need to engage the world. Taboo: The Journal of Culture \& Education, 9(1), 81-91.

Krishnamurti, J. (1929). Truth is a pathless land (Dissolution speech of the Order of the Star). Retrieved from: http://www.jkrishnamurti.org/about-krishnamurti/dissolution-speech.php Kumar, A. (2013). Curriculum as meditative inquiry. New York, NY: Palgrave Macmillan. Lamotte, É. (2001). The treatise on the great virtue of wisdom of Nagarjuna (Mahāprajñāpāramitā). (G. K. M. Chodron, Trans.). (Original work published 1949). Retrived from http://read.84000.co/resources/Indian\%20Buddhist $\% 20$ Classics/Lamotte, $\% 20 \% 20 \mathrm{Vol} \% 2$ 02.\%20Maha-prajnaparamita-sastra- 
\%20by $\% 20$ Nagarjuna $\% 20$ (english $\% 20$ translation).pdf

Lee, K. C., Sprague, M. R., Sussman, B. J., Nunn, J., Langford, N. K., Jin, X. M., . . Jaksch, D. (2011). Entangling macroscopic diamonds at room temperature. Science, 334(6060), 1253-1256.

Lomborg, B. (2004). Introduction. In B. Lomborg (Ed.), Global crises, global solutions (pp.1-9). New York, NY: Cambridge University Press.

Lusthaus, D. (2014). Buddhist phenomenology: A philosophical investigation of Yogacara Buddhism and the Ch'eng Wei-shih lun. New York, NY: RoutledgeCurzon.

Lutz, A., Greischar, L. L., Rawlings, N. B., Ricard, M., \& Davidson, R. J. (2004). Long-term meditators self-induce high-amplitude gamma synchrony during mental practice. Proceedings of the National Academy of Sciences of the United States of America, 101(46), 16369-16373.

McTaggart, L. (2007). The experiment: Using your thoughts to change your life and the world. New York, NY: Free Press.

Miller, J. P. (2000). Education and the soul: Toward a spiritual curriculum. Albany, NY: State University of New York Press.

Miller, J. P. (2006). Educating for wisdom and compassion: Creating conditions for timeless learning. Thousand Oaks, CA: Corwin Press.

Miller, J. P. (2007). The holistic curriculum (2nd Ed.). Toronto, ON: University of Toronto Press. Miller, J. P. (2010). Whole child education. Toronto, ON: University of Toronto Press. Miller, R. (2005). Philosophical sources of holistic education. The Turkish Journal Deðerler Eðitimi Dergisi [Journal of Values Education], 3(10). 
Mingyur, Y. (2007). The joy of living: Unlocking the secret and science of happiness. New York, NY: Harmony Books.

Mintz, J., \& Muscat, A. (1994). The handbook of alternative education. New York, NY: Macmillan Publishing Company.

Narlikar, J. V. (2013). John Archibald Wheeler: Man with picturesque imagination. Resonance, 18(1), 22-28.

Nickle, T. (2005). Positivism. In M. C. Horowitz (Ed.), New Dictionary of the History of Ideas, Vol. 5 (pp. 1852-1857). Detroit, MI: Charles Scribner's Sons.

Newland, G. (2009). Introduction to emptiness: As taught in Tsong-kha-pa's great treatise on the stages of the path (2nd Ed.). Ithaca, NY: Snow Lion Publications.

Null, J. W. (2008). Curriculum development in historical perspective. In F. M. Connelly, M. F. He, \& J. Phillion (Eds.), The SAGE handbook of curriculum and instruction (pp. 478490). Thousand Oaks, CA: Sage Publications.

Palmer, P. J. (2003a). Education as spiritual formation. Educational horizons, 82(1), 55-67. (Reprinted from To know as we are known: Education as a spiritual journey, pp. 17-32, by P. J. Palmer, 1983, New York, NY: HarperCollins)

Palmer, P. J. (2003b). Teaching with heart and soul: Reflections on spirituality in teacher education. Journal of Teacher Education, 54(5), 376-385.

Park, S. R. (2014). Embodied inner work: An educator's journey of body-mind-heart integration. (Unpublished doctoral dissertation). Simon Fraser University, Burnaby, Canada.

Phelan, A. M. (2001). The death of a child and the birth of practical wisdom. Studies in Philosophy and Education, 20(1), 41-55. 
Pinar, W. F. (1999). Introduction. In V. Hillis (Ed.), The lure of the transcendent: Collected essays by Dwayne E. Huebner (pp. xv-xxviii). New York, NY: Routledge.

Pinar, W. F. (2012). What Is Curriculum Theory? (2nd ed.). New York, NY: Routledge.

Rancière, J. (2010). On ignorant schoolmasters. In C. Bingham \& G. J. J. Biesta (Eds.), Jacques Rancière: Education, Truth, Emancipation (pp. 1-24). London: Continuum Publishing Group.

Riley-Taylor, E. (2002). Ecology, spirituality, education: Curriculum for relational knowing. New York: Peter Lang.

Rosa, R (2012). The Merli-Missiroli-Pozzi two-slit electron-interference experiment. Physics in Perspective 14, 178-195.

Schonert-Reichl, K. A., \& Lawlor, M. S. (2010). The effects of a mindfulness-based education program on pre-and early adolescents' well-being and social and emotional competence. Mindfulness, 1(3), 137-151.

Schwartz, J. M., Stapp, H. P., \& Beauregard, M. (2005). Quantum physics in neuroscience and psychology: A neurophysical model of mind-brain interaction. Philosophical Transactions of the Royal Society B: Biological Sciences, 360(1458), 1309-1327.

Siderits, M. (2007). Buddhism as philosophy: An introduction. Aldershot, England: Ashgate Pub.

Siderits, M., \& Katsura, S. (2013). Nāgārjuna's middle way. Somerville, MA: Wisdom Publications.

Smith, D. G. (2000). The specific challenges of globalization for teaching and vice versa. The Alberta Journal of Education Research. XLVI (1), 7-26.

Socratic Method. (n.d.). In Wikipedia. Retrieved June 27, 2016, from https://en.wikipedia.org/wiki/Socratic_method\#Method 
Sopa, L. (2004). Steps on the path to enlightenment: A commentary on Tsongkhapas' Lamrim Chenmo, volume I: The foundation practices. Somerville, MA: Wisdom Publications. Sopa, L. (2005). Steps on the path to enlightenment: A commentary on Tsongkhapas' Lamrim Chenmo, volume II: Karma. Somerville, MA: Wisdom Publications.

Sopa, L. (2008). Steps on the path to enlightenment: A commentary on Tsongkhapas' Lamrim Chenmo, volume III: The way of the bodhisattva. Somerville, MA: Wisdom Publications.

Sullivan, L. E. (2009). Positivism (education). In L. Sullivan (Ed.), The SAGE Glossary of the Social and Behavioral Sciences (p. 395). Thousand Oaks, CA: Sage Publications.

Talbot, M. (2011). The holographic universe (2nd ed.). New York, NY: Harper Perennial. Tsong-kha-pa (2000). The Great Treatise on the Stages of the Path to Enlightenment, volume One (The Lamrim Chenmo Translation Committee, Trans.). Ithaca, NY: Snow Lion Publications. (Original work published 1402)

Tsong-kha-pa (2002). The Great Treatise on the Stages of the Path to Enlightenment, volume three (The Lamrim Chenmo Translation Committee, Trans.). Ithaca, NY: Snow Lion Publications. (Original work published 1402)

Tsong-kha-pa (2004). The Great Treatise on the Stages of the Path to Enlightenment, volume two (The Lamrim Chenmo Translation Committee, Trans.). Ithaca, NY: Snow Lion Publications. (Original work published 1402)

Thurman, R. A. F. (1984). The central philosophy of Tibet: A study and translation of Jey Tsong Khapa's essence of true eloquence. Princeton, NJ: Princeton University Press.

Vienna University of Technology. (2015, April 27). Is the universe a hologram? ScienceDaily. Retrieved December 22, 2015 from www.sciencedaily.com/releases/2015/04/150427101633.htm 
Vella, J. (2000). A spirited epistemology. In L. English \& M. Gillen (Eds.), Addressing the spiritual dimensions of adult learning (pp. 7-16). San Francisco, CA: Jossey-Bass.

Walshe, M. O. (Trans.). (2007). Kaccaayanagotto Sutta: Kaccaayana [on Right View]. Retrived from http://www.accesstoinsight.org/tipitaka/sn/sn12/sn12.015.wlsh.html

Walton, J. (1996). Spiritual relationships: A concept analysis. Journal of Holistic Nursing, 14(3), 237-250.

Wei, T. (1973). Introduction. In Hsuan Tsang, Ch'eng wei-shi lun: The doctrine of mereconsciousness (T. Wei, Trans.). Hong Kong, China: The Ch'eng Wei-shih Lun Publication Committee. (Original work published 659). Retrieved from http://www.dhalbi.org/dhalbi/html_t/authors/author_main.php?p_id=8

Yin-shun (1998). The way to Buddhahood (W. H. Yeung, Trans.). Somerville, MA: Wisdom Publications. (Original work published 1960) 